University of Tennessee Health Science Center

UTHSC Digital Commons

$12-2009$

\title{
Preferences and Willingness to Pay for Osteoarthritis Treatments among the Medicare Population
}

Meghan Alexis Hufstader

University of Tennessee Health Science Center

Follow this and additional works at: https://dc.uthsc.edu/dissertations

Part of the Health and Medical Administration Commons, and the Pharmacoeconomics and Pharmaceutical Economics Commons

\section{Recommended Citation}

Hufstader, Meghan Alexis, "Preferences and Willingness to Pay for Osteoarthritis Treatments among the Medicare Population" (2009). Theses and Dissertations (ETD). Paper 119. http://dx.doi.org/10.21007/ etd.cghs.2009.0144.

This Dissertation is brought to you for free and open access by the College of Graduate Health Sciences at UTHSC Digital Commons. It has been accepted for inclusion in Theses and Dissertations (ETD) by an authorized administrator of UTHSC Digital Commons. For more information, please contact jwelch30@uthsc.edu. 


\title{
Preferences and Willingness to Pay for Osteoarthritis Treatments among the Medicare Population
}

\begin{abstract}
The design of this study is a non-random cross sectional survey to determine Medicare beneficiaries' preferences and willingness to pay for osteoarthritis $(\mathrm{OA})$ treatments. The population of interest in this study is the Medicare eligible (over age 65) population in Memphis, TN, and surrounding cities. Data were collected at Senior Centers and one internal medicine practice. The sample size was 181.

Choice-based conjoint analysis technique was utilized. The preferences and willingness to pay were determined using choice-based conjoint analysis, advanced design module with a dual-response none option. Choice-based conjoint analysis uses computer guided surveys to elicit patient preference for a series of comparisons of osteoarthritis treatments that are characterized differently.
\end{abstract}

This conjoint analysis study provides a greater understanding of how patients might incorporate complementary and alternative therapies into their osteoarthritis (OA) treatment regimen. This data enables clinicians and health care professionals to determine how patients may trade-off different levels of treatment attributes (e.g., cost, allopathic treatments, combination therapies, and Complementary and Alternative Medicine (CAM) therapies) for OA treatments.

Overall, for the total sample, prayer/spiritual healing had the highest utility value (.71). Therefore, all groups did not place higher utility on allopathic treatments over CAM treatments as hypothesized. When looking at product shares of preference, prayer/spiritual healing also had the highest share of preference $(16.32 \%)$. When the sample was segmented by gender, women did not place higher utility on CAM treatments as hypothesized. They were slightly different, however. Males preferred herbal mineral supplements more than women (.39 vs. .01) and women preferred massage over men (.39 vs. -.06). Men and women had virtually the same negative utility values for chiropractic care and acupuncture, and the same positive utility values for prayer. When the sample was segmented by race, blacks did not place higher utility on CAM than whites, and whites did not place higher utility on allopathic treatments then blacks. However, whites did place higher utility on herbal/mineral supplements (.26 vs. .07) than blacks. As hypothesized blacks did place a higher utility on prayer/spiritual healing than did whites ( 1.56 vs.-0.03).

These data indicate that doctors and other healthcare providers should be encouraged to develop methods to involve patients in making treatment decisions and take the time to understand the patients' treatment preferences. Patients in this sample desire treatments beyond the standard treatment protocol for osteoarthritis.

\section{Document Type}

Dissertation

Degree Name

Doctor of Philosophy (PhD)

\section{Program}

Health Outcomes and Policy Research

\section{Research Advisor}

Shelley White-Means, PhD 


\section{Keywords}

CAM, Conjoint Analysis, Health Care, Osteoarthritis, Preferences, Willingness to Pay

\section{Subject Categories}

Health and Medical Administration | Medicine and Health Sciences | Pharmacoeconomics and Pharmaceutical Economics 
PREFERENCES AND WILLINGNESS TO PAY FOR OSTEOARTHRITIS TREATMENTS AMONG THE MEDICARE POPULATION

\author{
A Dissertation \\ Presented for \\ The Graduate Studies Council \\ The University of Tennessee \\ Health Science Center
}

\author{
In Partial Fulfillment \\ Of the Requirements for the Degree \\ Doctor of Philosophy \\ From the University of Tennessee
}

\author{
By \\ Meghan Alexis Hufstader \\ December 2009
}


Copyright (C) 2009 by Meghan Alexis Hufstader All rights reserved 


\section{DEDICATION}

This dissertation is dedicated to:

My parents: Bob and Rusty Hufstader My sisters: Darcy and Emily Hufstader

My grandma: Rosemary Nusom Devito

My grandpa: Domenic Devito 


\section{ACKNOWLEDGEMENTS}

This work would not have been possible without the amazing support of my family and friends, the encouragement and friendship from my fellow students in the Health Outcomes and Policy Research program, the extraordinary assistance of my committee, and the generosity of others who helped me along the way.

I would like to thank my committee chair Dr. Shelley White-Means for her unyielding support of me throughout this experience. She has been infinitely patient with my endless trials and tribulations, while moving mountains to clear her schedule to help me. Without her mentorship, friendship, and advocacy I could not have completed this PhD. My success is because of her.

My committee members were integral to this research study. Dr. Dick Gourley is a remarkable professor, dean, and advisor, I am forever grateful to him for all the opportunities he has given me. Dr. Nancy Mele has been exceptionally responsive and kind to me. Her innovative ideas and expertise are unparalleled. Dr. Yi Yang brought a wealth of knowledge concerning primary data collection and has helped me understand the implications for this project. Dr. Song Hee Hong provided insightful comments and direction regarding the methodological considerations for this project.

I am grateful to Sawtooth Software for providing me with a dissertation grant to fund the purchase of my conjoint analysis software and the technical support to go along with it.

My family has been wonderful. This project could not have happened without the love of my parents, Bob and Rusty. I cannot express how much I appreciate Bob's cool-headed advice when I had my dramatic freak-outs and Rusty's constant encouragement to 'run hard and bark loud'. When the advice of my parents was not what I wanted to hear, I am so thankful I have my beautiful Grandma Rosemary to turn to. I appreciate her wisdom and unwavering bias towards me. I am also in deep appreciation to my funny and supportive Grandpa Dominic, who is the best travel buddy in the world. My daily telephone arguments with Darcy, my twin sister, have kept me from missing her too much. My sister Emily brightened many dark dissertation days with her constant barrage of funny text messages and pictures she sent of my nephew Dylan and niece Kalena. 


\begin{abstract}
The design of this study is a non-random cross sectional survey to determine Medicare beneficiaries' preferences and willingness to pay for osteoarthritis (OA) treatments. The population of interest in this study is the Medicare eligible (over age 65) population in Memphis, TN, and surrounding cities. Data were collected at Senior Centers and one internal medicine practice. The sample size was 181 .
\end{abstract}

Choice-based conjoint analysis technique was utilized. The preferences and willingness to pay were determined using choice-based conjoint analysis, advanced design module with a dual-response none option. Choice-based conjoint analysis uses computer guided surveys to elicit patient preference for a series of comparisons of osteoarthritis treatments that are characterized differently.

This conjoint analysis study provides a greater understanding of how patients might incorporate complementary and alternative therapies into their osteoarthritis (OA) treatment regimen. This data enables clinicians and health care professionals to determine how patients may trade-off different levels of treatment attributes (e.g., cost, allopathic treatments, combination therapies, and Complementary and Alternative Medicine (CAM) therapies) for OA treatments.

Overall, for the total sample, prayer/spiritual healing had the highest utility value (.71). Therefore, all groups did not place higher utility on allopathic treatments over CAM treatments as hypothesized. When looking at product shares of preference, prayer/spiritual healing also had the highest share of preference $(16.32 \%)$. When the sample was segmented by gender, women did not place higher utility on CAM treatments as hypothesized. They were slightly different, however. Males preferred herbal mineral supplements more than women (.39 vs. .01) and women preferred massage over men (.39 vs. -.06). Men and women had virtually the same negative utility values for chiropractic care and acupuncture, and the same positive utility values for prayer. When the sample was segmented by race, blacks did not place higher utility on CAM than whites, and whites did not place higher utility on allopathic treatments then blacks. However, whites did place higher utility on herbal/mineral supplements (.26 vs. .07) than blacks. As hypothesized blacks did place a higher utility on prayer/spiritual healing than did whites (1.56 vs.-0.03).

These data indicate that doctors and other healthcare providers should be encouraged to develop methods to involve patients in making treatment decisions and take the time to understand the patients' treatment preferences. Patients in this sample desire treatments beyond the standard treatment protocol for osteoarthritis. 


\section{TABLE OF CONTENTS}

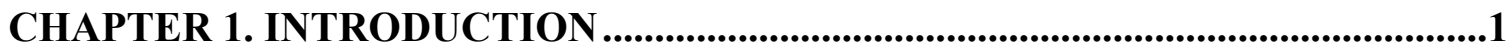

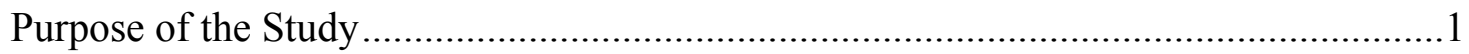

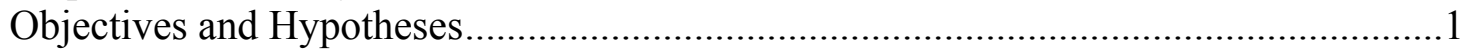

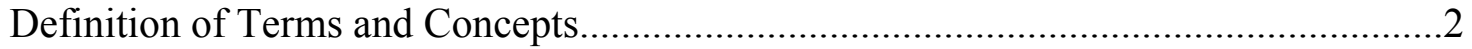

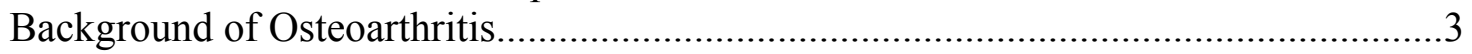

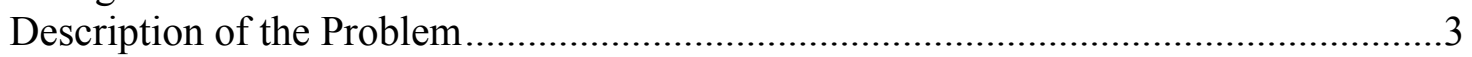

Relevance to Health Outcomes and Policy Research ....................................................

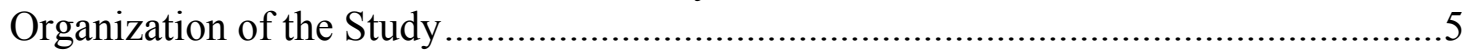

CHAPTER 2. REVIEW OF LITERATURE ................................................................6

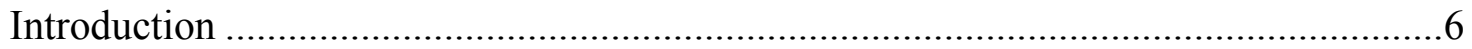

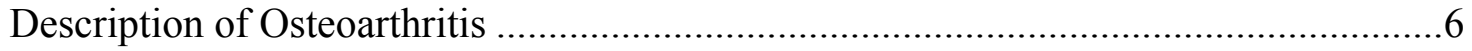

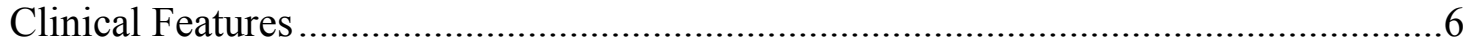

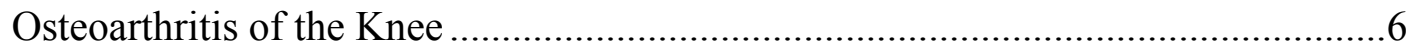

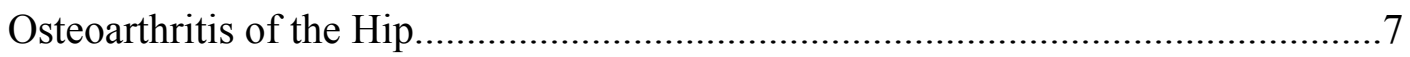

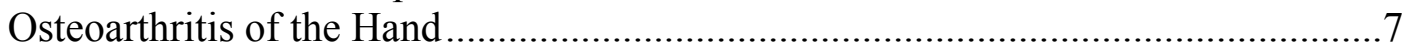

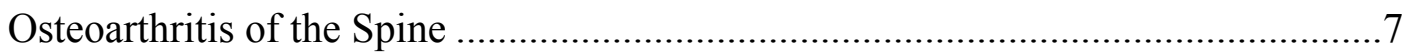

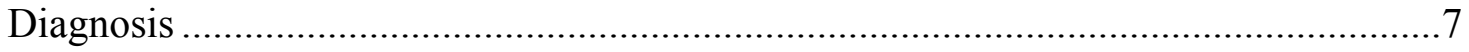

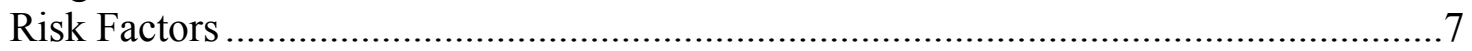

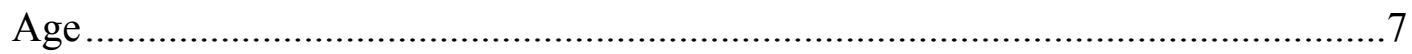

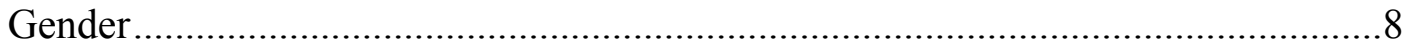

Race

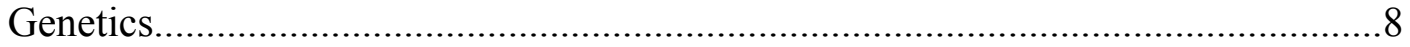

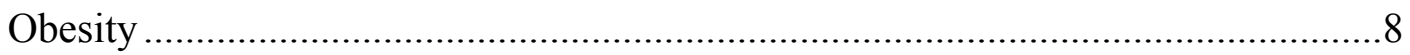

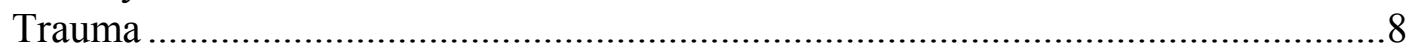

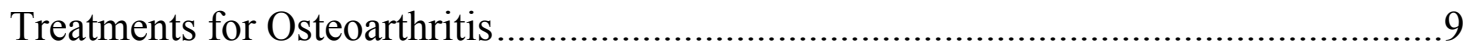

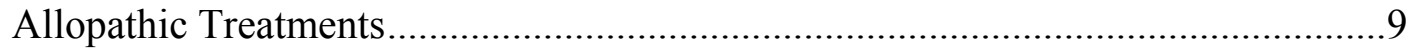

Complementary and Alternative Treatments .....................................................11

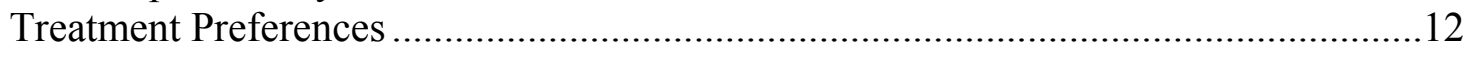

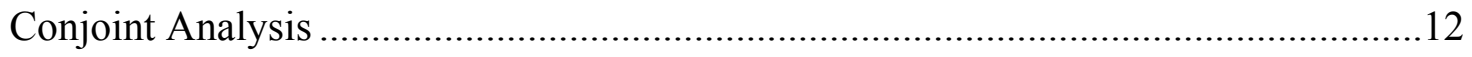

History of Conjoint Analysis .............................................................................13

Description of Conjoint Analysis.........................................................................13

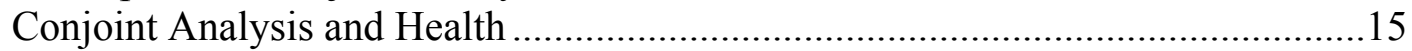

Conjoint Analysis and Patient Preferences ...........................................................15

Conjoint Analysis and Complementary and Alternative Medicine ..........................15

Conjoint Analysis and Willingness to Pay..........................................................16

Discrete Choice Analysis .................................................................................16

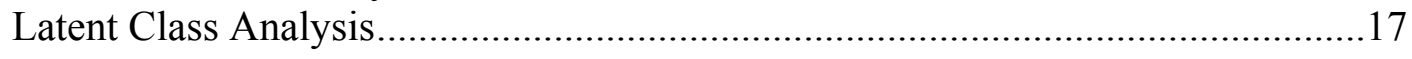

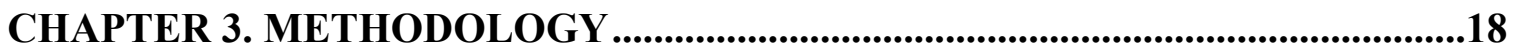

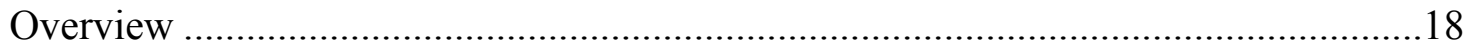

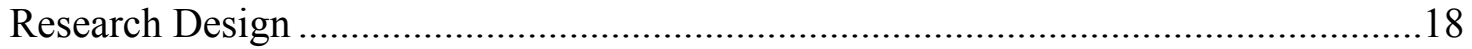

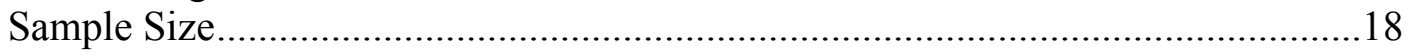




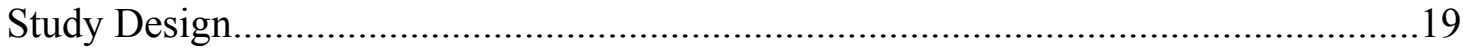

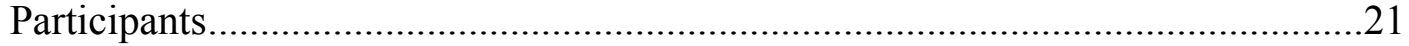

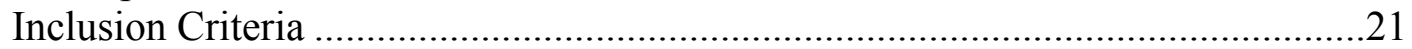

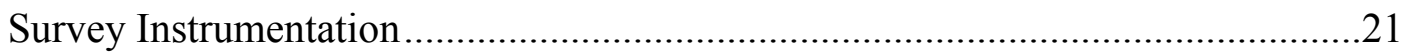

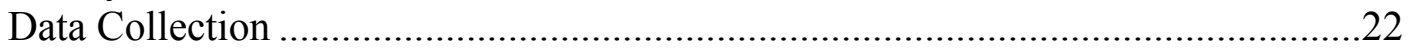

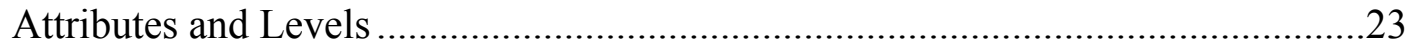

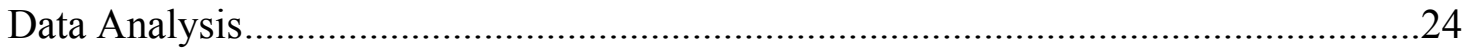

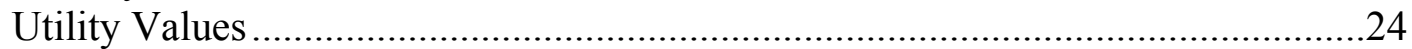

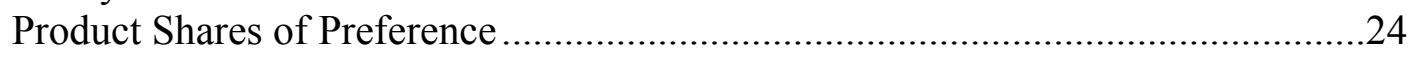

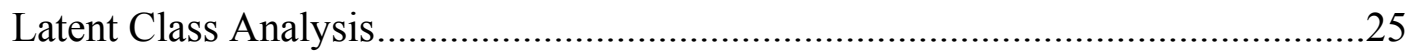

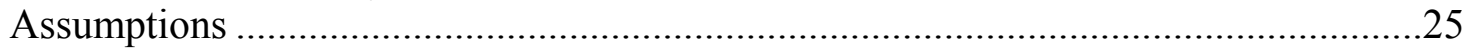

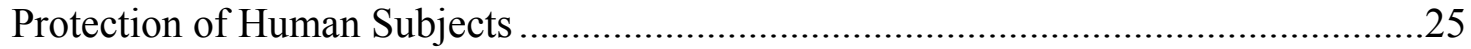

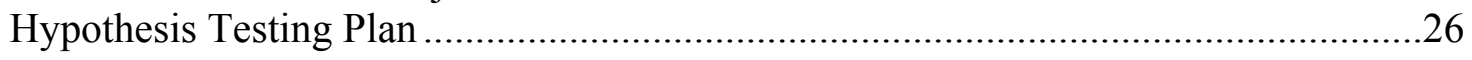

CHAPTER 4. RESULTS..............................................................................................27

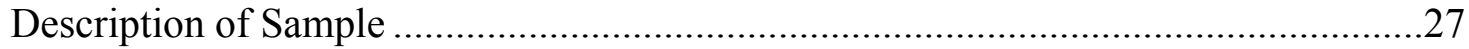

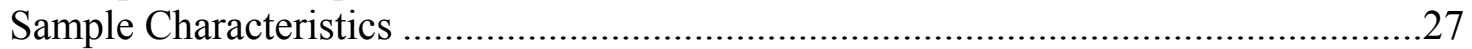

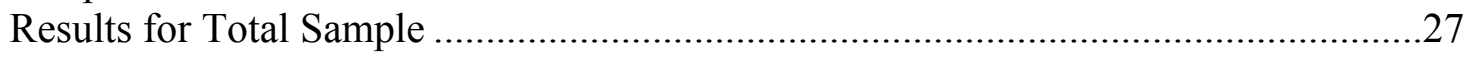

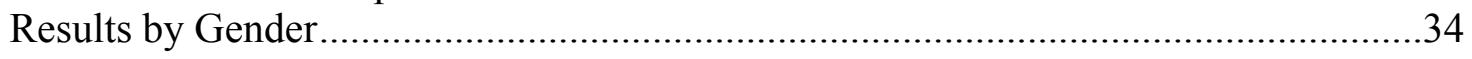

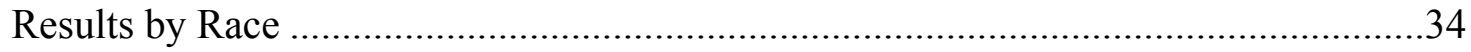

Results by Race and Gender ...................................................................................

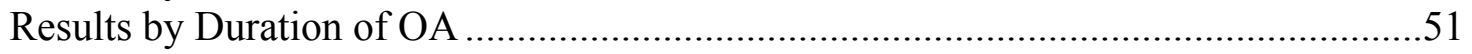

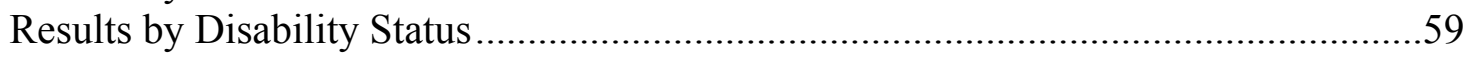

Results for Latent Class Segmentation .........................................................................65

CHAPTER 5. DISCUSSION ...................................................................................79

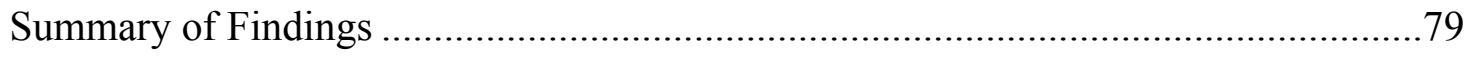

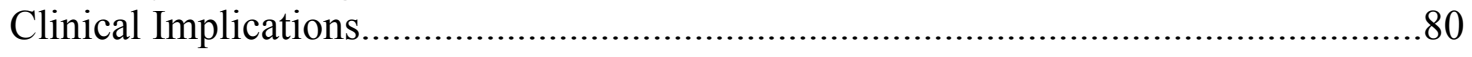

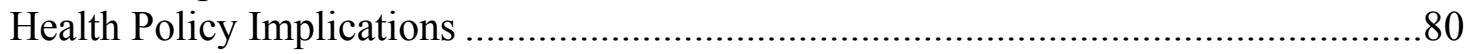

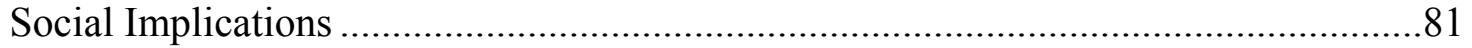

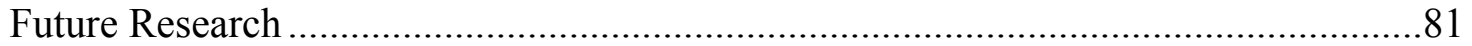

Limitations and Confounding Factors ....................................................................

LIST OF REFERENCES ....................................................................................................83

APPENDIX A. CONJOINT ANALYSIS SURVEY ...................................................

APPENDIX B. BRIEF PAIN INVENTORY LICENSE AND SURVEY ..................106

APPENDIX C. INFORMED CONSENT .....................................................................109

APPENDIX D. INSTITUTIONAL REVIEW BOARD APPROVAL LETTER .....110

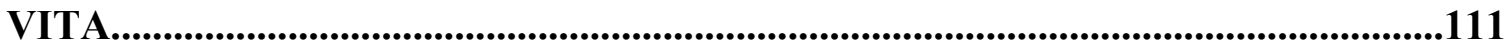




\section{LIST OF TABLES}

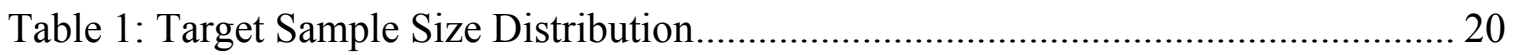

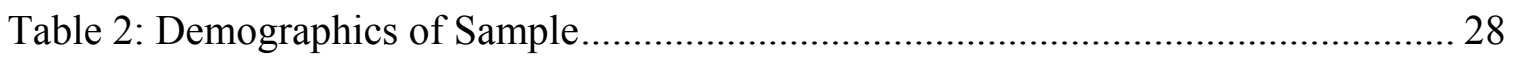

Table 3: Average Utility Values for Total Sample .......................................................... 29

Table 4: Importance Scores for Total Sample ................................................................ 31

Table 5: Product Shares of Preference for Total Sample.................................................. 32

Table 6: Marginal WTP for Treatments for Total Sample …………………………...... 33

Table 7: Utility Values by Gender ............................................................................. 35

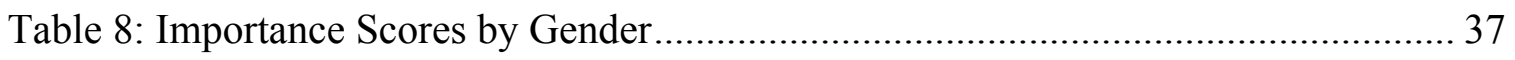

Table 9: Product Shares of Preference by Gender .......................................................... 37

Table 10: Average Utility Values by Race ……………………………...................... 39

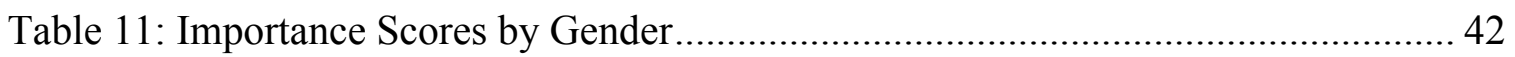

Table 12: Product Shares of Preference by Race............................................................ 42

Table 13: Marginal WTP for Treatment for Whites ………………………………....... 44

Table 14: Marginal WTP for Treatment for Blacks......................................................... 45

Table 15: Utility Values by Race/Gender (Whites) ......................................................... 47

Table 16: Utility Values for Race/Gender (Blacks)........................................................ 49

Table 17: Importance Scores by Race/Gender............................................................... 52

Table 18: Product Shares of Preference for Race/Gender ................................................ 52

Table 19: Utility Values for $0-5$ years Duration of OA ……………………………....... 55

Table 20: Utility Values for 6-10 Years of OA Duration ................................................ 56

Table 21: Utility Values for $>10$ Years of OA Duration ................................................. 58

Table 22: Importance Scores by Duration of OA …………............................................... 60

Table 23: Product Shares of Preferences by Duration of OA ............................................. 61 


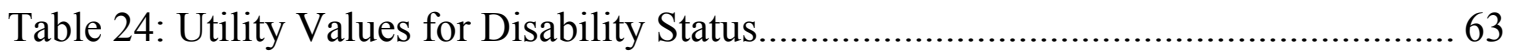

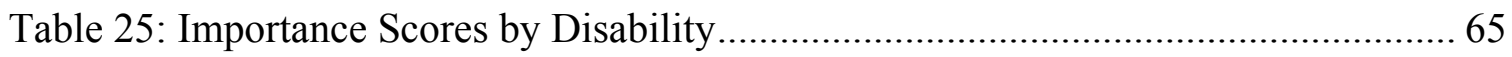

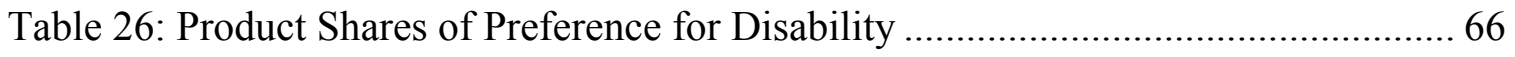

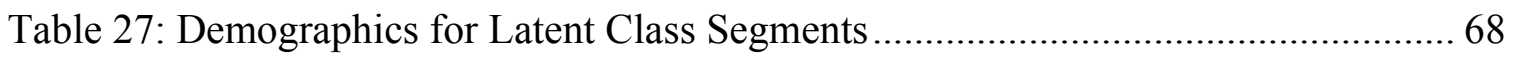

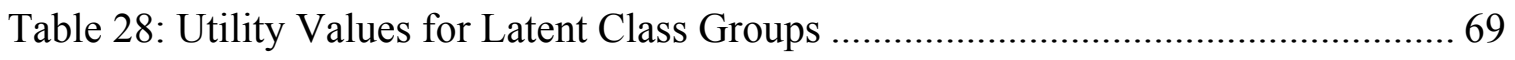

Table 29: Importance Scores for Latent Class Segments ......................................... 72

Table 30: Product Shares of Preferences for Latent Class Groups ................................ 73

Table 31: Marginal WTP for Treatment for Latent Class Segment 1............................ 75

Table 32: Marginal WTP for Treatment for Latent Class Segment 2 ........................... 76

Table 33: Marginal WTP for Treatment for Latent Class Segment 3............................ 77 


\section{CHAPTER 1. INTRODUCTION}

This study utilized conjoint analysis to elicit preferences for common osteoarthritis treatments and marginal willingness to pay (WTP) for those treatments among a sample of Medicare beneficiaries in Shelby County, Tennessee. Conjoint analysis is a technique taken from market research to understand how patients choose between different treatments. This study provides useful insight into the treatment preferences, treatment utility or value and the monetary value to patients of those treatments. This study may also help to inform policy decisions regarding osteoarthritis treatment coverage under Medicare or other third party health insurers.

\section{Purpose of the Study}

The purpose of the study is to elicit patient preferences and patient willingness to pay for common treatments for osteoarthritis including complementary and alternative therapies.

\section{Objectives and Hypotheses}

The objectives of this study are to:

1. Determine overall preferences for osteoarthritis treatments among different cohorts of people (black men, black women, white men, and white women) and among different segments of the market.

2. Determine the marginal willing to pay for various osteoarthritis treatments among different race/gender cohorts and market segments.

3. Determine if the duration of the disease affects the utility of CAM treatments.

4. Determine if the degree of disability affects the utility of CAM treatments.

The following is a list of the hypotheses for this research:

1. Blacks overall will place higher utility on CAM treatments than whites. ${ }^{1}$

2. Whites overall will place higher utility on allopathic treatments than blacks.

3. Women overall will place higher utility and on CAM treatments then men. ${ }^{1}$

4. All groups will place higher utility on allopathic treatments over CAM treatments.

5. Blacks will place higher utility on the CAM therapy of prayer/spiritual healing and will be willing to pay more for that therapy. ${ }^{1}$

6. Blacks will place higher utility on the CAM therapy of herbal/mineral supplements and will be willing to pay more for that therapy. ${ }^{1}$

7. Whites will place higher utility on service oriented CAM therapies such as chiropractic care and will be willing to pay more for that service. ${ }^{2}$

8. Whites will place higher utility on service oriented CAM therapies such as massage therapy and will be willing to pay more for that service. 
9. The longer survey respondents have had OA, the more they will value CAM therapies.

10. The more disabled the person has become due to osteoarthritis, the more likely the person will be to value CAM. ${ }^{1}$

\section{Definition of Terms and Concepts}

The following is a list of terms and concepts utilized throughout this study:

1. Attribute - A characteristic of a treatment such as cost. In conjoint analysis, every attribute must have at least two levels. ${ }^{3}$

2. Allopathic Medicine - Allopathic (Western/Conventional) medicine as defined for this study as medicine practiced by holders of M.D. (medical doctor) or D.O. (doctor of osteopathy) degrees and by other health professionals such as physical therapists and nurses.

3. Complementary and Alternative Medicine (CAM) - The practice of medicine that is outside the scope of western or allopathic medicine. Another common definition is simply therapies not taught in US Medical Schools. ${ }^{5}$

4. Choice Based Conjoint Analysis (CBC) - A term synonymous with discrete choice modeling (DCM). CBC is currently the most popular conjoint analysis technique. This technique more closely mimics reality than other conjoint analysis techniques and is currently the most popular Conjoint Analysis technique. ${ }^{3}$

5. Conjoint Analysis - A quantitative technique that asks patients to choose among multiple treatments, called attributes. This allows researchers to deduce preferences for treatments. ${ }^{3}$

6. Degrees of Freedom - In terms of conjoint analysis, the extra observations above the amount of parameters to be calculated. ${ }^{3}$ The number of independent pieces of information that go into the estimate of a parameter is called the degrees of freedom.

7. Discrete Choice Modeling (DCM) - Also known as CBC. Discrete Choice Modeling refers to a class of models in which the nominal dependent variable reflects choice. Currently, has the highest validity among the types of Conjoint Analysis. $^{3}$

8. Effect - A measurement of preference that the researcher seeks to summarize using a parameter in a conjoint analysis model. ${ }^{3}$

9. Importance Score - A percentage based off of utility values, showing the importance of the attribute. The importance scores for all attributes sum to one hundred.

10. Latent Class Analysis - A model and estimation technique for analyzing discrete choice (CBC) data that finds groups (classes) of patients that exhibit similar choice patterns and develops a set of utilities for each class. ${ }^{3}$

11. Level - A degree or amount of an attribute. Every attribute in conjoint analysis should have two or more levels. Levels should be mutually exclusive, with each treatment modality defined using only one level of an attribute. ${ }^{3}$ An example 
12. Likelihood - A measure of fit used in CBC. Likelihood indicates the probability that the observed choices' worth have resulted given the estimated utilities. ${ }^{3}$

13. Marginal Rate of Substitution (MRS) - The relative importance of attributes that estimate the trade-offs patients made between attributes. ${ }^{6}$

14. Marginal Willingness to Pay - This refers to the dollar amount that a person is willing to pay for an treatment over the referent.

15. Osteoarthritis - The most common joint disorder that is caused by the breakdown and eventual loss of the cartilage of one or more joints.

16. Shares of Preference - The shares of preference model capture information about each respondent's preferences for treatments. The simulation results give ratio information about the relative desirability of the remaining products.

17. Task - A single choice question in a CBC questionnaire. ${ }^{3}$

18. Utility - An economic concept that, when used in the context of conjoint analysis means the patients' preference of a specific treatment alternative. ${ }^{3}$

\section{Background of Osteoarthritis}

Osteoarthritis (OA) is the most common form of arthritis. ${ }^{7}$ It is known as the 'wear-andtear' arthritis. An estimated 21 million Americans suffer from OA. As our population ages, arthritis is expected to increase in prevalence. Arthritis is one of the leading causes of disability and decreased activities of daily living in the United States. ${ }^{8}$ NHIS survey showed that over $35 \%$ of those 45 and older have been told by a doctor that they have arthritis.

Patients with OA have soreness and inflammation, bony growths around the joint, grinding, and restriction of movement in their joints. This is caused by the cartilage losing its elasticity due to injury or over-use. When this happens, oftentimes patients wear down the cartilage, which in turn changes the underlying bone. This often leads to the development of bony growths called osteophytes that develop near the afflicted joint or joints. The bits of bone may break loose and float around in the joint space causing the joint lining, or synovium to become inflamed. This can lead to impaired movement and function of the joint.

In the elderly population, the prevalence of those suffering from osteoarthritis is very high. It affects more than $50 \%$ of those over 65 and is seen in almost all individuals over the age of $75 .{ }^{9}$ It is more prevalent in women, and elderly women are twice as likely as men to have osteoarthritis in their hands and knees. ${ }^{9}$ However, the prevalence rate for osteoarthritis in men over 65 years of age is $26.8 \% .^{10}$

\section{Description of the Problem}

It has been estimated that in 20 years, osteoarthritis will be the fourth leading cause of disability in the United States. ${ }^{11}$ Osteoarthritis can be painful, incapacitating, and 
expensive to treat. ${ }^{12}$ The Arthritis Foundation reported that more than $\$ 3$ billion dollars is spent yearly for complementary and alternative arthritis therapies. ${ }^{12,12}$ It has been suggested that the intractable nature of OA and other arthritic conditions leads to patients with these conditions being among the highest users of CAM. ${ }^{13}$ It has been shown that senior citizens are not properly informed about all available treatment options, oftentimes leading to therapies not to their preferences. ${ }^{14}$ The cost of suffering and health resource utilization will increase as the U.S. population ages and obesity increases in prevalence. ${ }^{15}$ However, although studies have focused on what osteoarthritis sufferers utilize to treat and manage their disease, no studies have explored patients' preferences regarding treatment regimens including CAM, and how much they value or their "willingness to pay" for various treatments.

A methodology known as conjoint analysis has been commonly used in marketing research to assess values placed on products to ensure successful product launch and to ensure continued product success. ${ }^{16}$ In the pharmaceutical industry, conjoint analysis has been utilized for pricing and the impact of new drugs on existing products. ${ }^{16}$ Recently, conjoint analysis has been used as a tool to help medical care become more patient centered and to determine what avenues of care patients will be comfortable with and follow. ${ }^{16}$

\section{Relevance to Health Outcomes and Policy Research}

This study will determine the preferences for osteoarthritis treatment among a sample of osteoarthritis patients. This study will not only determine the preferences for both allopathic and complementary and alternative treatments, but will also assign dollar valuation for those treatments.

The number of patients using CAM will influence the overall cost of arthritis treatments. This is an important individual and policy consideration, as supplementing or substituting expensive allopathic treatments for less expensive CAM treatments could result in a total reduction of overall osteoarthritis expenditures. Social implications are also possible. If patients show a high utility and valuation for spiritual healing/prayer, faith-based therapeutic venues may be important to take into consideration. Many people with OA utilize CAM exclusively, or in addition to allopathic treatments. Despite the fact that the literature is sparse regarding the efficacy of many CAM treatments, their frequent utilization may be due to the relatively low effectiveness of most allopathic non-surgical treatments and patients' desire for further relief of suffering. ${ }^{17}$

Regarding health policy, a Medicare beneficiary preference for less expensive treatments could result in changes in reimbursement patterns as cost-savings are sought. Thus this study may facilitate the establishment of priorities for health care expenditure and reimbursement among the Medicare population. Physicians, nurses, and pharmacists will benefit from increased understanding of CAM preferences among this population, potentially contributing to improved health outcomes. 
Treatment preferences that follow a patient's set of beliefs may improve compliance and motivate improved utilization of health services. A patient that is satisfied with their treatment is more likely to practice improved compliance with treatment and therefore experience improved quality of life.

Marginal willingness to pay is an important variable to consider when researching patient preferences for treatment. The underlying assumption is that their income levels limit patient choices of treatment, and they thus must make trade-offs for treatments based on the treatment's utility value. This is expressed as marginal willingness to pay.

Differences in treatment preferences among men and women, among differently aged cohorts, and among various ethnic groups will be explored. Previous research has documented that race and gender significantly impact a patient's health care decisions. Gender is an especially important variable, as women comprise approximately $60 \%$ of all Medicare beneficiaries. As Medicare has begun to reimburse for chiropractic coverage (a CAM modality), the CAM component is an increasingly important consideration for health care policy makers.

This study helps to clarify factors in patient choice that are often not well understood. These include race and spirituality. This study utilizes a convenience sample of patients from Memphis, Tennessee. As the sampling frame for this study is non-random, it cannot be generalized. Memphis is located in the Bible-Belt of the southern United States. Studies have shown that religious faith in healing is prevalent in the southern United States. ${ }^{18}$ These characteristics may influence utility values and marginal willingness to pay in the population studied.

\section{Organization of the Study}

This dissertation is organized into five chapters. Chapter 1 discusses the purpose of the study, defines the necessary terms, and relevance to health policy and outcomes research. Chapter 2 provides a review of the literature encompassing a description of osteoarthritis, the epidemiology of osteoarthritis, and the economic, clinical and humanistic outcomes of osteoarthritis. Chapter 3 presents the methods used in the research, while Chapter 4 provides the results of the research. Chapter $\mathbf{5}$ is a discussion of findings and possible future directions for further research. 


\section{CHAPTER 2. REVIEW OF LITERATURE}

\section{Introduction}

The goal of this chapter is to provide a review of literature relevant to this research. The chapter includes a brief history of osteoarthritis, an overview of the pathological and clinical features of osteoarthritis, the diagnostic criteria for osteoarthritis, and a detailed description of the epidemiology of osteoarthritis. Pharmaceutical treatments, surgical treatments, and ancillary treatments for osteoarthritis including complementary and alternative treatments are discussed. The remainder focuses on discrete choice analysis, the current literature regarding health and conjoint analysis, and conjoint analysis studies focusing on race/ethnicity.

\section{Description of Osteoarthritis}

Osteoarthritis is defined by the American College of Rheumatology as a "heterogeneous group of conditions that leads to joint symptoms and signs which are associated with defective integrity of articular cartilage, in addition to related changes in the underlying bone at the joint margins". ${ }^{11}$ Osteoarthritis involves the entire joint, including the bone, ligaments, muscles, capsule, and synovium. ${ }^{19}$ Osteoarthritis is the most common joint disorder. ${ }^{15}$ Osteoarthritis is present in $80 \%$ of people above 75 years of age in western countries. ${ }^{15}$

\section{Clinical Features}

The presentation of osteoarthritis varies, making it difficult to diagnose early in the disease process. Various guidelines have been created to assist in diagnosis. While osteoarthritis can oftentimes be confirmed by radiograph, there are cases where the osteoarthritis is undetectable. ${ }^{19}$

The typical presentation of an osteoarthritis patient is an older individual with complaints of pain in the knee, hip, hand or spine. ${ }^{15}$ The patient will complain that pain worsens when the joint is in use and is assuaged when the joint is at rest. Morning stiffness lasting less than half an hour is often present. ${ }^{15}$

\section{Osteoarthritis of the Knee}

Osteoarthritis of the knee is characterized by knee instability or buckling, especially when patients are stepping down on stairs or off of curbs. ${ }^{15}$ It is one of the joints most commonly affected by OA. ${ }^{20}$ Symptoms include pain, crepitation in the knee joints, limited range of motion, and joint instability. ${ }^{20}$ This can cause patients to reduce their movements, thus causing problematic muscular atrophy. ${ }^{20}$ 


\section{Osteoarthritis of the Hip}

Osteoarthritis of the hip can present as a dull or sharp pain in the groin, thigh, knee, or hip. ${ }^{15}$ This varied pattern of hip osteoarthritis pain can make diagnosis difficult. ${ }^{15}$

Stiffness of the hip is common after a period of inactivity. An early sign is usually limited mobility when trying to rotate the hip. ${ }^{15}$

\section{Osteoarthritis of the Hand}

Hand osteoarthritis can cause dexterity problems. ${ }^{15}$ Oftentimes, OA of the hand has osteophytes. These are ten times more common in women. ${ }^{20}$ Osteophytes may appear as nodes near joints which can become red, painful and swollen, particularly after use or trauma. ${ }^{20}$ A common first sign of hand OA is difficulty pinching or opening jars. ${ }^{20}$

\section{Osteoarthritis of the Spine}

The joints L3-L4 are the most commonly afflicted joints. ${ }^{20}$ Osteophytes and bony changes can overgrow nerve root openings exiting from the spinal canal, causing nerve root compression, which can be both painful and cause muscle weakness. ${ }^{20}$

\section{Diagnosis}

The symptoms of osteoarthritis vary among patients. Typically, the patient presents with joint crackling or grinding, pain, stiffness, and reduced joint mobility. ${ }^{19}$ The most common presentation for first diagnosis is joint pain. ${ }^{19}$ Diagnosis usually involves a physical examination that includes weighing the patient, assessment of muscle strength and ligament flexibility, as well as examination of the joints via radiograph. ${ }^{19}$

\section{Risk Factors}

\section{Age}

Osteoarthritis is unusual under the age of $40 .{ }^{19}$ The incidence of OA increases with age. Despite this, age alone is not the sole predictor of OA. Approximately $6 \%$ of adults aged 30 years and older in the United States have osteoarthritis of the knee with knee pain on most days, whereas $10 \%$ to $15 \%$ of persons aged 60 years and older have these symptoms. $^{21}$ 


\section{Gender}

Osteoarthritis has higher prevalence in women than in men. ${ }^{21}$ For most joints, before the age of 50 years, men have a higher prevalence of the disease than do women, possibly due to athletic or other over-use injuries. After age 50 years, women have a much higher prevalence of disease than do men. In the older population, women are twice as likely to have OA of the knee and hands. ${ }^{20}$ Women are also more likely to have the inflammatory form of $\mathrm{OA},{ }^{20}$ in which periarticular soft tissues become red, swollen, and tender. ${ }^{20}$ The causes for this are unclear but may be due to hormones after menopause. ${ }^{21}$

\section{Race}

The prevalence of knee osteoarthritis is roughly similar in whites and African Americans; however, African Americans may have more severe and disabling disease. ${ }^{21} \mathrm{OA}$ of the knee is twice as likely in black women than white women. ${ }^{20}$

\section{Genetics}

A positive family history of OA is found in at least $50 \%$ of hand and hip osteoarthritis cases, and a small amount of knee osteoarthritis cases. ${ }^{11}$ Research has shown that genetics plays a role in the development of OA, particularly in the hands. Genetic abnormalities of the bones that affect the form or steadiness of the joints can lead to OA.

\section{Obesity}

Obesity is a risk factor for developing OA. The heavier a person is, the more likely they are to develop OA. ${ }^{20}$ Overweight men have been shown to have a $50 \%$ higher likelihood of OA than non-overweight men, while overweight women have been shown to have a $210 \%$ higher likelihood than non-overweight women to develop OA. ${ }^{20}$ For heavier men, risk for severe knee OA was nearly double that of normal weight men, and heavier women the risk was more than three times that of normal weight women. ${ }^{20}$ It has been shown that a loss of 10 pounds may reduce risk of knee OA by $50 \%$. In the Framingham study, heavier participants in their thirties who did not have knee OA were at greater risk of developing the disease later. ${ }^{22}$

\section{Trauma}

Trauma to joints due to previous surgeries, injuries, or occupational utilization are associated with increased risk for osteoarthritis. ${ }^{23}$ Studies have shown that those with repetitive work activities have a higher incidence of $\mathrm{OA} .{ }^{20}$ Football players have been shown to have a higher incidence of lower extremity OA. However long distance runners 
have not been shown to have an increased risk. ${ }^{20}$ Severe knee injuries, especially in older age, have been shown to lead to the development of OA. ${ }^{20}$

\section{Treatments for Osteoarthritis}

The treatments for arthritis can combine two treatment paths: (1) allopathic or western medicine and (2) complementary and alternative (CAM) medicine. Due to the fact that arthritis cannot be cured, the goals of all treatments are to maintain mobility, relieve symptoms, and minimize disability.

As a first line osteoarthritis treatment, the American Geriatrics Society recommends acetaminophen. The Arthritis Foundation states that drug therapy such as analgesics or NSAIDs designed to ease the pain of the disease is the most common treatment for osteoarthritis. ${ }^{24}$ Other conventional medications utilized for osteoarthritis relief are NSAIDS, COX-2 inhibitors, tramadol, hyaluronic acid, and glucocorticoids. ${ }^{25}$ There are also surgical options available such as arthroscopic debridement and lavage, osteotomy, arthrodesis, and arthroplasty. ${ }^{25}$ Allopathic therapies are designed to reduce pain, improve joint mobility, and enhance the quality of life of osteoarthritis patients, They rarely alter the course of the disease. ${ }^{12,19}$ Due to this, osteoarthritis patients may turn to alternative therapies for relief. ${ }^{12}$ There is cause for concern with the use of CAM treatments, however. ${ }^{26}$ Although many treatments may help, or at a minimum cause some level of placebo effect, some treatments may be harmful or interact with certain medications. Most OA patients do not use CAM exclusively, but combine allopathic and CAM therapies to better manage their osteoarthritis. ${ }^{26}$ There are few studies that examine the utilization of CAM therapies among those who cannot afford or do not chose to use conventional care. ${ }^{26}$ Among rural adults with osteoarthritis, it has been shown that prescription medicine, OTC medicine, and prayer/spiritual healing were among the most common therapies used. ${ }^{26}$

CAM therapies included in this study can be self-administered, or patients may go to a CAM provider for treatment. ${ }^{27}$ The National Health Interview Survey last fielded in 2007 asks questions on 12 specific CAM treatments: acupuncture, relaxation techniques, massage, imagery, spiritual healing/prayer, lifestyle diet, herbal medicine, homeopathy treatment, energy healing, biofeedback, chiropractic services, and hypnosis. ${ }^{27}$ The most common CAM treatments that people use are spiritual healing/prayer (13.7\%), herbal medicine $(9.6 \%)$, and chiropractic services $(7.6 \%){ }^{27}$

\section{Allopathic Treatments}

\section{Exercise}

Despite the fact that over-utilization of joints may contribute to osteoarthritis progression, exercises that strengthen muscles necessary for a person's daily activities have been known to be successful in prevention and treatment of OA. ${ }^{11}$ Physical therapy has been 
shown to be effective in reduction of pain and improvement in physical functioning associated with osteoarthritis. ${ }^{11}$ Exercise is a critical factor that increases strength, mobility, joint stability, and reduces pain in patients with osteoarthritis. ${ }^{11}$

\section{Pharmaceutical Treatments}

Pharmaceutical treatments are the most common form of OA treatments. Management of OA can be a combination of both prescription and over the counter therapies.

Analgesics. Acetaminophen is the first line treatment for patients with mild to moderate osteoarthritis. ${ }^{19}$ However, with the elderly, nonsteroidal anti-inflammatory agents (NSAIDs - selective and non-selective) utilization has the potential for toxicity. ${ }^{19}$ Cyclooxygenase-2 (COX-2) selective inhibitors are utilized for moderate to severe osteoarthritis patients and those who have an increased risk for gastrointestinal side effects. ${ }^{19}$ COX-2 inhibitors are NSAIDs that received Food and Drug Administration (FDA) approval. These specific COX-2 inhibitors appear to be as effective as current non-selective NSAIDs in treating the pain and inflammation of arthritis. However, Cox-2 selective inhibitors can cause an increased risk of cardiovascular problems. ${ }^{19}$ For patients where oral NSAIDs are poorly tolerated, topical preparations of NSAIDs and the analgesic ointment capsaicin may be effective. ${ }^{19}$

Intra-Articular Steroids. For those patients with severe osteoarthritis, with severe increase in pain, or with abnormal fluid build-up, intra-articular steroids can be a short-term relief. ${ }^{19}$ However these inter-articular corticosteroids are limited in the duration of their effect and the frequency with which they can be used. ${ }^{19}$

\section{Surgical Treatments}

Most clinicians feel surgery should be avoided when symptoms of osteoarthritis can be controlled by other treatments. ${ }^{19}$ The characteristic indications for surgery are incapacitating pain and restriction of functions such as walking and daily activities or inability to sleep or work. ${ }^{19}$

Arthroscopic Debridement and Lavage. Arthroscopic debridement and lavage of painful joints is a controversial procedure. ${ }^{19}$ However, for some patients with flaps of meniscus or cartilage that are causing locking of the joint it may help to improve joint mobility and function. ${ }^{19}$

Osteotomy. An osteotomy is a surgical operation in which bones are shortened, lengthened, or changed in alignment by cutting. Osteotomy can delay the need for a joint replacement for 5-10 years and improve pain and function. ${ }^{19}$

Joint Replacement. For whom all the other treatments have failed joint replacement is an option. ${ }^{19}$ Osteoarthritis is the cause for $85 \%$ of all knee and hip replacement surgeries. ${ }^{19}$ In patients properly selected, positive results are achieved in $95 \%$ of cases. ${ }^{19}$ 


\section{Complementary and Alternative Treatments}

The use of CAM among adults in the U.S. is frequent, with $38 \%$ utilizing some form of CAM. When megavitamin therapy and prayer are included, $63 \%$ utilize some form of $\mathrm{CAM}^{28}$ This is especially true for older adults who have been diagnosed with a chronic condition, such as osteoarthritis. ${ }^{28}$ Overall the U.S. public spent approximately $\$ 36-\$ 47$ billion dollars on all CAM in $1997 .^{29}$ This amount is more than the public paid for all out of pocket physician services. ${ }^{29}$ Due to the chronic nature of osteoarthritis, some patients turn to alternative treatments to seek relief from pain and disability. A study of older adults diagnosed with osteoarthritis in Washington State showed that $47 \%$ of the sample utilized CAM for their condition. ${ }^{12}$ Another study found that $63 \%$ of patients from a rheumatology practice utilized at least one CAM therapy for their osteoarthritis. ${ }^{30}$ Individuals who use CAM regularly are more likely to have OA with severe pain. ${ }^{31} \mathrm{~A}$ total of $16.8 \%$ of CAM users sought alternative therapy for problems of the back, $6.6 \%$ utilized CAM for problems of the neck, $4.9 \%$ used CAM for arthritis and/or joint pain, and 2.4 percent used CAM for unspecified recurring pain. ${ }^{32}$ Approximately half of all arthritis patients have utilized some form of CAM. ${ }^{33}$ Many patients use CAM as a supplement to their allopathic treatments and in an attempt to exert control over their disease. $^{30}$

\section{Herbal/Mineral Supplements}

Herbal therapies are common. Patients suffering from musculoskeletal problems are likely to be users of herbal treatments. ${ }^{34}$ Among the most common treatments of this type are glucosamine and chondroitin sulfate. ${ }^{17}$ Several studies have shown glucosamine/chondroitin to be superior to placebos and have fewer adverse events than NSAIDs. ${ }^{17}$

\section{Prayer/Spirituality}

Prayer is also a commonly used alternative therapy for arthritis. ${ }^{35}$ Research in behavioral medicine suggests that the interactions of mind, body and spirit can have powerful effects on health. ${ }^{35}$

\section{Massage Therapy}

Massage therapy is the application of soft-tissue manipulation techniques to the body, generally intended to reduce stress and fatigue while improving circulation. Massage therapy has also proven beneficial for many chronic conditions, including arthritis.

\section{Chiropractic Care}

Chiropractic care emphasizes diagnosis, treatment and prevention of mechanical disorders of the musculoskeletal system, especially the spine. The main treatment involves manual therapy of joints. This treatment assumes that spinal joint dysfunction 
interferes with the body's function. It is common for chiropractors to treat conditions such as osteoarthritis.

\section{Acupuncture}

Acupuncture involves the stimulation of the specific acupuncture points (acupoints) on the skin by the insertion of needles ranging in length from $1 \mathrm{~cm}$ to $10 \mathrm{~cm}$. Acupuncture is viewed as CAM.

There are numerous treatments for osteoarthritis. As there is no cure and the treatments are mainly to decrease disability and increase quality of life. It is important to figure out what treatments have the most utility value for patients. Therefore utilizing a marketing methodology new to the healthcare field called conjoint analysis would be prudent. This study will answer the questions of who wants what regarding osteoarthritis treatments and how much they are willing to pay for them.

\section{Treatment Preferences}

Studying treatment preferences is very important in the design and implementation of any health-care policy or program. It is vital to understand how patients value different aspects of the health-care interventions they receive. If clinical practice, drug development, and health policies align with patient preferences, the effectiveness of health interventions may improve. ${ }^{36}$ As people grow older, they place more consideration on the prevention and treatment of their chronic illnesses, such as OA. ${ }^{37}$ They seek out various treatments that they feel will increase their health. Many of these are nonpharmacologic. Herbal/mineral supplements have increased in utilization dramatically over the past twenty years. ${ }^{37}$ Religion and spirituality are widely used as a means to improve health. Numerous research studies have examined the relationship between religion and spirituality and physical health. ${ }^{38}$ This is more significant among the elderly. ${ }^{38}$ Data indicate that prayer/spiritual healing is among the most commonly used CAM treatment. ${ }^{38}$ The most common users of prayer/spiritual healing for health promotion are the elderly, females, blacks, residents of the southern region, and those having chronic conditions. ${ }^{38}$

\section{Conjoint Analysis}

Conjoint analysis is a technique that is used in this study to evaluate how patients choose among different treatments or therapy regimens. Patients make decisions about complex, multi-attribute treatments and therapies based on a psychological function of combining the value or utilities of the separate yet conjoined parts. Conjoint analysis provides an approach to understanding the relative importance of treatment attributes, the value of attribute levels, and how patients might trade-off between different attribute levels. Various forms of conjoint analysis have been successfully applied to health care and pharmaceutical services. $^{39}$ 


\section{History of Conjoint Analysis}

Conjoint analysis is based on the statistical work of Luce and Tukey. ${ }^{40}$ In 1970, Paul Green, a marketing professor recognized that Luce and Tukey's work could be translated into solving marketing problems. ${ }^{3}$ Green realized that Luce and Tukey's work could help evaluate how consumers make multifaceted decisions to purchase and also to estimate market and consumer preferences. ${ }^{3}$ From this, McFadden based his 1974 conjoint analysis studies in transportation. ${ }^{41}$

The first conjoint analysis studies were done with a full profile. Each survey subject was given a card with a set of attributes, and survey participants would be asked to rank them in order of preference (best to worst). Attributes are the factors that when considered jointly define a product, service, or treatment. This would allow researchers to statistically determine which attributes were the most important for consumers. This approach however, proved quite burdensome for survey participants. To mitigate this problem, a researcher named Richard Johnson developed a trade-off method that broke the profiles into just two attributes from which survey respondents could choose. ${ }^{3}$ From there, the rank-ordered judgments were then used to estimate the preferences for each attribute for each respondent. ${ }^{42}$

Currently, there are three main types of Conjoint Analysis used in research: Traditional Full-Profile Conjoint Analysis, Adaptive Conjoint Analysis, and Choice-Based Conjoint Analysis. Traditional Full-Profile or Conjoint Value Analysis (CVA) is used about 10\% of the time in current research. ${ }^{3}$ For pen and paper studies, full-profile conjoint analysis is often used. Because survey respondents must choose all attributes at once, they often employ abridgement tactics, due to the large amount of information to process. ${ }^{3}$

\section{Description of Conjoint Analysis}

Conjoint analysis utilizes the idea of an additive model to predict preferences. ${ }^{43}$ It works well for preference and marginal willingness to pay (WTP) studies because it mirrors choices directly from real-life.

The theoretical framework of this methodology is based on Lancaster's 1966 and 1971 work in consumer theory. ${ }^{44}$ The theory states that 1) the characteristics of goods and services give utility to the consumer, 2) goods and services possess more than one different characteristic, and 3) a combination of goods and services may have different characteristics than goods/services separately. ${ }^{44}$ Conjoint analysis is based on Lancaster's theory, the idea that consumers (or patients) value the quantity of product or service attributes (characteristics). ${ }^{45}$

Conjoint analysis presents pairs or sets of alternative attribute bundles and asks survey subjects to choose among the options in the bundle. WTP is not directly estimated 
through conjoint analysis, however, it is inferred by regressing rankings on attribute levels and finding the part-worth utility values of different attributes. ${ }^{46}$ Levels are the mutually exclusive options within each attribute. The strength of conjoint analysis is that the methodology can provide values for both an entire treatment regimen and the partworth value of each attribute of the treatment. ${ }^{46}$ It also allows survey participants to think in terms of multi-attribute trade-offs rather than directly expressing dollar values.

However, conjoint analysis does have many weaknesses that can cause concern if not dealt with properly. If too many trade-offs are presented in the survey, respondent fatigue can reduce the validity of the data. If a 'none' option is not offered, respondents may feel forced into accepting options they would not normally accept. There are no standardized rules for creating a conjoint analysis survey, there are a numerous options for experimental designs. Conjoint analysis is an extremely flexible tool and represents an interdisciplinary method to understanding patient preferences. Many of the possible applications of conjoint analysis in healthcare have been unexplored or under explored, so best-practices in this field are difficult to establish.

Conjoint analysis allows for the indication of the relative importance or utility of various attributes of a product or service. ${ }^{47}$ When price is included as one of the attributes, WTP can be calculated. ${ }^{47}$ Conjoint Analysis is based on the following three concepts: ${ }^{47}$

- Each good or service is a bundle of attributes.

- Each individual has a set of unique utility weights for each attribute.

- Combining the utility weights for different attributes provides a measure of an individual's overall relative utility for that good or service.

Conjoint analysis demonstrates numerous benefits when compared with traditional WTP approaches. ${ }^{48}$ In conjoint analysis, subjects are asked to choose among different services, described in their attributes and associated levels. This establishes the relative importance of an attribute. Conjoint analysis methodology can also be used to estimate how individuals choose between these attributes, and can demonstrate at what point a study participant chooses one attribute over another attribute. This is known as the marginal rate of substitution (MRS). Because cost is also included as an attribute, WTP can be estimated as a price subjects are willing to trade for any changes in individual attributes of a service.

There are five stages in the conjoint analysis: attribute identification, assignment of levels, scenario presentation, preference obtainment and data analysis. ${ }^{48}$ Assigning levels to each attribute can cause some concerns. These concerns involve the identification of an appropriate range of levels, what the monetary intervals should be for WTP, and how to define qualitative levels. The levels should mimic real-life choices. This method asks respondents to choose between the tasks, and then asks them if they would really choose the treatment in real life. 
The 'dual-response none' option allows for the real life option of declining any treatment at any price. The dual response none option allows for more data points than just the option of choosing "none".

\section{Conjoint Analysis and Health}

Conjoint Analysis is a relatively new methodology for health care. It holds promise as a tool for evaluating patient preferences, since treatment desirability can lead to better compliance and therefore better health outcomes, an improvement in health for patients.

\section{Conjoint Analysis and Patient Preferences}

A study that investigated preferences for preventative asthma medication found that the main attribute patients wanted was no medication side effects and a maximum level of physical activity ability. ${ }^{49}$ This discrete choice survey sampled 57 adults with mildmoderate asthma. The researchers used 16 scenarios with three choices for drug treatment: a hypothetical medication, the patient's current medication, and a 'none' option for no medication. ${ }^{49}$ A study exploring patient preferences for the attributes associated with the efficacy and side effects of OA treatments found that respondents were more concerned about the potential risk of serious-to-moderate side effects than they were for mild-to-moderate side effects of osteoarthritis treatment. The intent of the study was to explore patient preferences for the attributes associated with the efficacy and side-effects of osteoarthritis treatments. ${ }^{50}$ The level of risk preferences changes with the disease state. A study examining the risk-benefit preference in elderly Alzheimer's patients showed that that they are willing to accept significant increases in the risk of death or disability in exchange for treatments that modify the course of Alzheimer's disease. ${ }^{52}$ Conjoint analysis literature and health care is still a new and developing body of literature, but even early efforts have shown conjoint analysis' potential for clarifying the 'what' and 'why' regarding patient preferences.

\section{Conjoint Analysis and Complementary and Alternative Medicine}

There are only a handful of conjoint analysis studies evaluating preferences for the utilization of CAM. A study examining preferences among asthma patients who utilized homeopathic or conventional treatment showed that patients who utilized homeopathic doctors preferred to be seen as a whole patient, but preferences did not vary significantly between the two groups. ${ }^{53}$ The study proved that it is not just the outcome that is important to patients. The process of delivery of asthma services is important to patients as well. ${ }^{53}$ 


\section{Conjoint Analysis and Willingness to Pay}

Researchers in health and medicine have been moving more towards choice based conjoint analysis to determine WTP for various treatments. ${ }^{54}$ Swedish analyses estimated WTP for asthma treatments including attributes of asthma treatment options including type of maintenance treatment, additional treatment providing relief, time to onset and duration of relief, number of symptom-free days, and out of pocket costs per month. ${ }^{56}$ The researchers studied a sample of 289 asthmatics, and found that they were willing to pay the equivalent of $\$ 36$ a month for more symptom-free days. ${ }^{56}$ Another study examined the treatment option preference of parents with asthmatic children in the United States. ${ }^{57}$ The study found that episode-free days was the attribute most important to parents followed by the out of pocket cost associated with their children's asthma treatments. $^{57}$

\section{Discrete Choice Analysis}

This research utilizes choice-based conjoint analysis, also known as discrete choice analysis. It more closely mimics real-life decision-making and so has become the most widely-used conjoint analysis technique. ${ }^{3}$ Discrete choice analysis is gaining in popularity among health researchers. ${ }^{58}$ Discrete choice differs from traditional conjoint analysis methodology. In traditional conjoint analysis, a patient is given a number of different combinations of products that vary based on attribute levels and asked to score each. In discrete choice conjoint analysis, the patient is presented with a number of panels made up of different treatment attribute levels (e.g., 4 different treatment regimens varied on the attributes of cost, side effects, route of administration, etc.). The patient is then asked to select which of the treatments they would prefer from each of the panels. From the choices the subject makes, the utility for each attribute level can be determined.

Discrete choice assumes that each product or treatment option is a composite of different characteristics. Current research supports the idea that discrete choice survey participants can conduct between 9 and 16 discrete tasks before they lose interest or experience fatigue from the scenario comparisons. ${ }^{59}$ The strength of this methodology is its ability to ask realistic questions that mimic the tradeoffs patients make when deciding on their treatments. Discrete choice modeling is best for examining the complex decisions patients make when different services can be purchased and combined. It is also useful for pricing and WTP studies. There is also a benefit because unlike full-profile conjoint analysis, discrete choice reduces respondent overload.

A patient's preference for osteoarthritis treatment at a point in time is a series of hierarchical decision states. Patients may go through several stages before making healthcare choices. ${ }^{60}$ Therefore:

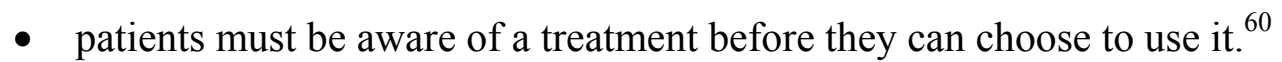

- patients have constraints ${ }^{60}$ on their treatment choices such as income level, time, insurance status, social influences, health beliefs. 
In discrete choice analysis there may also be an 'opt-out' option for respondents to specify if they would really choose one of the treatment profiles in reality.

\section{Latent Class Analysis}

Latent Class analysis was developed in the early 1950s by Lazarsfeld, and further developed by Goodman who allowed for the practical application to marketing research. ${ }^{61}$ Latent class analysis allow market researchers to uncover segments in the market that are not observable directly. Latent class analysis groups respondents not by observable characteristics, such as age, gender, or income. Rather, latent class analysis

groups individuals by their preferences. Latent class analysis is way to detect and model market segments composed of persons who share similar values, characteristics, and behaviors. 


\section{CHAPTER 3. METHODOLOGY}

\section{Overview}

This study uses choice-based conjoint analysis survey design to determine preferences and WTP for specific osteoarthritis treatments.

\section{Research Design}

The design of this study is a non-random cross sectional survey to determine Medicare beneficiaries' preferences and willingness to pay for osteoarthritis treatments. The population of interest in this study is the Medicare eligible (over age 65) population has many reasons. Osteoarthritis occurs mostly in older adults, and the cost burden of osteoarthritis on Medicare is vast.

Choice based conjoint analysis technique was utilized. The preferences and willingness to pay were determined using choice-based conjoint analysis, advanced design module with a dual-response none option. Choice-based conjoint analysis uses computer guided surveys to elicit patient preference for a series of comparisons of osteoarthritis treatments that are characterized differently. Discrete Choice Conjoint Analysis collects and analyzes preference data using an interactive computer-based survey program. Each comparison had a 'dual response none' option to better mimic real life decisions. This option required seniors to chose between 3 treatment bundles, and then asks the question "based on your budget and what you know about your osteoarthritis treatment options, would you really choose this treatment"(Appendix A). This was done to force a trade-off between the three treatment options, but still capture whether or not respondents would chose that treatment in reality.

This conjoint analysis study provides a greater understanding of how patients might incorporate complementary and alternative therapies into their OA treatment regimen. This data enables clinicians and health care professionals to determine how patients may trade-off different levels of treatment attributes (e.g., cost, allopathic treatments, combination therapies, and CAM therapies) for OA treatments.

\section{Sample Size}

Conjoint Analysis has no specific sample size power calculator, however there is a 'rule of thumb ${ }^{62}$ Sample sizes for conjoint analysis choice-based experiments usually fall between 150-1,200 respondents. ${ }^{3}$ Sample size represent a major challenge in conjoint analysis. ${ }^{36,54}$ The formula for this 'rule of thumb' is:

$$
\mathrm{nta} / \mathrm{c} \geq 500
$$


Where $\mathrm{n}=$ the number of respondents, $\mathrm{t}=$ the number of tasks, $\mathrm{a}=$ the number of alternatives per task, and $\mathrm{c}=$ number of analysis cells. The discrete choice conjoint analysis component of this study has 14 tasks for each participant to complete ( $t), 4$ alternatives or choices per task (a) including the 'dual-response none' option, and the largest number of levels in any one attribute is 20 (c). Therefore, the sample size calculation formula is $(n * 14 * 4) / 20 \geq 500$. Therefore we can calculate that we should have a minimum sample size of greater than or equal to 179 persons. Therefore the study participant sample of 181 enables a robust discrete choice conjoint analysis study. The sampling frame for a sample size of 181 is shown in Table 1.

According to the U.S. Census of $2000,45 \%$ of Shelby County is white, and $51 \%$ is African-American. ${ }^{63,64}$ Therefore the sampling frame will be demographically representative, with approximately half of the sample white, and half of the sample black. The overall disability as defined by Medicare and the overall percentages of disability will be utilized for the sampling framework; none to mild disability $84 \%$, moderate disability $11 \%$, and severe disability is $5 \% .{ }^{65}$ The study oversamples patients with moderate and severe disability.

\section{Study Design}

The greater Memphis metropolitan area (Shelby County) has a population of $909,035 .{ }^{63}$ The percent of those 65 years of age or older is $10.9 \%$. The city has six senior centers operated by the Parks Service with membership ranging from 800-1200 at each center. Depending on locations, senior centers consist of predominantly African American, Caucasian, or females.

Data for this convenience sample were collected at four senior centers and one internal medicine practice. These sites were chosen based on factors such as cost, time, and the accessibility of Medicare beneficiaries with osteoarthritis. Considerations regarding representativeness were addressed by racial, gender, and disease severity sample distributions. Figure 1 shows the locations of the senior centers: The Lewis Senior Center, the Bartlett Senior Center, The Frayser-Raleigh Senior Center, and the Ruth Tate Senior Center. The Lewis Senior center is located in mid-town Memphis and is racially diverse, where about half of the seniors are white, and half of the seniors are black. The Bartlett Senior Center is located just outside the city limits of Memphis, in a more rural area, where members are majority white. The Frayser-Raleigh Senior Center is located in North Memphis, and is comprised of approximately $70 \%$ whites and $30 \%$ blacks. The Ruth Tate Senior Center is located in South Memphis, and its members are majority black. All of the senior centers had more female members than male members. Seniors with severe OA were surveyed at Southhaven Internal Medicine Associates in Memphis, through courtesy of Dr. Mary Missak and Dr. Magdi Wassef. This is because none of the seniors surveyed at any of the senior centers had severe osteoarthritis according to the Brief Pain Inventory $\left(\mathrm{BPI}^{\circledR}\right)$ cutpoint scale. 
Table 1: Target Sample Size Distribution

\begin{tabular}{lccc}
\hline Sample: & Mild OA & Moderate OA & Severe OA \\
\hline Black Men & 25 & 6 & 5 \\
Black Women & 38 & 8 & 7 \\
White Men & 26 & 4 & 6 \\
White Women & 40 & 8 & 8 \\
\hline
\end{tabular}

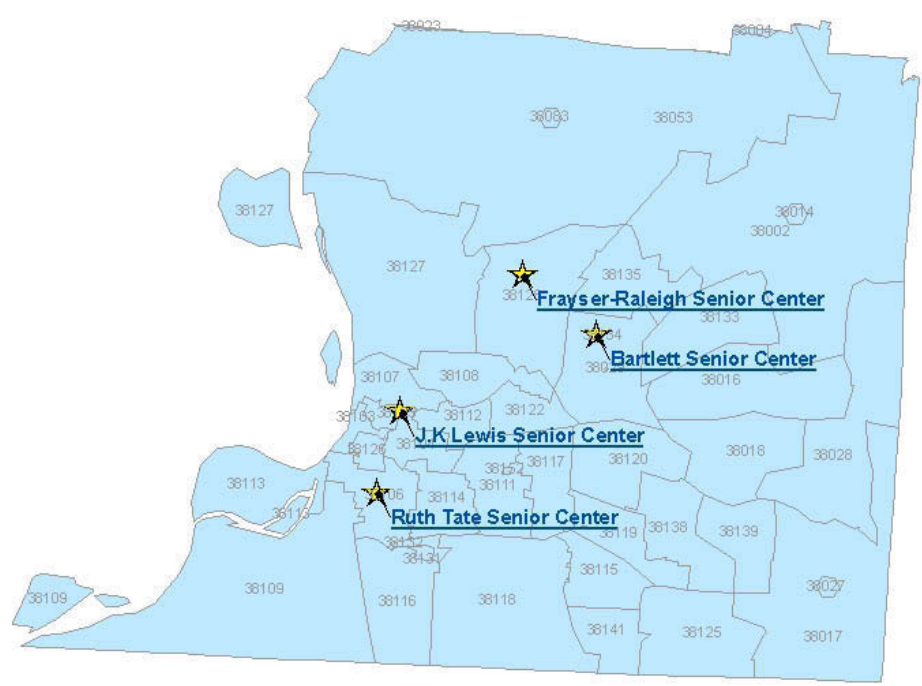

Figure 1: Senior Center Data Collection Sites 


\section{Participants}

The study had a sample of at 181 Medicare beneficiaries with osteoarthritis from three of the seven senior centers in Memphis/Shelby County. This included sampling from urban, suburban, and rural parts of the county. The sample included $60 \%$ women and $40 \%$ men, as this is the demographic of Medicare. The sample also included $50 \%$ black patients and $50 \%$ white patients, as this is the basic cross section of Memphis/Shelby County. Asians and Hispanics were excluded due to potentially small sample size.

\section{Inclusion Criteria}

The inclusion criteria were black and white Medicare beneficiaries aged 65+ with a selfreported diagnosis of osteoarthritis. All patients were able to understand English, and were asked if they were willing to participate in a study examining patients' preferences about treatments for osteoarthritis.

\section{Survey Instrumentation}

A discrete choice, advanced design module survey was developed. It included treatments from the American Geriatrics Society treatment guidelines for osteoarthritis and the most common CAM supplements, services, and treatments from the National Health Interview Survey. In addition, to determine patients with mild, moderate, or severe OA, the BPI ${ }^{\circledR}$ was given after reading the consent form and prior to beginning the conjoint survey.

The cut points for mild, moderate, and severe osteoarthritis patients were derived from the BPI ${ }^{\circledR}$ (Appendix B). This validated survey was designed by and used with permission of Dr. Charles S. Cleeland of the University of Texas MD Anderson Cancer Center. The BPI is a short, self-administered questionnaire designed to evaluate the intensity of pain and the impairment caused by pain during the past 24 hours. Four items measure pain intensity (pain now, average pain, worst pain, and least pain) using 0 (no pain) to 10 (pain as bad as you can imagine) numeric rating scales. Seven items measure the level of interference with function caused by pain (general activity, mood, walking ability, normal work, relations with other persons, sleep, and enjoyment of life) using 0 (no interference) to 10 (complete interference) rating scales. Originally, the BPI was developed to evaluate cancer pain, but has been shown to be valid and reliable for chronic non-cancer pain. ${ }^{66}$ For mild OA, the cut points were a score of $0-4$, for moderate OA, the cut points were a score of $>4$ to 7 , and for severe OA, the cut points were $>7$ to $10 .^{66}$

Prior to launch, the survey was pilot tested among staff and faculty at the University of Tennessee Health Science Center. To decrease participant boredom and fatigue, several demographic questions were included among the conjoint questions to break up the survey. Then, a feasibility study was carried out using a small sample of ten participants from Bartlett Senior Center to help identify and resolve any problems the target respondents may have responding to the BPI and the conjoint analysis survey. 
Preferences were derived by asking respondents to make trade-offs between the characteristics of competing treatment options rather than explicitly naming these options. Treatment options included the most common treatments for osteoarthritis among CAM modalities derived from the National Health Interview Survey $2007 .{ }^{32}$ For allopathic treatment modalities, the characteristics were derived from the best practices proposed by the American Geriatrics Society. Spiritual healing/prayer was included in the treatment levels. Spiritual healing is not reimbursable through Medicare. This CAM therapy was included because the dollar valuation found in this study (marginal willingness to pay) for prayer/spiritual healing could impact social policy. Marginal WTP was acquired from the cost variable included in the questionnaire.

\section{Data Collection}

At the senior centers, recruitment signs were posted prior to the survey date stating that a voluntary survey about patient preferences for osteoarthritis would be given out and the eligibility criteria was if they were over 65 and had osteoarthritis. Participants were informed they would receive a University of Tennessee coffee mug as a token of the researcher's appreciation. Patients that expressed interest in taking the survey were verbally asked if they had osteoarthritis. Patients that self-reported that they did have osteoarthritis and were interested in taking the survey were read the informed consent letter and were given a copy (Appendix $\mathbf{C}$ ). The reading of the informed consent took approximately 2 minutes. Patients then were read and given a brief informational hand out regarding treatment options for osteoarthritis. The reading of the informational hand out took approximately 3 minutes. The survey participants were then given the BPI to determine osteoarthritis severity. The survey and scoring took approximately 6-15 minutes depending on the participant. The participants were then read the computerbased conjoint survey, and that took 8-15 minutes depending on the participants. Cheaptalk strategies were utilized. ${ }^{36}$ Cheap talk was designed to alert subjects to the consequences for the validity of the study if they are not attentive in answering questions. Cheap talk simply explained the problem of hypothetical bias to study participants prior to administration the survey. ${ }^{67}$ Results of previous literature regarding cheap talk used with health related conjoint studies are clear: cheap talk effectively reduces hypothetical bias.

Interviewer-led administration of conjoint data can improve the quality of the data because the interviewer can fully explain the task, answer any questions the survey participant may have, and recognize if more explanation is needed. ${ }^{36}$ Most of the participants took 20 minutes to complete the entire survey, but some participants took as long as 35 minutes. Test-retest reliability was calculated from the two fixed tasks. The Kappa statistic was .952, showing a 95.2\% agreement among fixed choice 1 and fixed choice 2 , meaning that survey respondents were paying attention, and answering questions to the best of their ability.

$$
\kappa=\frac{\operatorname{Pr} o-\operatorname{Pr} e}{1-\operatorname{Pr} e}
$$


Data were collected over a period of ten weeks. The data were collected during morning hours, prior to lunchtime at each senior center. The Bartlett Senior center was visited four times, the Ruth Tate Senior Center was visited four times, the Frayser Raleigh Senior Center was visited three times, and the Lewis Senior Center was visited five times. Data collection continued until the sampling frame was satisfied. Twenty-six severe OA patients were collected over a period of two weeks at Southaven Internal Medicine Associates.

\section{Attributes and Levels}

The following attributes and levels were selected for the study:

1. Treatment Options

a. Allopathic Treatment Only

b. CAM Treatment Only

c. Combination Treatment (one allopathic treatment and one CAM treatment)

2. Allopathic Treatment

a. Prescription Pain Medication (3x daily, 90 tablets per month)

b. Prescription OA Medication (2x daily, 60 tablets per month)

c. OTC Pain Medication (4x daily, 120 tablets per month)

d. Physical Therapy (2x week, $8 \mathrm{x}$ per month)

3. CAM Treatment
a. Massage Therapy ( $2 \mathrm{x}$ per month)
b. Acupuncture Therapy (1x per month)
c. Chiropractic Therapy (1x per month)
d. Prayer/Spiritual Healing (as needed or desired)
e. Herbal/Mineral Supplements (one month supply)

4. Treatment Cost
a. $\$ 25$
b. $\$ 50$
c. $\$ 75$
d. $\$ 100$
e. $\$ 125$

Preference data were derived from discrete choice conjoint analysis software called Sawtooth Software and analyzed along with the patient characteristics data set. ${ }^{68}$ This patient characteristics data set included age, race, gender, income level, education level, disability status, and duration of osteoarthritis. 


\section{Data Analysis}

\section{Utility Values}

Using multinomial logit analysis, the utility values were calculated for the overall sample, specific cohorts, and the latent class segments. Utility value calculations were calculated using the SMRT program by Sawtooth Software. Utility values were calculated using effect coding. Within each attribute, the effects of the levels sum to zero. That is because one level is omitted in each attribute in doing the estimation, and then a value supply is supplied afterward for the missing level that is equal to the negative of the sum of the others. The software uses an iterative procedure to find the maximum likelihood solution for fitting a multinomial logit model to the data. It starts with a model with all utility weights equal to zero. Within each attribute, logit deletes the last level. Then the likelihood of the respondents' choices is computed. An estimate is then provided for the deleted level by computing the negative of the sum of the included levels. Therefore, all utility values within each attribute will sum to zero. The values produced for each attribute level, can be interpreted as an average utility value for the respondents that were surveyed. In logit analysis, effect is synonymous with utility.

It is important to note that a negative utility value does not mean that no one in the sample chose this treatment. It does mean however, that it is the least preferred level in that attribute. Logit analyses are evaluated by chi-square statistics. The procedure is to determine the log likelihood that would be obtained, given the sample size and nature of the data, if the effects were all zero. Therefore, the chi-square analysis simply compares the results of the analysis to what would be obtained with no effects at all. In multinomial logit, the alternative hypothesis is that the model effects do not equal zero and that there is variation in the utilities between attributes and levels. The significance level of the chi-square can be calculated by using the degrees of freedom equal to the number of parameters estimated. The t-values are a measure of the significance of the difference between each level effect and the average of zero.

\section{Product Shares of Preference}

Product shares of preference were also calculated in Sawtooth software. The calculation was done in Sawtooth Software Market Research Tools (SMRT). This is a separate program. Its is used primarily to estimate the likely acceptance or interest in different product concepts defined using the attributes and levels included in this conjoint analysis study. SMRT converts raw conjoint data into something more managerially useful: simulated market choices. The product shares of preference do not assume that the respondent always chooses the product with highest utility. Instead, it provides an estimate of the probability of choosing the product. This is done by taking the total utilities for a treatment and taking the anti-log: $s=\exp$ (utility) then rescaling the numbers so they sum to 100 and can be easily interpreted. The Share of Preference models are 
designed to simulate what would occur in the real world. The Share of Preference models capture information about preferences for products.

\section{Latent Class Analysis}

Latent Class analysis is possible with choice based conjoint analysis. This analysis method allows for the analysis of previously unobserved market segments. ${ }^{61}$ Aggregate analyses for conjoint analysis data can obscure important aspects of the data. Therefore latent class analysis is an important method for detecting and modeling underlying latent market segments that share similar preferences. Latent class analysis detects segments of the survey respondents that have similar preferences based on their choices in the choice based survey. Latent class analysis does not assume that each survey respondent is wholly in one group or another. Each respondent does receive a non-zero probability of belonging to each market segment. When the probabilities become very close to zero or one, the solution fits the data well.

$$
P(Y=y)=\sum_{x=1}^{C} P(X=x) \prod_{\ell=1}^{L} P\left(Y_{\ell}=y_{\ell} \mid X=x\right)
$$

Where $\mathrm{X}$ represents the latent variable and $\mathrm{Y} \ell$ one of the $\mathrm{L}$ observed variables, where $1 \leq \ell \leq L$, where $\mathrm{k}=$ number of groups, $\mathrm{n}=$ number of independent parameters per group, $\mathrm{N}=$ total number of choice tasks in the data. The symbol $\mathrm{C}$ is the number of latent classes. Each specific latent class segment is enumerated by $\mathrm{x}, \mathrm{x}=1,2, \ldots, \mathrm{C}$, and a specific value of $\mathrm{Y}_{\ell}$ by $\mathrm{y} \ell, \mathrm{y}_{\ell}=1,2, \ldots, \mathrm{D} \ell$. The $\mathrm{L}$ manifest variable is mutually independent within each latent class segment.

\section{Assumptions}

The following assumptions were made regarding this research:

- Patients must be aware of the available treatments before they can use them, ${ }^{60}$ and

- Patients have constraints ${ }^{60}$ on their treatment choices such as income, time, insurance status, social influences, health beliefs, and cultural practices, and

- Patients are limited by these constraints, and thus make trade-offs for treatments based on utility value.

\section{Protection of Human Subjects}

The study protocol was submitted to and approved by the Institutional Review Board of the University of Tennessee Health Science Center in Memphis, TN (APPENDIX D). 


\section{Hypothesis Testing Plan}

This study adds to the literature in that the results of this analysis will examine packages of care involving combinations of treatment modalities, including CAM, and emphasizes patient preferences and willingness to pay for the most preferred treatments.

To answer the hypothesis that blacks will place higher utility on CAM than whites a model including only whites and only blacks will be used to compute utility scores for the two groups. Then, importance scores will be calculated for each attribute to see if the null should be accepted. The same method will be used to determine whether or not whites overall place higher utility on allopathic treatments than blacks. For the hypothesis regarding how women place higher utility on CAM treatments than men, two multinomial logit models will be developed, one for males and one for females. Then utility values will be calculated, and from the utility scores importance scores will used to either reject or fail to reject the null hypothesis. To determine whether or not to reject or accept the null hypothesis regarding whether survey respondents overall will place higher utility on allopathic treatments over CAM treatments a model was developed utilizing all respondents. The hypothesis that blacks will differ in CAM valuation than whites, and will place higher utility on CAM treatments of prayer/spiritual healing and herbal/mineral supplements and therefore will be willing to pay more for them will be tested with two models, and marginal willingness to pay will be tested utilizing the market simulator SMRT from Sawtooth Software. The same method will be used to test the hypothesis that whites will place higher utility on service-oriented CAM therapies that are serviceoriented, such as chiropractic care and massage therapy and will be willing to pay more for these services. The hypothesis that duration of OA affects the valuation of CAM therapies will be tested by grouping those that have been diagnosed with OA for $0-5$ years, those that have been diagnosed for 6-10 years, and those that have been diagnosed for more than 10 years. Then three models will be developed and importance scores will be calculated from the utility values. The hypothesis that the more disabled a person has become, the more they will value CAM will be determined by the BPI, and the established cut points for mild, moderate, and severe OA. The moderate and severe groups will be combined because of small sample size. Then two separate models will be run for each group, mild, and then moderate-severe. From there the utility values will also for importance score calculation. 


\section{CHAPTER 4. RESULTS}

\section{Description of Sample}

The sample was collected from Senior Centers in Shelby County, Tennessee and from an internal medicine clinic located near Memphis, TN. The sample included 181 Medicare beneficiaries with osteoarthritis. Table 2 provides a descriptive analysis of demographics associated with the sample.

\section{Sample Characteristics}

The mean age of the sample was 75 years old. The sample consisted of $39.56 \%$ males and $60.44 \%$ females. The participants were $50.28 \%$ white and $47.72 \%$ black. The sample's educational attainment consisted of $13.74 \%$ not completing high school, $41.21 \%$ high school graduates, $25.82 \%$ receiving a community college degree or attending trade school, $18.13 \%$ had graduated from college, and $1.1 \%$ received a graduate degree. The overall sample had a relatively low income. This is due to the fact that most were retirees on fixed incomes. A total of $5.52 \%$ had an annual income less than $\$ 10,000$, $13.26 \%$ had an annual income from $\$ 10,001$ to $\$ 15,000 ; 18.78 \%$ of the sample had an income range of $\$ 15,001$ to $\$ 20,000 ; 22.65 \%$ of the sample had an annual income range of $\$ 20,001$ to $\$ 30,000 ; 23.76 \%$ had an income range of $\$ 30,001$ to $\$ 40,000$ annually; $7.18 \%$ had an income range of $\$ 40,001$ to $\$ 50,000$ annually; and $8.84 \%$ of the sample had an income of $\$ 50,000$ or more per year. This sample suffered from much comorbidity. The vast majority of the sample $(75.27 \%)$ had high blood pressure. Approximately a quarter of the sample self-reported obesity and heart disease. Diabetics were also common, with $31.87 \%$ of the sample reporting a doctor had told them they had diabetes. Nearly $13 \%$ of the sample self-reported a doctor's diagnosis of asthma. COPD and renal disease were relatively uncommon co-morbidities with only $2.2 \%$ and $.55 \%$ of the sample reporting having those conditions respectively. Only $8.79 \%$ of the sample self-reported suffering from depression. Over $11 \%$ of the sample stated that other than osteoarthritis, they did not suffer from any co-morbidity.

\section{Results for Total Sample}

Table 3 describes the overall utility values for the total sample. For the attribute of allopathic treatment, the levels with the most utility, or value, are prescription pain medication and over the counter medication, with utility values of .35 , and .34 respectively. For the total sample, osteoarthritis medication and physical therapy had the lowest utility values, and thus were the least preferred overall.

In the attribute complimentary and alternative treatment the most preferred treatment by the overall sample was prayer/spiritual healing with a utility value of .71. Massage was valued second with a utility value of .22 , and herbal/mineral supplements were the third 
Table 2: Demographics of Sample

\begin{tabular}{|c|c|c|}
\hline Variables & Mean & $\%$ \\
\hline \multicolumn{3}{|l|}{ Gender } \\
\hline Male & 72 & 39.56 \\
\hline Female & 110 & 60.44 \\
\hline \multicolumn{3}{|l|}{ Race } \\
\hline White & 91 & 50.28 \\
\hline Black & 90 & 49.72 \\
\hline \multicolumn{3}{|l|}{ Education } \\
\hline Less than High School & 25 & 13.81 \\
\hline High School Graduate & 74 & 40.88 \\
\hline Trade School or Community College & 47 & 25.96 \\
\hline College Graduate & 33 & 18.23 \\
\hline Graduate School & 2 & 1.10 \\
\hline \multicolumn{3}{|l|}{ Income } \\
\hline$\$ 0-\$ 10,000$ & 10 & 5.52 \\
\hline$\$ 10,001-\$ 15,000$ & 24 & 13.26 \\
\hline$\$ 15,001-\$ 20,000$ & 34 & 18.78 \\
\hline$\$ 20,001-\$ 30,000$ & 41 & 22.65 \\
\hline$\$ 30,001-\$ 40,000$ & 43 & 23.76 \\
\hline$\$ 40,001-\$ 50,000$ & 13 & 7.18 \\
\hline More than $\$ 50,000$ & 16 & 8.84 \\
\hline \multicolumn{3}{|l|}{ Co-Morbidities } \\
\hline High Blood Pressure & 137 & 75.27 \\
\hline Obesity & 49 & 26.92 \\
\hline Heart Disease & 45 & 24.73 \\
\hline Diabetes & 58 & 31.87 \\
\hline Asthma & 23 & 12.64 \\
\hline COPD & 4 & 2.2 \\
\hline Renal Disease & 1 & 0.55 \\
\hline Depression & 16 & 8.79 \\
\hline None & 21 & 11.54 \\
\hline \multicolumn{3}{|l|}{ Severity of Osteoarthritis } \\
\hline Mild & 129 & 71.27 \\
\hline Moderate & 26 & 14.36 \\
\hline Severe & 26 & 14.36 \\
\hline \multicolumn{3}{|l|}{ Duration } \\
\hline Less than one year & 2 & 1.10 \\
\hline $1-5$ years & 38 & 20.99 \\
\hline $6-10$ years & 59 & 32.59 \\
\hline $10+$ years & 82 & 45.30 \\
\hline
\end{tabular}

Mean age $(\mathrm{SD})=75.64(7.21)$ 
Table 3: Average Utility Values for Total Sample

\begin{tabular}{|c|c|c|c|}
\hline Attributes & Effect & SE & t-Value \\
\hline \multicolumn{4}{|l|}{ Allopathic Treatment } \\
\hline Prescription Pain Medication & 0.35 & 0.05 & 6.6 \\
\hline Prescription OA Medication & 0.03 & 0.06 & 0.46 \\
\hline Over the Counter Medication & 0.34 & 0.05 & 6.46 \\
\hline Physical Therapy & -0.72 & 0.06 & -11.23 \\
\hline \multicolumn{4}{|l|}{ Complimentary and Alternative Treatment } \\
\hline Massage & 0.22 & 0.06 & 3.43 \\
\hline Acupuncture & -0.54 & 0.07 & -7.35 \\
\hline Chiropractic & -0.54 & 0.07 & -7.57 \\
\hline Prayer/Spiritual Healing & 0.71 & 0.06 & 11.54 \\
\hline Herbal/Mineral & 0.16 & 0.06 & 2.46 \\
\hline \multicolumn{4}{|l|}{ Combination Treatment } \\
\hline Prescription Pain Medication and Massage & -0.3 & 0.16 & -1.91 \\
\hline Prescription Pain Medication and Acupuncture & 0.42 & 0.18 & 2.36 \\
\hline Prescription Pain Medication and Chiropractic & -0.22 & 0.17 & -1.28 \\
\hline $\begin{array}{l}\text { Prescription Pain Medication and } \\
\text { Prayer/Spiritual Healing }\end{array}$ & 0.18 & 0.16 & 1.11 \\
\hline $\begin{array}{l}\text { Prescription Pain Medication and } \\
\text { Herbal/Mineral }\end{array}$ & -0.07 & 0.16 & -0.43 \\
\hline Prescription OA Medication and Massage & 0.05 & 0.16 & 0.32 \\
\hline Prescription OA Medication and Acupuncture & -0.18 & 0.18 & -1 \\
\hline Prescription OA Medication and Chiropractic & 0.08 & 0.18 & 0.45 \\
\hline $\begin{array}{l}\text { Prescription OA Medication and } \\
\text { Prayer/Spiritual Healing }\end{array}$ & 0.02 & 0.16 & 0.13 \\
\hline $\begin{array}{l}\text { Prescription OA Medication and } \\
\text { Herbal/Mineral }\end{array}$ & 0.03 & 0.16 & 0.18 \\
\hline Over the Counter Medication and Massage & -0.00 & 0.17 & -0.02 \\
\hline Over the Counter Medication and Acupuncture & 0.05 & 0.17 & 0.26 \\
\hline Over the Counter Medication and Chiropractic & -0.04 & 0.18 & -0.25 \\
\hline $\begin{array}{l}\text { Over the Counter Medication and } \\
\text { Prayer/Spiritual Healing }\end{array}$ & -0.16 & 0.16 & -1.04 \\
\hline $\begin{array}{l}\text { Over the Counter Medication and } \\
\text { Herbal/Mineral }\end{array}$ & 0.16 & 0.16 & 1.03 \\
\hline Physical Therapy and Massage & 0.25 & 0.17 & 1.46 \\
\hline Physical Therapy and Acupuncture & -0.28 & 0.23 & -1.19 \\
\hline Physical Therapy and Chiropractic & 0.18 & 0.21 & 0.87 \\
\hline Physical Therapy and Prayer/Spiritual Healing & -0.04 & 0.17 & -0.21 \\
\hline Physical Therapy and Herbal/Mineral & -0.12 & 0.18 & -0.68 \\
\hline
\end{tabular}


Table 3 (continued)

\begin{tabular}{lccc}
\hline Price & Effect & SE & t-Value \\
\hline$\$ 25$ & 0.44 & 0.05 & 9.26 \\
$\$ 50$ & 0.25 & 0.05 & 5.24 \\
$\$ 75$ & -0.07 & 0.05 & -1.43 \\
$\$ 100$ & -0.21 & 0.05 & -3.98 \\
$\$ 125$ & -0.41 & 0.05 & -7.48 \\
\hline
\end{tabular}

Chi Square $=531.76$ 
most preferred with a utility value of .16. Acupuncture and chiropractic treatments were the least preferred by the sample, they both had a utility value of -.54.

The respondents were also given a choice for combination treatments. The treatment with the highest utility for the combination attribute was for prescription pain medication and acupuncture, with a utility value of .42. Price, as expected followed the trend that the lowest price had the highest utility values. Values of $\$ 25, \$ 50, \$ 75, \$ 100$, and $\$ 125$ had utility values of $.44, .25,-0.07,-0.21,-0.41$ respectively. The importance scores (Table 4) for the attributes were: allopathic treatment (18.4\%), complementary and alternative treatments $(27.7 \%)$, combination treatment carried an importance of $36.1 \%$ and price carried an importance of $17.6 \%$. Importance scores are calculated for each attribute, and shows the relative importance of each attribute. Therefore, the most important attribute for the overall sample was the combination treatment therapy. The data show that the hypothesis that survey respondents overall will place higher utility on allopathic treatments over CAM treatments cannot be rejected, however, survey respondents overall placed a higher importance on the combination therapy over the CAM therapy.

It is interesting to note that the utility values mirror the shares of preference table for the total sample in Table 5. Product shares of preference shows the percentage of respondents projected to choose each product in this specific simulated market scenario. It is clear that prescription pain medication with prayer/spiritual healing is among the most preferred from this sample. Prescription pain medicine with prayer/spiritual healing has a $10.79 \%$ chance of being chosen by the group surveyed. . The lowest share of preference was physical therapy with acupuncture, with a share of preference of only 67 .

The marginal willingness to pay for the most preferred treatment also mirrors the utility values and share of preference percentages, as seen in Table 6. As there is no market standard, a referent was used. The referent is based on the product shares of preference. It is a treatment that is a middle value; therefore the sample did not have strong preference for or against this treatment. Overall, the total sample would not pay any more money to switch from the referent (prescription osteoarthritis medication and herbal/mineral supplement) to prescription pain medication and massage and over the counter medication and massage, therefore they value those therapies similarly. The total sample is willing to pay five dollars more for prayer/spiritual healing than the referent. The sample would pay nine dollars less for physical therapy and chiropractic than they would for the referent.

Table 4: Importance Scores for Total Sample

\begin{tabular}{lc}
\hline Attributes & Importance Scores \\
\hline Allopathic & $18.4 \%$ \\
CAM & $27.7 \%$ \\
Combination & $36.1 \%$ \\
Price & $17.6 \%$ \\
\hline
\end{tabular}

$\mathrm{CAM}=$ Complementary and Alternative Medicine 
Table 5: Product Shares of Preference for Total Sample

\begin{tabular}{lcc}
\hline Product Shares of Preference (n=181) & \% Share & SE \\
\hline Prescription Pain Medication & 4.46 & 0.05 \\
Prescription OA Medication & 3.22 & 0.02 \\
Over the Counter Medication & 4.43 & 0.05 \\
Physical Therapy & 1.52 & 0.04 \\
Massage & 1.83 & 0.28 \\
Acupuncture & 1.83 & 0.19 \\
Chiropractic & 1.83 & 0.08 \\
Prayer/Spiritual Healing & 1.83 & 0.82 \\
Herbal/Mineral & 1.83 & 0.80 \\
Prescription Pain Medication and Massage & 4.09 & 0.24 \\
Prescription Pain Medication and Acupuncture & 3.96 & 0.05 \\
Prescription Pain Medication and Chiropractic & 2.07 & 0.05 \\
Prescription Pain Medication and Prayer/Spiritual Healing & 10.79 & 0.53 \\
Prescription Pain Medication and Herbal/Mineral & 4.89 & 0.15 \\
Prescription OA Medication and Massage & 4.22 & 0.16 \\
Prescription OA Medication and Acupuncture & 1.56 & 0.03 \\
Prescription OA Medication and Chiropractic & 2.04 & 0.04 \\
Prescription OA Medication and Prayer/Spiritual Healing & 6.65 & 0.44 \\
Prescription OA Medication and Herbal/Mineral & 3.87 & 0.10 \\
Over the Counter Medication and Massage & 5.50 & 0.25 \\
Over the Counter Medication and Acupuncture & 2.69 & 0.05 \\
Over the Counter Medication and Chiropractic & 2.44 & 0.06 \\
Over the Counter Medication and Prayer/Spiritual Healing & 7.66 & 0.51 \\
Over the Counter Medication and Herbal/Mineral & 6.12 & 0.15 \\
Physical Therapy and Massage & 2.43 & 0.26 \\
Physical Therapy and Acupuncture & 0.67 & 0.05 \\
Physical Therapy and Chiropractic & 1.08 & 0.06 \\
Physical Therapy and Prayer/Spiritual Healing & 2.95 & 0.19 \\
Physical Therapy and Herbal/Mineral & 1.56 & 0.10 \\
\hline
\end{tabular}


Table 6: Marginal WTP for Treatments for Total Sample

\begin{tabular}{lc}
\hline Treatments & MWTP \\
\hline Prayer/Spiritual Healing & $\$ 5.00$ \\
Prescription Pain Medication and Prayer & $\$ 4.00$ \\
Over the Counter Medication and Prayer/Spiritual Healing & $\$ 4.00$ \\
Herbal/Mineral & $\$ 3.00$ \\
Massage & $\$ 2.00$ \\
Prescription OA Medication and Prayer/Spiritual Healing & $\$ 2.00$ \\
Prescription Pain Medication and Herbal/Mineral & $\$ 1.00$ \\
Over the Counter Medication and Herbal/Mineral & $\$ 1.00$ \\
Prescription Pain Medication and Massage & $\$ 0.00$ \\
Over the Counter Medication and Massage & $\$ 0.00$ \\
Prescription OA Medication and Massage & $-\$ 1.00$ \\
Acupuncture & $-\$ 2.00$ \\
Physical Therapy and Prayer/Spiritual Healing & $-\$ 2.00$ \\
Chiropractic & $-\$ 3.00$ \\
Prescription Pain Medication and Acupuncture & $-\$ 3.00$ \\
Over the Counter Medication and Acupuncture & $-\$ 3.00$ \\
Prescription Pain Medication and Chiropractic & $-\$ 4.00$ \\
Physical Therapy and Herbal/Mineral & $-\$ 4.00$ \\
Prescription OA Medication and Acupuncture & $-\$ 5.00$ \\
Over the Counter Medication and Chiropractic & $-\$ 5.00$ \\
Physical Therapy & $-\$ 5.00$ \\
Physical Therapy and Massage & $-\$ 5.00$ \\
Prescription Pain Medication & $-\$ 6.00$ \\
Over the Counter Medication & $-\$ 6.00$ \\
Prescription OA Medication and Chiropractic & $-\$ 6.00$ \\
Prescription OA Medication & $-\$ 7.00$ \\
Physical Therapy and Acupuncture & $-\$ 8.00$ \\
Physical Therapy and Chiropractic & $-\$ 9.00$ \\
\hline Referent: Prescription OA Medication and Herbal/Mineral Supplements
\end{tabular}




\section{Results by Gender}

The utility values were calculated for various demographic groups. Table 7 gives the utility values for males and females. Overall, utility values were very similar among males and females. Marked differences included the higher utility of massage among females (.39) as opposed to males (-0.06). Similar trends exist between both genders in terms of preferences. The strongest preference for treatment among males and females for complementary and alternative medicine was prayer, with utility values at .74 and .70 respectively. The least preferred treatments in the attribute of complementary and alternative medicine were acupuncture and chiropractic. Males had a -.52 utility for acupuncture and a -.55 utility for chiropractics. Females had a -.57 utility for acupuncture and -.53 utility for chiropractics. For allopathic treatments prescription pain medication and over the counter medications were the most preferred. Prescription pain medication carried with it a .39 utility value, and over the counter medication .41 for males. Females had a utility value of .33 and .32 utility value for prescription pain medication and over the counter medication respectively. Price, as expected followed the hypothesized trend for both genders, with higher utility values for the lower prices.

As seen in Table 8, males and females place similar importance on CAM therapies, with males having an importance score of $24.1 \%$ and females placing $25.8 \%$ of importance on CAM therapy, but females did place more importance on CAM. They both valued CAM more than allopathic therapies. The hypothesis that females will place higher importance on CAM than males holds true, but combination therapy was the most important attribute for both genders.

The product shares of preference results by gender in Table 9 follow the same trend as the utility values and importance scores in Tables 7-8. Males and females were not that different in terms of their shares of preference; both genders gave the largest share of preference to prayer/spiritual healing and herbal/mineral supplements. Prayer had a $17.74 \%$ chance of being the preferred product for men, and a $15.39 \%$ chance of being the preferred product for women. For both men $(15.0 \%)$ and women $(7.46 \%)$ herbal/mineral supplements made up a large part of the product shares. For prescription medication and prayer and also over the counter medication and prayer, the preference shares were over

$8 \%$ and over $9 \%$ for men and women respectively. Prescription osteoarthritis medication had the smallest product share for both men and women.

\section{Results by Race}

To further analyze the sample, utility values were calculated for race in Table 10. Whites preferred massage over blacks, with whites having a significant utility value for massage of .44, and blacks having a non-significant value of .2. Prayer/spiritual healing was very significant with for blacks with a utility value of 1.56 , while whites had a nonsignificant negative utility value of -.03 . Whites, with a utility value of .26, also significantly preferred Herbal/mineral supplements. For allopathic treatments, both 
Table 7: Utility Values by Gender

\begin{tabular}{|c|c|c|c|c|c|c|}
\hline \multirow[b]{2}{*}{ Attributes } & \multicolumn{3}{|c|}{ Males } & \multicolumn{3}{|c|}{ Females } \\
\hline & Effect & SE & t-Value & Effect & SE & t-Value \\
\hline \multicolumn{7}{|l|}{ Allopathic Treatment } \\
\hline Prescription Pain Medication & 0.39 & 0.09 & 4.55 & 0.33 & 0.07 & 4.77 \\
\hline Prescription OA Medication & 0.12 & 0.09 & 1.4 & -0.04 & 0.07 & -0.61 \\
\hline Over the Counter Medication & 0.41 & 0.09 & 4.72 & 0.32 & 0.07 & 4.68 \\
\hline Physical Therapy & -0.92 & 0.11 & -8.47 & -0.6 & 0.08 & -7.5 \\
\hline \multicolumn{7}{|l|}{ Complimentary and Alternative Treatment } \\
\hline Massage & -0.06 & 0.11 & -0.6 & 0.39 & 0.08 & 4.83 \\
\hline Acupuncture & -0.52 & 0.12 & -4.38 & -0.57 & 0.09 & -5.98 \\
\hline Chiropractic & -0.55 & 0.12 & -4.7 & -0.53 & 0.09 & -5.86 \\
\hline Prayer/Spiritual Healing & 0.74 & 0.1 & 7.48 & 0.7 & 0.08 & 8.97 \\
\hline Herbal/Mineral & 0.39 & 0.1 & 3.79 & 0.01 & 0.08 & 0.14 \\
\hline \multicolumn{7}{|l|}{ Combination Treatment } \\
\hline Prescription Pain Medication and Massage & -0.24 & 0.26 & -0.93 & -0.34 & 0.2 & -1.71 \\
\hline Prescription Pain Medication and Acupuncture & 0.36 & 0.29 & 1.26 & 0.5 & 0.23 & 2.22 \\
\hline Prescription Pain Medication and Chiropractic & -0.33 & 0.29 & -1.14 & -0.15 & 0.22 & -0.7 \\
\hline Prescription Pain Medication and Prayer/Spiritual Healing & 0.25 & 0.26 & 0.99 & 0.13 & 0.2 & 0.66 \\
\hline Prescription Pain Medication and Herbal/Mineral & -0.04 & 0.25 & -0.16 & -0.15 & 0.21 & -0.68 \\
\hline Prescription OA Medication and Massage & 0.19 & 0.26 & 0.73 & 0.01 & 0.21 & 0.02 \\
\hline Prescription OA Medication and Acupuncture & 0.16 & 0.28 & 0.58 & -0.48 & 0.26 & -1.87 \\
\hline Prescription OA Medication and Chiropractic & 0.03 & 0.28 & 0.12 & 0.13 & 0.24 & 0.55 \\
\hline Prescription OA Medication and Prayer/Spiritual Healing & -0.22 & 0.26 & -0.85 & 0.18 & 0.2 & 0.89 \\
\hline Prescription OA Medication and Herbal/Mineral & -0.17 & 0.27 & -0.62 & 0.17 & 0.21 & 0.79 \\
\hline Over the Counter Medication and Massage & -0.01 & 0.28 & -0.03 & -0.01 & 0.21 & -0.06 \\
\hline
\end{tabular}


Table 7 (continued)

\begin{tabular}{|c|c|c|c|c|c|c|}
\hline \multirow[b]{2}{*}{ Attributes } & \multicolumn{3}{|c|}{ Males } & \multicolumn{3}{|c|}{ Females } \\
\hline & Effect & SE & t-Value & Effect & SE & t-Value \\
\hline Over the Counter Medication and Acupuncture & -0.27 & 0.27 & -1 & 0.25 & 0.22 & 1.14 \\
\hline Over the Counter Medication and Chiropractic & -0.01 & 0.28 & -0.03 & -0.08 & 0.23 & -0.35 \\
\hline Over the Counter Medication and Prayer/Spiritual Healing & -0.09 & 0.25 & -0.37 & -0.23 & 0.2 & -1.14 \\
\hline Over the Counter Medication and Herbal/Mineral & 0.38 & 0.27 & 1.44 & 0.07 & 0.2 & 0.33 \\
\hline Physical Therapy and Massage & 0.06 & 0.31 & 0.19 & 0.35 & 0.22 & 1.62 \\
\hline Physical Therapy and Acupuncture & -0.25 & 0.4 & -0.62 & -0.28 & 0.29 & -0.95 \\
\hline Physical Therapy and Chiropractic & 0.3 & 0.36 & 0.85 & 0.1 & 0.26 & 0.38 \\
\hline Physical Therapy and Prayer/Spiritual Healing & 0.06 & 0.28 & 0.22 & -0.08 & 0.22 & -0.38 \\
\hline Physical Therapy and Herbal/Mineral & -0.18 & 0.31 & -0.58 & -0.09 & 0.23 & -0.38 \\
\hline \multicolumn{7}{|l|}{ Price } \\
\hline$\$ 25$ & 0.54 & 0.08 & 6.99 & 0.38 & 0.06 & 6.31 \\
\hline$\$ 50$ & 0.14 & 0.08 & 1.74 & 0.32 & 0.06 & 5.24 \\
\hline$\$ 75$ & -0.09 & 0.08 & -1.09 & -0.07 & 0.06 & -1.08 \\
\hline$\$ 100$ & -0.21 & 0.08 & -2.5 & -0.2 & 0.07 & -3.03 \\
\hline$\$ 125$ & -0.38 & 0.09 & -4.28 & -0.43 & 0.07 & -6.11 \\
\hline
\end{tabular}

Males: Chi Square $=255.92(\mathrm{p}<.001)$, Females: Chi Square $=311.65(\mathrm{p}<.001)$ 
Table 8: Importance Scores by Gender

\begin{tabular}{lcc}
\hline Attributes & $\begin{array}{c}\text { Males } \\
\text { Importance Scores }\end{array}$ & $\begin{array}{c}\text { Females } \\
\text { Importance Scores }\end{array}$ \\
\hline Allopathic & $20.6 \%$ & $14.0 \%$ \\
CAM & $24.1 \%$ & $25.8 \%$ \\
Combination & $39.4 \%$ & $43.8 \%$ \\
Price & $15.9 \%$ & $16.4 \%$ \\
\hline
\end{tabular}

Table 9: Product Shares of Preference by Gender

\begin{tabular}{lcccc}
\hline & \multicolumn{3}{c}{ Males } & \multicolumn{2}{c}{ Females } \\
\cline { 2 - 5 } Treatments & \% Share & SE & \% Share & SE \\
\hline Prescription Pain Medication & 0.56 & 0.10 & 0.72 & 0.06 \\
Prescription OA Medication & 0.28 & 0.04 & 0.43 & 0.03 \\
Over the Counter Medication & 0.56 & 0.09 & 0.74 & 0.06 \\
Physical Therapy & 0.31 & 0.06 & 0.56 & 0.05 \\
Massage & 7.16 & 0.48 & 5.98 & 0.33 \\
Acupuncture & 3.78 & 0.33 & 2.08 & 0.21 \\
Chiropractic & 1.81 & 0.13 & 1.42 & 0.09 \\
Prayer/Spiritual Healing & 17.74 & 1.12 & 15.39 & 1.13 \\
Herbal/Mineral & 15.00 & 1.37 & 7.46 & 0.85 \\
Prescription Pain Medication and Massage & 2.95 & 0.29 & 4.74 & 0.33 \\
Prescription Pain Medication and Acupuncture & 1.16 & 0.07 & 1.13 & 0.06 \\
Prescription Pain Medication and Chiropractic & 0.70 & 0.07 & 1.08 & 0.08 \\
Prescription Pain Medication and Prayer/Spiritual Healing & 8.75 & 0.88 & 9.78 & 0.66 \\
Prescription Pain Medication and Herbal/Mineral & 4.40 & 0.26 & 3.47 & 0.16 \\
Prescription OA Medication and Massage & 1.89 & 0.20 & 3.10 & 0.22 \\
Prescription OA Medication and Acupuncture & 0.71 & 0.05 & 0.72 & 0.04
\end{tabular}


Table 9 (continued)

\begin{tabular}{lcccc}
\hline & \multicolumn{3}{c}{ Males } & \multicolumn{2}{c}{ Females } \\
\cline { 2 - 5 } Treatments & \% Share & SE & \% Share & SE \\
\hline Prescription OA Medication and Chiropractic & 0.44 & 0.05 & 0.70 & 0.05 \\
Prescription OA Medication and Prayer/Spiritual Healing & 6.23 & 0.72 & 7.04 & 0.55 \\
Prescription OA Medication and Herbal/Mineral & 2.81 & 0.17 & 2.26 & 0.11 \\
Over the Counter Medication and Massage & 3.01 & 0.31 & 4.92 & 0.35 \\
Over the Counter Medication and Acupuncture & 1.16 & 0.07 & 1.16 & 0.06 \\
Over the Counter Medication and Chiropractic & 0.71 & 0.07 & 1.12 & 0.08 \\
Over the Counter Medication and Prayer/Spiritual Healing & 8.63 & 0.85 & 9.74 & 0.63 \\
Over the Counter Medication and Herbal/Mineral & 4.40 & 0.26 & 3.53 & 0.16 \\
Physical Therapy and Massage & 1.48 & 0.32 & 3.88 & 0.36 \\
Physical Therapy and Acupuncture & 0.38 & 0.06 & 0.77 & 0.06 \\
Physical Therapy and Chiropractic & 0.34 & 0.07 & 0.89 & 0.08 \\
Physical Therapy and Prayer/Spiritual Healing & 1.62 & 0.25 & 3.30 & 0.25 \\
Physical Therapy and Herbal/Mineral & 1.03 & 0.13 & 1.86 & 0.14 \\
\hline
\end{tabular}

$\mathrm{SE}=$ Standard Error

*males $(\mathrm{n}=71)$, females $(\mathrm{n}=110)$ 
Table 10: Average Utility Values by Race

\begin{tabular}{|c|c|c|c|c|c|c|}
\hline \multirow[b]{2}{*}{ Attributes } & \multicolumn{3}{|c|}{ Whites } & \multicolumn{3}{|c|}{ Blacks } \\
\hline & Effect & SE & t-Value & Effect & SE & t-Value \\
\hline \multicolumn{7}{|l|}{ Allopathic Treatment } \\
\hline Prescription Pain Medication & 0.22 & 0.07 & 2.91 & 0.56 & 0.08 & 6.91 \\
\hline Prescription OA Medication & 0.09 & 0.08 & 1.15 & -0.01 & 0.09 & -0.16 \\
\hline Over the Counter Medication & 0.44 & 0.07 & 6 & 0.2 & 0.08 & 2.43 \\
\hline Physical Therapy & -0.75 & 0.09 & -8.24 & -0.74 & 0.1 & -7.73 \\
\hline \multicolumn{7}{|l|}{ Complimentary and Alternative Treatment } \\
\hline Massage & 0.34 & 0.09 & 3.92 & 0.11 & 0.1 & 1.11 \\
\hline Acupuncture & -0.28 & 0.1 & -2.74 & -0.9 & 0.12 & -7.78 \\
\hline Chiropractic & -0.29 & 0.09 & -3.12 & -0.83 & 0.11 & -7.27 \\
\hline Prayer/Spiritual Healing & -0.03 & 0.09 & -0.34 & 1.56 & 0.1 & 15.71 \\
\hline Herbal/Mineral & 0.26 & 0.09 & 2.97 & 0.07 & 0.1 & 0.73 \\
\hline \multicolumn{7}{|l|}{ Combination Treatment } \\
\hline Prescription Pain Medication and Massage & -0.29 & 0.22 & -1.31 & -0.34 & 0.24 & -1.41 \\
\hline Prescription Pain Medication and Acupuncture & 0.38 & 0.24 & 1.57 & 0.58 & 0.27 & 2.16 \\
\hline Prescription Pain Medication and Chiropractic & -0.19 & 0.23 & -0.83 & -0.24 & 0.27 & -0.88 \\
\hline \multicolumn{7}{|l|}{ Prescription Pain Medication and Prayer/Spiritual } \\
\hline Healing & 0.19 & 0.23 & 0.82 & 0.15 & 0.27 & 0.57 \\
\hline Prescription Pain Medication and Herbal/Mineral & -0.09 & 0.22 & -0.39 & -0.16 & 0.24 & -0.65 \\
\hline Prescription OA Medication and Massage & -0.02 & 0.22 & -0.11 & 0.15 & 0.26 & 0.58 \\
\hline Prescription OA Medication and Acupuncture & 0.11 & 0.25 & 0.46 & -0.56 & 0.31 & -1.84 \\
\hline Prescription OA Medication and Chiropractic & 0.14 & 0.24 & 0.58 & -0.01 & 0.3 & -0.04 \\
\hline \multicolumn{7}{|l|}{ Prescription OA Medication and Prayer/Spiritual } \\
\hline Healing & -0.23 & 0.23 & -1 & 0.42 & 0.27 & 1.56 \\
\hline
\end{tabular}


Table 10 (continued)

\begin{tabular}{|c|c|c|c|c|c|c|}
\hline \multirow[b]{2}{*}{ Attributes } & \multicolumn{3}{|c|}{ Whites } & \multicolumn{3}{|c|}{ Blacks } \\
\hline & Effect & SE & t-Value & Effect & SE & t-Value \\
\hline Prescription OA Medication and Herbal/Mineral & 0 & 0.23 & 0.01 & 0.01 & 0.25 & 0.03 \\
\hline Over the Counter Medication and Massage & -0.12 & 0.23 & -0.55 & 0.22 & 0.25 & 0.86 \\
\hline Over the Counter Medication and Acupuncture & 0.16 & 0.22 & 0.69 & -0.42 & 0.3 & -1.43 \\
\hline Over the Counter Medication and Chiropractic & -0.32 & 0.24 & -1.33 & 0.26 & 0.27 & 0.99 \\
\hline \multicolumn{7}{|l|}{ Over the Counter Medication and Prayer/Spiritual } \\
\hline Healing & -0.05 & 0.22 & -0.23 & -0.17 & 0.25 & -0.68 \\
\hline Over the Counter Medication and Herbal/Mineral & 0.34 & 0.23 & 1.51 & 0.11 & 0.24 & 0.48 \\
\hline Physical Therapy and Massage & 0.44 & 0.23 & 1.9 & -0.03 & 0.27 & -0.1 \\
\hline Physical Therapy and Acupuncture & -0.65 & 0.34 & -1.89 & 0.4 & 0.33 & 1.24 \\
\hline Physical Therapy and Chiropractic & 0.38 & 0.27 & 1.37 & -0.02 & 0.34 & -0.05 \\
\hline Physical Therapy and Prayer/Spiritual Healing & 0.09 & 0.27 & 0.34 & -0.4 & 0.25 & -1.61 \\
\hline Physical Therapy and Herbal/Mineral & -0.26 & 0.25 & -1.02 & 0.04 & 0.27 & 0.14 \\
\hline \multicolumn{7}{|l|}{ Price } \\
\hline$\$ 25$ & 0.37 & 0.07 & 5.59 & 0.55 & 0.07 & 7.45 \\
\hline$\$ 50$ & 0.23 & 0.07 & 3.39 & 0.3 & 0.07 & 4.05 \\
\hline$\$ 75$ & -0.15 & 0.07 & -2.03 & 0 & 0.08 & 0.03 \\
\hline$\$ 100$ & -0.13 & 0.07 & -1.86 & -0.31 & 0.08 & -3.77 \\
\hline$\$ 125$ & -0.31 & 0.07 & -4.18 & -0.54 & 0.09 & -6.36 \\
\hline
\end{tabular}

Whites: Chi Square $=189.09(\mathrm{p}<.001)$, Blacks: Chi Square $=526.32(\mathrm{p}<.001)$ 
whites and blacks preferred physical therapy the least with utility values of -.75 and -.74 , respectively.

The importance scores (Table 11) for blacks and whites show that price was similar in importance. CAM was much more important to blacks $(30.2 \%)$ than whites $(14.2 \%)$. Also, whites (17.1\%) placed more importance on allopathic therapy than blacks $(13.9 \%)$ did. However, combination therapy was the most important attribute for both blacks and whites.

Product shares of preference for both whites and blacks followed a similar pattern, shown in Table 12. Prayer/spiritual healing had the most share of preference with $12.43 \%$ for whites and $20.20 \%$ for blacks. Herbal/mineral supplements were also very preferred, with a $15.42 \%$ product share for whites, and a $5.36 \%$ product share for blacks. Prescription pain medication and prayer/spiritual healing also had a large product share with $5.78 \%$ for whites, and $13.05 \%$ for blacks. Physical Therapy was equally preferred with a small product share of preference (.46). The least preferred allopathic treatment was prescription osteoarthritis medication, with a product share of $.37 \%$ for both blacks and whites.

Marginal WTP reflects both the utility values and the product shares of preference for both whites and blacks. For whites overall (Table 12), they were not willing to pay anything to switch from massage or prescription pain medicine and massage to their most preferred treatment, herbal/mineral supplements. Whites overall were only willing to pay one dollar to switch from prescription pain medicine and prayer/spiritual healing, prescription pain medicine and herbal/mineral supplements, and over the counter medication and prayer/spiritual healing to receive their most preferred treatment, herbal/mineral supplements (Table 13). The most they were willing to pay to switch to their most preferred treatment was to pay twelve dollars to switch from physical therapy to herbal/mineral supplements. Blacks were much less price elastic than whites in their marginal willingness to pay to switch from a treatment to their most preferred treatment of prayer/spiritual healing (Table 14). They were only willing to pay two dollars to switch from prescription pain medication and prayer/spiritual healing to their most preferred treatment of prayer/spiritual healing. They were also only willing to pay one dollar to switch from over the counter medication and prayer/spiritual healing to their most preferred treatment of prayer/spiritual healing. They were willing to pay a lot of money to avoid physical therapy as a treatment method. Blacks were willing to pay fortyone dollars to switch from physical therapy to their most preferred treatment. They were also willing to pay forty and forty-six dollars to switch from physical therapy and acupuncture and physical therapy and chiropractic care to their most preferred treatment of prayer/spiritual healing. 
Table 11: Importance Scores by Gender

\begin{tabular}{lcc}
\hline Attributes & $\begin{array}{c}\text { Whites } \\
\text { Importance Scores }\end{array}$ & $\begin{array}{c}\text { Blacks } \\
\text { Importance Scores }\end{array}$ \\
\hline Allopathic & $17.1 \%$ & $13.9 \%$ \\
CAM & $14.2 \%$ & $30.2 \%$ \\
Combination & $53.9 \%$ & $40.1 \%$ \\
Price & $14.7 \%$ & $15.8 \%$ \\
\hline
\end{tabular}

Table 12: Product Shares of Preference by Race

\begin{tabular}{lrrrc}
\hline & \multicolumn{2}{c}{ Whites } & \multicolumn{2}{c}{ Blacks } \\
\cline { 2 - 5 } Treatments & \% Share & SE & \% Share & SE \\
\hline Prescription Pain Medication & 0.64 & 0.07 & 0.65 & 0.08 \\
Prescription OA Medication & 0.37 & 0.03 & 0.37 & 0.04 \\
Over the Counter Medication & 0.66 & 0.07 & 0.66 & 0.08 \\
Physical Therapy & 0.46 & 0.05 & 0.46 & 0.05 \\
Massage & 8.41 & 0.28 & 4.44 & 0.39 \\
Acupuncture & 3.94 & 0.27 & 1.51 & 0.21 \\
Chiropractic & 2.11 & 0.09 & 1.03 & 0.10 \\
Prayer/Spiritual Healing & 12.43 & 0.80 & 20.20 & 1.32 \\
Herbal/Mineral & 15.42 & 1.21 & 5.36 & 0.72 \\
Prescription Pain Medication and Massage & 4.49 & 0.30 & 3.60 & 0.37 \\
Prescription Pain Medication and Acupuncture & 1.41 & 0.04 & 0.86 & 0.07 \\
Prescription Pain Medication and Chiropractic & 1.06 & 0.07 & 0.80 & 0.09 \\
Prescription Pain Medication and Prayer/Spiritual Healing & 5.78 & 0.44 & 13.05 & 0.82 \\
Prescription Pain Medication and Herbal/Mineral & 4.87 & 0.17 & 2.79 & 0.18 \\
Prescription OA Medication and Massage & 2.93 & 0.20 & 2.34 & 0.25 \\
Prescription OA Medication and Acupuncture & 0.90 & 0.03 & 0.53 & 0.05
\end{tabular}


Table 12 (continued)

\begin{tabular}{lrrrr}
\hline & \multicolumn{2}{c}{ Whites } & \multicolumn{2}{c}{ Blacks } \\
\cline { 2 - 5 } Treatments & \% Share & SE & \% Share & SE \\
\hline Prescription OA Medication and Chiropractic & 0.69 & 0.05 & 0.51 & 0.06 \\
Prescription OA Medication and Prayer/Spiritual Healing & 3.85 & 0.35 & 9.67 & 0.69 \\
Prescription OA Medication and Herbal/Mineral & 3.15 & 0.12 & 1.80 & 0.11 \\
Over the Counter Medication and Massage & 4.62 & 0.32 & 3.72 & 0.39 \\
Over the Counter Medication and Acupuncture & 1.43 & 0.04 & 0.88 & 0.08 \\
Over the Counter Medication and Chiropractic & 1.09 & 0.07 & 0.83 & 0.09 \\
Over the Counter Medication and Prayer/Spiritual Healing & 5.84 & 0.43 & 12.85 & 0.77 \\
Over the Counter Medication and Herbal/Mineral & 4.92 & 0.17 & 2.82 & 0.18 \\
Physical Therapy and Massage & 3.01 & 0.38 & 2.87 & 0.37 \\
Physical Therapy and Acupuncture & 0.64 & 0.06 & 0.59 & 0.07 \\
Physical Therapy and Chiropractic & 0.70 & 0.09 & 0.66 & 0.08 \\
Physical Therapy and Prayer/Spiritual Healing & 2.57 & 0.27 & 2.70 & 0.27 \\
Physical Therapy and Herbal/Mineral & 1.63 & 0.14 & 1.44 & 0.16 \\
\hline
\end{tabular}


Table 13: Marginal WTP for Treatment for Whites

\begin{tabular}{lc}
\hline Treatments & MWTP \\
\hline Herbal/Mineral & $\$ 3.00$ \\
Massage & $\$ 2.00$ \\
Prayer/Spiritual Healing & $\$ 2.00$ \\
Over the Counter Medication and Herbal/Mineral & $\$ 1.00$ \\
Over the Counter Medication and Massage & $\$ 1.00$ \\
Over the Counter Medication and Prayer/Spiritual Healing & $\$ 1.00$ \\
Prescription Pain Medication and Herbal/Mineral & $\$ 1.00$ \\
Prescription Pain Medication and Prayer/Spiritual Healing & $\$ 1.00$ \\
Acupuncture & $\$ 0.00$ \\
Prescription OA Medication and Prayer/Spiritual Healing & $\$ 0.00$ \\
Prescription Pain Medication and Massage & $\$ 0.00$ \\
Prescription OA Medication and Massage & $-\$ 1.00$ \\
Over the Counter Medication and Acupuncture & $-\$ 2.00$ \\
Prescription Pain Medication and Acupuncture & $-\$ 2.00$ \\
Chiropractic & $-\$ 3.00$ \\
Over the Counter Medication and Chiropractic & $-\$ 3.00$ \\
Prescription OA Medication and Acupuncture & $-\$ 3.00$ \\
Prescription Pain Medication and Chiropractic & $-\$ 3.00$ \\
Physical Therapy and Herbal/Mineral & $-\$ 4.00$ \\
Physical Therapy and Massage & $-\$ 4.00$ \\
Physical Therapy and Prayer/Spiritual Healing & $-\$ 4.00$ \\
Prescription OA Medication and Chiropractic & $-\$ 4.00$ \\
Over the Counter Medication & $-\$ 6.00$ \\
Physical Therapy and Acupuncture & $-\$ 6.00$ \\
Prescription Pain Medication & $-\$ 6.00$ \\
Prescription OA Medication & $-\$ 7.00$ \\
Physical Therapy and Chiropractic & $-\$ 7.00$ \\
Physical Therapy & $-\$ 7.00$ \\
\hline
\end{tabular}

MWTP = Marginal Willingness to Pay

Referent: Prescription OA Medication and Herbal/Mineral Supplements 
Table 14: Marginal WTP for Treatment for Blacks

\begin{tabular}{lc}
\hline Treatments & MWTP \\
\hline Prescription OA Medication and Prayer/Spiritual Healing & $\$ 10.00$ \\
Prayer/Spiritual Healing & $\$ 8.00$ \\
Over the Counter Medication and Prayer/Spiritual Healing & $\$ 7.00$ \\
Prescription Pain Medication and Prayer/Spiritual Healing & $\$ 7.00$ \\
Herbal/Mineral & $\$ 5.00$ \\
Over the Counter Medication and Herbal/Mineral & $\$ 2.00$ \\
Prescription Pain Medication and Herbal/Mineral & $\$ 2.00$ \\
Massage & $\$ 1.00$ \\
Prescription OA Medication and Herbal/Mineral & $\$ 1.00$ \\
Physical Therapy and Prayer/Spiritual Healing & $\$ 0.00$ \\
Prescription Pain Medication and Massage & $\$ 0.00$ \\
Prescription OA Medication and Massage & $-\$ 1.00$ \\
Acupuncture & $-\$ 4.00$ \\
Over the Counter Medication & $-\$ 6.00$ \\
Over the Counter Medication and Acupuncture & $-\$ 6.00$ \\
Physical Therapy and Herbal/Mineral & $-\$ 6.00$ \\
Prescription OA Medication and Acupuncture & $-\$ 6.00$ \\
Prescription Pain Medication & $-\$ 6.00$ \\
Prescription Pain Medication and Acupuncture & $-\$ 6.00$ \\
Chiropractic & $-\$ 7.00$ \\
Over the Counter Medication and Chiropractic & $-\$ 7.00$ \\
Prescription OA Medication & $-\$ 7.00$ \\
Prescription OA Medication and Chiropractic & $-\$ 7.00$ \\
Prescription Pain Medication and Chiropractic & $-\$ 7.00$ \\
Physical Therapy and Massage & $-\$ 10.00$ \\
Physical Therapy and Acupuncture & $-\$ 13.00$ \\
Physical Therapy and Chiropractic & $-\$ 14.00$ \\
Physical Therapy & $-\$ 15.00$ \\
\hline MWTP Marg &
\end{tabular}

MWTP = Marginal Willingness to Pay

Referent: Over the Counter Medications and Massage 
Therefore, the hypothesis that blacks overall will place higher utility on CAM than whites cannot be rejected. Also, whites did place higher utility on allopathic treatments over blacks. But the hypotheses do not tell the entire picture, because both blacks and whites placed the highest importance on combination therapy. The hypothesis that whites will place higher value on chiropractic care was not proven. Chiropractic care was the least preferred therapy for whites, and they were not willing to pay more for that service. In fact, they were willing to pay three dollars less than the referent. Regarding the hypothesis that whites will place higher value on massage therapy and be willing to pay more for this service, the null hypothesis was rejected. Massage therapy was the most preferred CAM therapy among whites, and they were willing to pay two dollars more for that therapy over the referent. The hypothesis that blacks will place higher value on prayer/spiritual healing and will be willing to pay for that therapy was proven. Blacks preferred prayer more than whites did, and are willing to pay eight dollars more for prayer/spiritual healing over the referent. The hypothesis that blacks will place higher utility on the CAM therapy of herbal/mineral supplements and be willing to pay more for that therapy was not proven. Whites preferred herbal/mineral supplements more than blacks did.

\section{Results by Race and Gender}

To further examine preferences by demographics, utility values were calculated by race and gender. Table 15 describes utility values for white males and white females. The least preferred treatment for both white males and white females was chiropractic care, with utility values for -.27 and -.29 respectively. The most marked difference for the allopathic treatment attribute between the genders was with prescription osteoarthritis medications. Males had a significant utility value for prescription osteoarthritis medication of .31 , while females had a non-significant utility value of -0.05 . For the complementary and alternative treatment attribute the most marked difference between the genders was with massage. White females had a significant utility value of .49 while males had a non significant utility value of .03 for massage

The utility values for black males and black females are explored in Table 16. Trends were similar, with the most marked difference being the difference between utility values for black males and black females regarding massage. Black males have a negative, although not significant utility value of -.19 , while females have a positive, significant utility value of .31 for massage. Similarly, the highest significant treatment was prayer for both groups, with black males having a utility value of 1.52 and black females having a utility value of 1.65 . Acupuncture, physical therapy, and chiropractic treatments were the three least preferred treatments. For the allopathic attribute, physical therapy was the least preferred with a significant utility value of -.88 for black males and -.65 for black females. Among the complementary and alternative treatment attributes, acupuncture had utility values of -.81 for black males and -1.02 for black females. Chiropractic treatment was the other least preferred attribute, with utility values of -.81 for black males and -.83 for black females. Levels for price followed the expected trend. 
Table 15: Utility Values by Race/Gender (Whites)

\begin{tabular}{lcccccc}
\hline & \multicolumn{3}{c}{ White Males } & \multicolumn{3}{c}{ White Females } \\
\cline { 2 - 7 } Attributes & Effect & SE & t-Value & Effect & SE & t-Value \\
\hline Allopathic Treatment & & & & & & \\
Prescription Pain Medication & 0.30 & 0.12 & 2.5 & 0.16 & 0.1 & 1.64 \\
Prescription OA Medication & 0.31 & 0.12 & 2.54 & -0.05 & 0.1 & -0.48 \\
Over The Counter Medication & 0.42 & 0.12 & 3.38 & 0.47 & 0.09 & 5.01 \\
Physical Therapy & -1.04 & 0.16 & -6.52 & -0.58 & 0.11 & -5.17 \\
Complimentary and Alternative Treatment & & & & & & \\
Massage & 0.03 & 0.15 & 0.18 & 0.49 & 0.11 & 4.48 \\
Acupuncture & -0.24 & 0.16 & -1.49 & -0.3 & 0.13 & -2.33 \\
Chiropractic & -0.27 & 0.16 & -1.73 & -0.29 & 0.12 & -2.44 \\
Prayer/Spiritual Healing & 0.01 & 0.15 & 0.06 & -0.05 & 0.12 & -0.39 \\
Herbal/Mineral & 0.48 & 0.15 & 3.25 & 0.15 & 0.11 & 1.31 \\
Combination Treatment & & & & & & \\
Prescription Pain Medication and Massage & -0.26 & 0.37 & -0.71 & -0.27 & 0.28 & -0.98 \\
Prescription Pain Medication and Acupuncture & 0.13 & 0.39 & 0.35 & 0.53 & 0.31 & 1.7 \\
Prescription Pain Medication and Chiropractic & -0.16 & 0.38 & -0.43 & -0.17 & 0.3 & -0.58 \\
Prescription Pain Medication and & & & & & & \\
$\quad$ Prayer/Spiritual Healing & 0.4 & 0.37 & 1.09 & 0.02 & 0.29 & 0.05 \\
Prescription Pain Medication and Herbal/Mineral & -0.11 & 0.35 & -0.30 & -0.11 & 0.29 & -0.37 \\
Prescription OA Medication and Massage & 0.37 & 0.36 & 1.05 & -0.23 & 0.29 & -0.78 \\
Prescription OA Medication and Acupuncture & 0.36 & 0.39 & 0.92 & -0.08 & 0.33 & -0.24 \\
Prescription OA Medication and Chiropractic & 0.11 & 0.4 & 0.27 & 0.17 & 0.31 & 0.57 \\
Prescription OA Medication and Prayer/Spiritual & & & & & & -0.19 \\
$\quad$ Healing & -0.49 & 0.39 & -1.25 & -0.06 & 0.29 & -0.19
\end{tabular}




\begin{tabular}{|c|c|c|c|c|c|c|}
\hline \multirow[b]{2}{*}{ Attributes } & \multicolumn{3}{|c|}{ White Males } & \multicolumn{3}{|c|}{ White Females } \\
\hline & Effect & SE & t-Value & Effect & SE & t-Value \\
\hline Prescription OA Medication and Herbal/Mineral & -0.35 & 0.38 & -0.92 & 0.19 & 0.29 & 0.64 \\
\hline Over the Counter Medication and Massage & -0.43 & 0.41 & -1.06 & 0.02 & 0.29 & 0.08 \\
\hline Over the Counter Medication and Acupuncture & -0.29 & 0.38 & -0.76 & 0.39 & 0.29 & 1.36 \\
\hline Over the Counter Medication and Chiropractic & -0.21 & 0.39 & -0.53 & -0.38 & 0.32 & -1.19 \\
\hline Over the Counter Medication and & & & & & & \\
\hline Prayer/Spiritual Healing & 0.02 & 0.37 & 0.04 & -0.11 & 0.28 & -0.4 \\
\hline Over the Counter Medication and & & & & & & \\
\hline Herbal/Mineral & 0.91 & 0.41 & 2.23 & 0.08 & 0.28 & 0.27 \\
\hline Physical Therapy and Massage & 0.33 & 0.42 & 0.78 & 0.48 & 0.29 & 1.67 \\
\hline Physical Therapy and Acupuncture & -0.21 & 0.57 & -0.36 & -0.85 & 0.44 & -1.95 \\
\hline Physical Therapy and Chiropractic & 0.26 & 0.49 & 0.53 & 0.38 & 0.34 & 1.13 \\
\hline Physical Therapy and Prayer/Spiritual Healing & 0.07 & 0.48 & 0.16 & 0.15 & 0.34 & 0.44 \\
\hline Physical Therapy and Herbal/Mineral & -0.45 & 0.44 & -1.03 & -0.16 & 0.31 & -0.5 \\
\hline Price & & & & & & \\
\hline$\$ 25$ & 0.48 & 0.11 & 4.41 & 0.31 & 0.08 & 3.73 \\
\hline$\$ 50$ & 0.12 & 0.11 & 1.03 & 0.30 & 0.08 & 3.51 \\
\hline$\$ 75$ & -0.17 & 0.12 & -1.41 & -0.16 & 0.09 & -1.79 \\
\hline$\$ 100$ & -0.21 & 0.12 & -1.77 & -0.09 & 0.09 & -1.03 \\
\hline$\$ 125$ & -0.21 & 0.12 & -1.75 & -0.35 & 0.1 & -3.62 \\
\hline
\end{tabular}

White Males: Chi Square $=106.29(\mathrm{p}<.001)$, White Females: Chi Square $=112.58(\mathrm{p}<.001)$ 
Table 16: Utility Values for Race/Gender (Blacks)

\begin{tabular}{|c|c|c|c|c|c|c|}
\hline \multirow[b]{2}{*}{ Attributes } & \multicolumn{3}{|c|}{ Black Males } & \multicolumn{3}{|c|}{ Black Females } \\
\hline & Effect & SE & t-Value & Effect & SE & t-Value \\
\hline \multicolumn{7}{|l|}{ Allopathic Treatment } \\
\hline Prescription Pain Medication & 0.53 & 0.13 & 4.15 & 0.58 & 0.11 & 5.45 \\
\hline Prescription OA Medication & -0.05 & 0.13 & -0.4 & -0.01 & 0.12 & -0.1 \\
\hline Over the Counter Medication & 0.4 & 0.13 & 3.1 & 0.08 & 0.11 & 0.72 \\
\hline Physical Therapy & -0.88 & 0.16 & -5.59 & -0.65 & 0.13 & -5.16 \\
\hline \multicolumn{7}{|l|}{ Complimentary and Alternative Treatment } \\
\hline Massage & -0.19 & 0.16 & -1.18 & 0.31 & 0.13 & 2.44 \\
\hline Acupuncture & -0.81 & 0.18 & -4.48 & -1.02 & 0.16 & -6.39 \\
\hline Chiropractic & -0.88 & 0.18 & -4.85 & -0.83 & 0.15 & -5.49 \\
\hline Prayer/Spiritual Healing & 1.52 & 0.16 & 9.78 & 1.65 & 0.13 & 12.48 \\
\hline Herbal/Mineral & 0.36 & 0.15 & 2.4 & -0.11 & 0.13 & -0.9 \\
\hline \multicolumn{7}{|l|}{ Combination Treatment } \\
\hline Prescription Pain Medication and Massage & -0.17 & 0.38 & -0.45 & -0.46 & 0.31 & -1.45 \\
\hline Prescription Pain Medication and Acupuncture & 0.65 & 0.43 & 1.51 & 0.72 & 0.36 & 2.03 \\
\hline Prescription Pain Medication and Chiropractic & -0.79 & 0.47 & -1.68 & 0.06 & 0.33 & 0.17 \\
\hline \multicolumn{7}{|l|}{ Prescription Pain Medication and } \\
\hline Prayer/Spiritual Healing & 0.31 & 0.43 & 0.73 & 0.09 & 0.35 & 0.25 \\
\hline Prescription Pain Medication and Herbal/Mineral & 0 & 0.37 & -0.01 & -0.41 & 0.34 & -1.21 \\
\hline Prescription OA Medication and Massage & -0.17 & 0.44 & -0.4 & 0.31 & 0.33 & 0.92 \\
\hline Prescription OA Medication and Acupuncture & -0.11 & 0.43 & -0.26 & -0.93 & 0.45 & -2.04 \\
\hline Prescription OA Medication and Chiropractic & 0.19 & 0.43 & 0.43 & -0.09 & 0.41 & -0.21 \\
\hline \multicolumn{7}{|l|}{ Prescription OA Medication and Prayer/Spiritual } \\
\hline Healing & 0.23 & 0.41 & 0.55 & 0.56 & 0.36 & 1.55 \\
\hline Prescription OA Medication and Herbal/Mineral & -0.13 & 0.4 & -0.31 & 0.15 & 0.33 & 0.45 \\
\hline
\end{tabular}


Table 16 (continued)

\begin{tabular}{|c|c|c|c|c|c|c|}
\hline \multirow[b]{2}{*}{ Attributes } & \multicolumn{3}{|c|}{ Black Males } & \multicolumn{3}{|c|}{ Black Females } \\
\hline & Effect & SE & t-Value & SE & Effect & t-Value \\
\hline Over the Counter Medication and Massage & 0.57 & 0.4 & 1.43 & -0.03 & 0.34 & -0.08 \\
\hline Over the Counter Medication and Acupuncture & -0.49 & 0.42 & -1.17 & -0.48 & 0.45 & -1.07 \\
\hline Over the Counter Medication and Chiropractic & 0.15 & 0.42 & 0.36 & 0.37 & 0.35 & 1.07 \\
\hline Over the Counter Medication and & & & & & & \\
\hline Prayer/Spiritual Healing & -0.28 & 0.38 & -0.72 & -0.08 & 0.34 & -0.25 \\
\hline Over the Counter Medication and & & & & & & \\
\hline Herbal/Mineral & 0.04 & 0.38 & 0.11 & 0.23 & 0.31 & 0.74 \\
\hline Physical Therapy and Massage & -0.22 & 0.47 & -0.47 & 0.18 & 0.35 & 0.51 \\
\hline Physical Therapy and Acupuncture & -0.06 & 0.57 & -0.1 & 0.69 & 0.41 & 1.7 \\
\hline Physical Therapy and Chiropractic & 0.45 & 0.53 & 0.87 & -0.34 & 0.46 & -0.74 \\
\hline Physical Therapy and Prayer/Spiritual Healing & -0.26 & 0.39 & -0.68 & -0.56 & 0.33 & -1.71 \\
\hline Physical Therapy and Herbal/Mineral & 0.09 & 0.44 & 0.19 & 0.03 & 0.35 & 0.1 \\
\hline Price & & & & & & \\
\hline$\$ 25$ & 0.66 & 0.12 & 5.57 & 0.48 & 0.1 & 5.02 \\
\hline$\$ 50$ & 0.17 & 0.12 & 1.43 & 0.38 & 0.1 & 3.86 \\
\hline$\$ 75$ & -0.01 & 0.12 & -0.08 & 0.03 & 0.1 & 0.3 \\
\hline$\$ 100$ & -0.25 & 0.12 & -1.98 & -0.35 & 0.11 & -3.23 \\
\hline$\$ 125$ & -0.57 & 0.14 & -4.18 & -0.54 & 0.11 & -4.86 \\
\hline
\end{tabular}

Black Males: Chi Square $=220.91(\mathrm{p}<.001)$, Black Females: Chi Square $=330.02(\mathrm{p}<.001)$ 
was the other least preferred attribute, with utility values of -.81 for black males and -.83 for black females. Levels for price followed the expected trend.

Importance scores were calculated (Table 17). Black females placed the lowest importance on allopathic therapy $(9.0 \%)$, and white males placed the highest importance on allopathic therapy (20.1\%). Combination therapy was the most important attribute for all race/gender cohorts. Price stays of similar importance for everyone as well. Blacks placed more importance on CAM than whites.

Product shares of preference were explored by race/gender in Table 18. Prayer had the largest share across all groups, but was higher among blacks. Herbals also had large shares, except with black females, with a product share of $3.23 \%$. Prescription medication and prayer and also over the counter medication and prayer had approximately $13 \%$ of the shares for both black women and men. Massage had higher shares of preferences for whites than with blacks. Physical therapy, and the combination treatments with physical therapy had the lowest shares of preference for all groups. Acupuncture had very low shares of preference for all groups except for white males, with a product share of preference of $5.45 \%$.

\section{Results by Duration of OA}

Duration of OA and its effect on utility values and shares of preference were explored (Tables 19-21). Utility values for relatively new OA patients (Table 19) that have had OA for $0-5$ years (sample size of 40) were highest for over the counter medication (.27), massage (.55), prayer/spiritual healing (.47), prescription pain medication and acupuncture (.64), over the counter medication and prayer/spiritual healing (.41). Utility values were lowest for this group for physical therapy (-.25), acupuncture (-.69), chiropractic (-.66), and physical therapy and acupuncture (-.57) Price follows the expected utility path. For those that have had OA for 6-10 years (60 people) the utility values (Table 20) are not much different. The highest utility values were for prescription pain medication (.29), prayer/spiritual healing (.68), and prescription OA medicine and herbal/mineral supplements (.40). Price follows the expected utility path. For those who have had OA for eleven or more years, utility values were also calculated (Table 21). The highest utility values for those suffering from OA long-term were for prescription pain medication (.58), prayer/spiritual healing (.90), prescription pain medication and acupuncture (.64), and physical therapy and chiropractic (.72). Price followed the expected utility path. The lowest valued treatment was physical therapy (-1.22). We can therefore reject hypothesis number 7 , the data show that no matter how long a person has had OA, it does not affect their the value they place on CAM. They are willing to use CAM therapies in general. 
Table 17: Importance Scores by Race/Gender

\begin{tabular}{lcccc}
\hline & \multicolumn{4}{c}{ Importance Scores } \\
\cline { 2 - 5 } Attributes & White Males & White Females & Black Males & Black Females \\
\hline Allopathic & $20.1 \%$ & $14.6 \%$ & $14.6 \%$ & $9.0 \%$ \\
CAM & $10.3 \%$ & $13.4 \%$ & $29.5 \%$ & $28.4 \%$ \\
Combination & $57.7 \%$ & $58.1 \%$ & $42.5 \%$ & $49.4 \%$ \\
Price & $11.9 \%$ & $13.9 \%$ & $13.4 \%$ & $12.8 \%$ \\
\hline
\end{tabular}

Table 18: Product Shares of Preference for Race/Gender

\begin{tabular}{lrrrrrrrr}
\hline Treatments & $\begin{array}{c}\text { White } \\
\text { Males }\end{array}$ & SE & $\begin{array}{c}\text { White } \\
\text { Females }\end{array}$ & SE & $\begin{array}{c}\text { Black } \\
\text { Males }\end{array}$ & SE & $\begin{array}{c}\text { Black } \\
\text { Females }\end{array}$ & SE \\
\hline Prescription Pain Medication & 0.52 & 0.14 & 0.72 & 0.08 & 0.59 & 0.13 & 0.69 & 0.09 \\
Prescription OA Medication & 0.25 & 0.05 & 0.44 & 0.04 & 0.31 & 0.05 & 0.41 & 0.05 \\
Over the Counter Medication & 0.52 & 0.14 & 0.74 & 0.08 & 0.60 & 0.13 & 0.71 & 0.09 \\
Physical Therapy & 0.27 & 0.08 & 0.57 & 0.07 & 0.35 & 0.08 & 0.54 & 0.07 \\
Massage & 9.55 & 0.39 & 7.70 & 0.36 & 4.90 & 0.67 & 4.12 & 0.46 \\
Acupuncture & 5.45 & 0.35 & 3.00 & 0.33 & 2.20 & 0.41 & 1.03 & 0.18 \\
Chiropractic & 2.49 & 0.11 & 1.87 & 0.11 & 1.17 & 0.18 & 0.93 & 0.12 \\
Prayer/Spiritual Healing & 13.69 & 0.89 & 11.64 & 1.16 & 21.56 & 1.80 & 19.25 & 1.85 \\
$\quad$ Herbal/Mineral & 21.96 & 1.62 & 11.33 & 1.44 & 8.41 & 1.52 & 3.23 & 0.40 \\
Prescription Pain Medication and & 3.12 & 0.32 & 5.34 & 0.40 & 2.79 & 0.48 & 4.16 & 0.52 \\
$\quad$ Massage & & & & & & & & \\
Prescription Pain Medication and & 1.46 & 0.05 & 1.38 & 0.05 & 0.87 & 0.12 & 0.85 & 0.10 \\
$\quad$ Acupuncture & & & & & & & & \\
Prescription Pain Medication and & 0.78 & 0.07 & 1.24 & 0.09 & 0.62 & 0.11 & 0.93 & 0.12 \\
$\quad$ Chiropractic & & & & & & & &
\end{tabular}


Table 18 (continued)

\begin{tabular}{|c|c|c|c|c|c|c|c|c|}
\hline Treatments & $\begin{array}{l}\text { White } \\
\text { Males }\end{array}$ & $\mathbf{S E}$ & $\begin{array}{c}\text { White } \\
\text { Females }\end{array}$ & $\mathbf{S E}$ & $\begin{array}{l}\text { Black } \\
\text { Males }\end{array}$ & SE & $\begin{array}{c}\text { Black } \\
\text { Females }\end{array}$ & $\mathbf{S E}$ \\
\hline $\begin{array}{l}\text { Prescription Pain Medication and } \\
\text { Prayer/Spiritual Healing }\end{array}$ & 4.59 & 0.63 & 6.53 & 0.57 & 12.69 & 1.32 & 13.30 & 1.04 \\
\hline $\begin{array}{l}\text { Prescription Pain Medication and } \\
\text { Herbal/Mineral }\end{array}$ & 5.65 & 0.25 & 4.39 & 0.21 & 3.21 & 0.34 & 2.49 & 0.18 \\
\hline $\begin{array}{l}\text { Prescription OA Medication and } \\
\text { Massage }\end{array}$ & 2.00 & 0.22 & 3.51 & 0.27 & 1.79 & 0.32 & 2.72 & 0.34 \\
\hline $\begin{array}{l}\text { Prescription OA Medication and } \\
\text { Acupuncture }\end{array}$ & 0.91 & 0.04 & 0.89 & 0.03 & 0.52 & 0.07 & 0.54 & 0.06 \\
\hline $\begin{array}{l}\text { Prescription OA Medication and } \\
\text { Chiropractic }\end{array}$ & 0.49 & 0.05 & 0.81 & 0.06 & 0.39 & 0.07 & 0.60 & 0.08 \\
\hline $\begin{array}{l}\text { Prescription OA Medication and } \\
\text { Prayer/Spiritual Healing }\end{array}$ & 2.94 & 0.49 & 4.41 & 0.45 & 9.34 & 1.11 & 9.91 & 0.89 \\
\hline $\begin{array}{l}\text { Prescription OA Medication and } \\
\text { Herbal/Mineral }\end{array}$ & 3.60 & 0.20 & 2.86 & 0.14 & 2.05 & 0.22 & 1.63 & 0.10 \\
\hline $\begin{array}{l}\text { Over the Counter Medication and } \\
\text { Massage }\end{array}$ & 3.16 & 0.34 & 5.53 & 0.43 & 2.86 & 0.51 & 4.32 & 0.54 \\
\hline $\begin{array}{l}\text { Over the Counter Medication and } \\
\text { Acupuncture }\end{array}$ & 1.46 & 0.05 & 1.41 & 0.05 & 0.88 & 0.12 & 0.88 & 0.10 \\
\hline $\begin{array}{l}\text { Over the Counter Medication and } \\
\text { Chiropractic }\end{array}$ & 0.79 & 0.07 & 1.28 & 0.10 & 0.64 & 0.12 & 0.96 & 0.13 \\
\hline $\begin{array}{l}\text { Over the Counter Medication and } \\
\text { Prayer/Spiritual Healing }\end{array}$ & 4.59 & 0.62 & 6.62 & 0.55 & 12.46 & 1.26 & 13.12 & 0.97 \\
\hline $\begin{array}{l}\text { Over the Counter Medication and } \\
\text { Herbal/Mineral }\end{array}$ & 5.65 & 0.25 & 4.46 & 0.20 & 3.22 & 0.34 & 2.54 & 0.19 \\
\hline
\end{tabular}


Table 18 (continued)

\begin{tabular}{|c|c|c|c|c|c|c|c|c|}
\hline Treatments & $\begin{array}{l}\text { White } \\
\text { Males }\end{array}$ & SE & $\begin{array}{c}\text { White } \\
\text { Females }\end{array}$ & SE & $\begin{array}{l}\text { Black } \\
\text { Males }\end{array}$ & SE & $\begin{array}{c}\text { Black } \\
\text { Females }\end{array}$ & $\mathbf{S E}$ \\
\hline Physical Therapy and Massage & 1.19 & 0.41 & 4.15 & 0.50 & 1.75 & 0.48 & 3.66 & 0.51 \\
\hline $\begin{array}{l}\text { Physical Therapy and } \\
\text { Acupuncture }\end{array}$ & 0.35 & 0.07 & 0.82 & 0.08 & 0.41 & 0.09 & 0.71 & 0.09 \\
\hline $\begin{array}{l}\text { Physical Therapy and } \\
\text { Chiropractic }\end{array}$ & 0.28 & 0.09 & 0.96 & 0.11 & 0.40 & 0.11 & 0.83 & 0.12 \\
\hline $\begin{array}{l}\text { Physical Therapy and } \\
\text { Prayer/Spiritual Healing }\end{array}$ & 1.28 & 0.32 & 3.38 & 0.36 & 1.94 & 0.37 & 3.23 & 0.37 \\
\hline $\begin{array}{l}\text { Physical Therapy and } \\
\text { Herbal/Mineral }\end{array}$ & 1.00 & 0.16 & 2.02 & 0.19 & 1.07 & 0.21 & 1.70 & 0.22 \\
\hline
\end{tabular}

Sample Sizes: White Males $(n=35)$, White Females $(n=56)$, Black Males $(n=37)$, Black Females $(n=53)$ 
Table 19: Utility Values for 0-5 years Duration of OA

\begin{tabular}{|c|c|c|c|}
\hline Attributes & Effect & SE & t-Value \\
\hline \multicolumn{4}{|l|}{ Allopathic Treatment } \\
\hline Prescription Pain Medication & 0.10 & 0.12 & 0.89 \\
\hline Prescription OA Medication & -0.12 & 0.12 & -0.98 \\
\hline Over the Counter Medication & 0.27 & 0.12 & 2.30 \\
\hline Physical Therapy & -0.25 & 0.13 & -1.98 \\
\hline \multicolumn{4}{|l|}{ Complimentary and Alternative Treatment } \\
\hline Massage & 0.55 & 0.13 & 4.18 \\
\hline Acupuncture & -0.69 & 0.16 & -4.24 \\
\hline Chiropractic & -0.66 & 0.16 & -4.21 \\
\hline Prayer/Spiritual Healing & 0.47 & 0.13 & 3.52 \\
\hline Herbal/Mineral & 0.34 & 0.13 & 2.52 \\
\hline \multicolumn{4}{|l|}{ Combination Treatment } \\
\hline Prescription Pain Medication and Massage & -0.43 & 0.36 & -1.19 \\
\hline Prescription Pain Medication and Acupuncture & 0.64 & 0.36 & 1.76 \\
\hline Prescription Pain Medication and Chiropractic & -0.05 & 0.38 & -0.13 \\
\hline \multicolumn{4}{|l|}{ Prescription Pain Medication and Prayer/Spiritual } \\
\hline Healing & -0.27 & 0.35 & -0.79 \\
\hline Prescription Pain Medication and Herbal/Mineral & 0.11 & 0.34 & 0.34 \\
\hline Prescription OA Medication and Massage & 0.27 & 0.35 & 0.76 \\
\hline Prescription OA Medication and Acupuncture & -0.19 & 0.44 & -0.43 \\
\hline Prescription OA Medication and Chiropractic & 0.24 & 0.40 & 0.59 \\
\hline \multicolumn{4}{|l|}{ Prescription OA Medication and Prayer/Spiritual } \\
\hline Healing & -0.05 & 0.35 & -0.16 \\
\hline Prescription OA Medication and Herbal/Mineral & -0.26 & 0.35 & -0.74 \\
\hline Over the Counter Medication and Massage & -0.14 & 0.34 & -0.42 \\
\hline Over the Counter Medication and Acupuncture & 0.12 & 0.37 & 0.33 \\
\hline Over the Counter Medication and Chiropractic & -0.21 & 0.42 & -0.50 \\
\hline \multicolumn{4}{|l|}{ Over the Counter Medication and Prayer/Spiritual } \\
\hline Healing & 0.41 & 0.33 & 1.25 \\
\hline Over the Counter Medication and Herbal/Mineral & -0.18 & 0.35 & -0.51 \\
\hline Physical Therapy and Massage & 0.31 & 0.35 & 0.87 \\
\hline Physical Therapy and Acupuncture & -0.57 & 0.50 & -1.14 \\
\hline Physical Therapy and Chiropractic & 0.02 & 0.44 & 0.05 \\
\hline Physical Therapy and Prayer/Spiritual Healing & -0.08 & 0.35 & -0.23 \\
\hline Physical Therapy and Herbal/Mineral & 0.32 & 0.33 & 0.97 \\
\hline \multicolumn{4}{|l|}{ Price } \\
\hline$\$ 25$ & 0.46 & 0.10 & 4.57 \\
\hline$\$ 50$ & 0.32 & 0.10 & 3.19 \\
\hline$\$ 75$ & -0.03 & 0.11 & -0.26 \\
\hline$\$ 100$ & -0.22 & 0.11 & -1.99 \\
\hline$\$ 125$ & -0.53 & 0.12 & -4.37 \\
\hline
\end{tabular}

Chi Square $=116.69(\mathrm{p}<.001)$ 
Table 20: Utility Values for 6-10 Years of OA Duration

\begin{tabular}{|c|c|c|c|}
\hline Attributes & Effect & SE & t-Value \\
\hline \multicolumn{4}{|l|}{ Allopathic Treatment } \\
\hline Prescription Pain Medication & 0.29 & 0.09 & 3.15 \\
\hline Prescription OA Medication & -0.02 & 0.10 & -0.17 \\
\hline Over the Counter Medication & 0.26 & 0.09 & 2.78 \\
\hline Physical Therapy & -0.54 & 0.11 & -5.04 \\
\hline \multicolumn{4}{|l|}{ Complimentary and Alternative Treatment } \\
\hline Massage & 0.28 & 0.11 & 2.61 \\
\hline Acupuncture & -0.53 & 0.12 & -4.31 \\
\hline Chiropractic & -0.55 & 0.13 & -4.42 \\
\hline Prayer/Spiritual Healing & 0.68 & 0.11 & 6.40 \\
\hline Herbal/Mineral & 0.12 & 0.11 & 1.11 \\
\hline \multicolumn{4}{|l|}{ Combination Treatment } \\
\hline Prescription Pain Medication and Massage & 0.10 & 0.27 & 0.38 \\
\hline Prescription Pain Medication and Acupuncture & -0.07 & 0.32 & -0.21 \\
\hline Prescription Pain Medication and Chiropractic & 0.10 & 0.31 & 0.33 \\
\hline \multicolumn{4}{|l|}{ Prescription Pain Medication and } \\
\hline Prayer/Spiritual Healing & 0.13 & 0.27 & 0.49 \\
\hline Prescription Pain Medication and Herbal/Mineral & -0.27 & 0.28 & -0.98 \\
\hline Prescription OA Medication and Massage & -0.23 & 0.28 & -0.82 \\
\hline Prescription OA Medication and Acupuncture & -0.10 & 0.31 & -0.32 \\
\hline Prescription OA Medication and Chiropractic & -0.04 & 0.32 & -0.13 \\
\hline \multicolumn{4}{|l|}{ Prescription OA Medication and Prayer/Spiritual } \\
\hline Healing & -0.02 & 0.27 & -0.09 \\
\hline Prescription OA Medication and Herbal/Mineral & 0.40 & 0.30 & 1.32 \\
\hline Over the Counter Medication and Massage & 0.12 & 0.29 & 0.43 \\
\hline Over the Counter Medication and Acupuncture & -0.13 & 0.29 & -0.43 \\
\hline Over the Counter Medication and Chiropractic & 0.13 & 0.29 & 0.45 \\
\hline \multicolumn{4}{|l|}{ Over the Counter Medication and } \\
\hline Prayer/Spiritual Healing & -0.25 & 0.28 & -0.89 \\
\hline \multicolumn{4}{|l|}{ Over the Counter Medication and } \\
\hline Herbal/Mineral & 0.12 & 0.29 & 0.40 \\
\hline Physical Therapy and Massage & 0.00 & 0.29 & 0.02 \\
\hline Physical Therapy and Acupuncture & 0.29 & 0.36 & 0.81 \\
\hline Physical Therapy and Chiropractic & -0.19 & 0.36 & -0.53 \\
\hline Physical Therapy and Prayer/Spiritual Healing & 0.14 & 0.29 & 0.49 \\
\hline Physical Therapy and Herbal/Mineral & -0.24 & 0.31 & -0.76 \\
\hline
\end{tabular}


Table 20 (continued)

\begin{tabular}{lrrr}
\hline Attributes & Effect & SE & t-Value \\
\hline Price & & & \\
$\$ 25$ & 0.43 & 0.08 & 5.21 \\
$\$ 50$ & 0.32 & 0.08 & 3.89 \\
$\$ 75$ & -0.04 & 0.09 & -0.45 \\
$\$ 100$ & -0.42 & 0.10 & -4.41 \\
$\$ 125$ & -0.29 & 0.09 & -3.09 \\
\hline
\end{tabular}

Chi Square $=162.91(\mathrm{p}<.001)$ 
Table 21: Utility Values for $>10$ Years of OA Duration

\begin{tabular}{|c|c|c|c|}
\hline Attributes & Effect & SE & t-Value \\
\hline \multicolumn{4}{|l|}{ Allopathic Treatment } \\
\hline Prescription Pain Medication & 0.58 & 0.08 & 7.00 \\
\hline Prescription OA Medication & 0.18 & 0.09 & 2.11 \\
\hline Over the Counter Medication & 0.47 & 0.08 & 5.69 \\
\hline Physical Therapy & -1.22 & 0.11 & -10.87 \\
\hline \multicolumn{4}{|l|}{ Complimentary and Alternative Treatment } \\
\hline Massage & -0.01 & 0.10 & -0.08 \\
\hline Acupuncture & -0.48 & 0.12 & -4.10 \\
\hline Chiropractic & -0.46 & 0.11 & -4.26 \\
\hline Prayer/Spiritual Healing & 0.90 & 0.10 & 9.36 \\
\hline Herbal/Mineral & 0.05 & 0.11 & 0.46 \\
\hline \multicolumn{4}{|l|}{ Combination Treatment } \\
\hline Prescription Pain Medication and Massage & -0.58 & 0.24 & -2.40 \\
\hline Prescription Pain Medication and Acupuncture & 0.64 & 0.28 & 2.27 \\
\hline Prescription Pain Medication and Chiropractic & -0.63 & 0.26 & -2.46 \\
\hline $\begin{array}{l}\text { Prescription Pain Medication and Prayer/Spiritual } \\
\text { Healing }\end{array}$ & 0.48 & 0.26 & 1.83 \\
\hline Prescription Pain Medication and Herbal/Mineral & 0.09 & 0.26 & 0.33 \\
\hline Prescription OA Medication and Massage & 0.11 & 0.25 & 0.44 \\
\hline Prescription OA Medication and Acupuncture & -0.28 & 0.29 & -0.96 \\
\hline Prescription OA Medication and Chiropractic & 0.01 & 0.27 & 0.05 \\
\hline \multicolumn{4}{|l|}{ Prescription OA Medication and Prayer/Spiritual } \\
\hline Prescription OA Medication and Herbal/Mineral & 0.05 & 0.25 & 0.19 \\
\hline Over the Counter Medication and Massage & -0.04 & 0.26 & -0.15 \\
\hline Over the Counter Medication and Acupuncture & 0.23 & 0.27 & 0.84 \\
\hline Over the Counter Medication and Chiropractic & -0.10 & 0.26 & -0.38 \\
\hline \multicolumn{3}{|l|}{ Over the Counter Medication and Prayer/Spiritual } & -2.05 \\
\hline Over the Counter Medication and Herbal/Mineral & 0.41 & 0.24 & 1.68 \\
\hline Physical Therapy and Massage & 0.51 & 0.30 & 1.71 \\
\hline Physical Therapy and Acupuncture & -0.59 & 0.43 & -1.38 \\
\hline Physical Therapy and Chiropractic & 0.72 & 0.33 & 2.14 \\
\hline Physical Therapy and Prayer/Spiritual Healing & -0.09 & 0.29 & -0.31 \\
\hline Physical Therapy and Herbal/Mineral & -0.54 & 0.36 & -1.51 \\
\hline \multicolumn{4}{|l|}{ Price } \\
\hline$\$ 25$ & 0.50 & 0.07 & 6.71 \\
\hline$\$ 50$ & 0.14 & 0.08 & 1.84 \\
\hline$\$ 75$ & -0.14 & 0.08 & -1.78 \\
\hline
\end{tabular}


Table 21 (continued)

\begin{tabular}{lccc}
\hline Attributes & Effect & SE & t-Value \\
\hline$\$ 100$ & -0.07 & 0.08 & -0.87 \\
$\$ 125$ & -0.43 & 0.08 & -5.11 \\
\hline
\end{tabular}

Chi Square $=359.79(\mathrm{p}<.001)$

Table 22 shows the importance scores by duration of OA. Those that have had OA for $0-5$ years place $18.2 \%$ importance on CAM, those that have had OA for 6-10 years place $27.4 \%$ importance on CAM, and those that have had OA for eleven or more years place $15.3 \%$ importance on CAM. Therefore the hypothesis that the longer survey respondents have had OA, the more they will value CAM was not proven. In fact, combination treatment is the most important for every group, and for the group that have been diagnosed with OA for over 10 years, they place the most importance on allopathic medicine when compared to everyone else. Combination therapy was once again the most important attribute for all groups.

Table 23 shows the product shares of preference for treatments by duration of OA. The highest shares of preference were not very different among the three groups. The two highest shares of preference belong to prescription pain medication and prayer/spiritual healing and over the counter medication and prayer/spiritual healing.

\section{Results by Disability Status}

Disability status was calculated using the validated Brief Pain Inventory® (BPI) used by permission from the Pain Research Group. The responses were categorized into none to mild, moderate, and severe disability. For sample size concerns, moderate and severe OA patients were grouped together. Table $\mathbf{2 4}$ describes the utility values by disability status. The none-mild group and the moderate-severe group followed similar trends throughout. The marked difference was the significant preference for prescription pain medication with acupuncture from the moderate-severe group (.94). Also the none-mild group had a significant preference for massage therapy (.33) while the moderate-severe group did not. The none-mild group had a positive effect (.22) for prescription pain medication and acupuncture but was not significant. Prayer, prescription pain medication, and over the counter medication were the most preferred treatments. For allopathic treatments, prescription pain medication had a significant value of .28 in the non-mild group, and a significant value of .56 in the moderatesevere group. For over the counter medication, the none-mild group had a significant value of .39 , while the moderate-severe group had a utility value of .24 for over the counter medication. Prayer was the most preferred complementary and alternative treatment with significant utility values of .69 and .78 for none-mild and moderatesevere groups respectively. We can therefore reject the hypothesis number 8 . The more disabled a person has become due to OA, the person is not more likely to value CAM more. In fact, both groups place high utility on CAM treatments. Table 25 shows that 
Table 22: Importance Scores by Duration of OA

\begin{tabular}{lccc}
\hline Attributes & $\begin{array}{c}\mathbf{0 - 5} \text { Years } \\
\text { Importance Scores }\end{array}$ & $\begin{array}{c}\mathbf{6 - 1 0} \text { Years } \\
\text { Importance Scores }\end{array}$ & $\begin{array}{c}>\text { 10 Years } \\
\text { Importance Scores }\end{array}$ \\
\hline Allopathic & $5.6 \%$ & $13.9 \%$ & $19.8 \%$ \\
CAM & $18.2 \%$ & $27.4 \%$ & $15.3 \%$ \\
Combination & $65.8 \%$ & $39.6 \%$ & $54.3 \%$ \\
Price & $10.05 \%$ & $18.8 \%$ & $10.3 \%$ \\
\hline
\end{tabular}


Table 23: Product Shares of Preferences by Duration of OA

\begin{tabular}{|c|c|c|c|c|c|c|}
\hline \multirow[b]{2}{*}{ Treatments } & \multicolumn{6}{|c|}{ \% Share } \\
\hline & $0-5$ yrs & SE & 6-10 yrs & SE & $11+$ yrs & SE \\
\hline Prescription Pain Medication & 1.18 & 0.06 & 1.17 & 0.05 & 0.97 & 0.04 \\
\hline Prescription OA Medication & 0.79 & 0.03 & 0.79 & 0.02 & 0.69 & 0.02 \\
\hline Over the Counter Medication & 1.22 & 0.07 & 1.21 & 0.05 & 0.99 & 0.04 \\
\hline Physical Therapy & 0.84 & 0.11 & 0.79 & 0.09 & 0.49 & 0.07 \\
\hline Massage & 2.26 & 0.07 & 2.29 & 0.06 & 2.47 & 0.05 \\
\hline Acupuncture & 2.26 & 0.07 & 2.29 & 0.06 & 2.47 & 0.05 \\
\hline Chiropractic & 2.26 & 0.07 & 2.29 & 0.06 & 2.47 & 0.05 \\
\hline Prayer/Spiritual Healing & 2.26 & 0.07 & 2.29 & 0.06 & 2.47 & 0.05 \\
\hline Herbal/Mineral & 2.26 & 0.07 & 2.29 & 0.06 & 2.47 & 0.05 \\
\hline Prescription Pain Medication and Massage & 5.74 & 0.43 & 5.63 & 0.35 & 4.29 & 0.29 \\
\hline $\begin{array}{l}\text { Prescription Pain Medication and } \\
\text { Acupuncture }\end{array}$ & 1.58 & 0.06 & 1.57 & 0.05 & 1.35 & 0.04 \\
\hline $\begin{array}{l}\text { Prescription Pain Medication and } \\
\text { Chiropractic }\end{array}$ & 1.45 & 0.13 & 1.42 & 0.10 & 1.03 & 0.08 \\
\hline $\begin{array}{l}\text { Prescription Pain Medication and } \\
\text { Prayer/Spiritual Healing }\end{array}$ & 12.46 & 0.98 & 12.74 & 0.79 & 15.73 & 0.65 \\
\hline $\begin{array}{l}\text { Prescription Pain Medication and } \\
\text { Herbal/Mineral }\end{array}$ & 4.84 & 0.14 & 4.91 & 0.11 & 5.23 & 0.08 \\
\hline Prescription OA Medication and Massage & 3.81 & 0.25 & 3.75 & 0.20 & 2.97 & 0.17 \\
\hline $\begin{array}{l}\text { Prescription OA Medication and } \\
\text { Acupuncture }\end{array}$ & 1.07 & 0.03 & 1.07 & 0.03 & 0.96 & 0.02 \\
\hline $\begin{array}{l}\text { Prescription OA Medication and } \\
\text { Chiropractic }\end{array}$ & 0.96 & 0.08 & 0.94 & 0.06 & 0.70 & 0.05 \\
\hline $\begin{array}{l}\text { Prescription OA Medication and } \\
\text { Prayer/Spiritual Healing }\end{array}$ & 9.04 & 0.82 & 9.26 & 0.66 & 11.82 & 0.55 \\
\hline $\begin{array}{l}\text { Prescription OA Medication and } \\
\text { Herbal/Mineral }\end{array}$ & 3.41 & 0.14 & 3.47 & 0.11 & 3.86 & 0.09 \\
\hline
\end{tabular}


Table 23 (continued)

\begin{tabular}{|c|c|c|c|c|c|c|}
\hline \multirow[b]{2}{*}{ Treatments } & \multicolumn{6}{|c|}{ \% Share } \\
\hline & 0-5 yrs & SE & 6-10 yrs & $\mathbf{S E}$ & $11+$ yrs & SE \\
\hline $\begin{array}{l}\text { Over the Counter Medication and } \\
\text { Massage }\end{array}$ & 5.99 & 0.47 & 5.86 & 0.38 & 4.42 & 0.31 \\
\hline $\begin{array}{l}\text { Over the Counter Medication and } \\
\text { Acupuncture }\end{array}$ & 1.63 & 0.07 & 1.62 & 0.06 & 1.38 & 0.05 \\
\hline $\begin{array}{l}\text { Over the Counter Medication and } \\
\text { Chiropractic }\end{array}$ & 1.52 & 0.14 & 1.48 & 0.11 & 1.06 & 0.09 \\
\hline $\begin{array}{l}\text { Over the Counter Medication and } \\
\text { Prayer/Spiritual Healing }\end{array}$ & 12.59 & 0.93 & 12.88 & 0.75 & 15.69 & 0.62 \\
\hline $\begin{array}{l}\text { Over the Counter Medication and } \\
\text { Herbal/Mineral }\end{array}$ & 4.95 & 0.11 & 5.01 & 0.09 & 5.26 & 0.07 \\
\hline Physical Therapy and Massage & 4.49 & 0.62 & 4.17 & 0.48 & 2.57 & 0.39 \\
\hline Physical Therapy and Acupuncture & 1.08 & 0.14 & 1.02 & 0.11 & 0.64 & 0.09 \\
\hline Physical Therapy and Chiropractic & 1.19 & 0.17 & 1.10 & 0.13 & 0.67 & 0.11 \\
\hline $\begin{array}{l}\text { Physical Therapy and Prayer/Spiritual } \\
\text { Healing }\end{array}$ & 4.49 & 0.36 & 4.39 & 0.29 & 3.30 & 0.24 \\
\hline Physical Therapy and Herbal/Mineral & 1.03 & 0.13 & 1.86 & 0.14 & 1.86 & 0.14 \\
\hline
\end{tabular}


Table 24: Utility Values for Disability Status

\begin{tabular}{lrrrrrr}
\hline & \multicolumn{3}{c}{ None-Mild } & \multicolumn{3}{c}{ Moderate-Severe } \\
\cline { 2 - 7 } Attributes & Effect & SE & t-Value & Effect & SE & t-Value \\
\hline Allopathic Treatment & & & & & & \\
Prescription Pain Medication & 0.28 & 0.06 & 4.43 & 0.56 & 0.1 & 5.51 \\
Prescription OA Medication & -0.03 & 0.07 & -0.45 & 0.19 & 0.1 & 1.78 \\
Over the Counter Medication & 0.39 & 0.06 & 6.09 & 0.24 & 0.1 & 2.38 \\
Physical Therapy & -0.64 & 0.07 & -8.58 & -0.98 & 0.13 & -7.47 \\
Complimentary and Alternative Treatment & & & & & & \\
Massage & 0.33 & 0.07 & 4.45 & -0.11 & 0.13 & -0.87 \\
Acupuncture & -0.59 & 0.09 & -6.76 & -0.42 & 0.14 & -2.98 \\
Chiropractic & -0.54 & 0.08 & -6.37 & -0.52 & 0.14 & -3.86 \\
Prayer/Spiritual Healing & 0.69 & 0.07 & 9.48 & 0.78 & 0.12 & 6.71 \\
Herbal/Mineral & 0.11 & 0.08 & 1.43 & 0.27 & 0.12 & 2.27 \\
Combination Treatment & & & & & & -0.78 \\
Prescription Pain Medication and Massage & -0.33 & 0.19 & -1.76 & -0.24 & 0.31 & -0.73 \\
Prescription Pain Medication and Acupuncture & 0.22 & 0.21 & 1.02 & 0.94 & 0.34 & 2.78 \\
Prescription Pain Medication and Chiropractic & 0.05 & 0.2 & 0.25 & -0.85 & 0.33 & -2.56 \\
Prescription Pain Medication and & 0.07 & 0.19 & 0.38 & 0.33 & 0.3 & 1.1 \\
$\quad$ Prayer/Spiritual Healing & & & & & & -0.6 \\
Prescription Pain Medication and Herbal/Mineral & -0.01 & 0.19 & -0.05 & -0.18 & 0.3 & -0.6 \\
Prescription OA Medication and Massage & 0.15 & 0.2 & 0.78 & -0.12 & 0.31 & -0.4 \\
Prescription OA Medication and Acupuncture & -0.06 & 0.22 & -0.27 & -0.44 & 0.36 & -1.23 \\
Prescription OA Medication and Chiropractic & 0.01 & 0.22 & 0.05 & 0.24 & 0.34 & 0.72 \\
Prescription OA Medication and Prayer/Spiritual & -0.05 & 0.19 & -0.25 & 0.28 & 0.31 & 0.88 \\
$\quad$ Healing & & & & & &
\end{tabular}


Table 24 (continued)

\begin{tabular}{|c|c|c|c|c|c|c|}
\hline \multirow[b]{2}{*}{ Attributes } & \multicolumn{3}{|c|}{ None-Mild } & \multicolumn{3}{|c|}{ Moderate-Severe } \\
\hline & Effect & SE & t-Value & Effect & $\mathbf{S E}$ & t-Value \\
\hline Prescription OA Medication and Herbal/Mineral & -0.06 & 0.2 & -0.28 & 0.04 & 0.29 & 0.15 \\
\hline Over the Counter Medication and Massage & -0.06 & 0.19 & -0.29 & 0.06 & 0.34 & 0.17 \\
\hline Over the Counter Medication and Acupuncture & -0.01 & 0.2 & -0.03 & 0.16 & 0.32 & 0.49 \\
\hline Over the Counter Medication and Chiropractic & -0.09 & 0.21 & -0.43 & 0.08 & 0.33 & 0.24 \\
\hline $\begin{array}{l}\text { Over the Counter Medication and } \\
\text { Prayer/Spiritual Healing }\end{array}$ & 0.03 & 0.19 & 0.17 & -0.65 & 0.3 & -2.17 \\
\hline $\begin{array}{l}\text { Over the Counter Medication and } \\
\text { Herbal/Mineral }\end{array}$ & 0.12 & 0.18 & 0.65 & 0.36 & 0.32 & 1.13 \\
\hline Physical Therapy and Massage & 0.23 & 0.2 & 1.16 & 0.3 & 0.36 & 0.83 \\
\hline Physical Therapy and Acupuncture & -0.15 & 0.27 & -0.56 & -0.65 & 0.5 & -1.32 \\
\hline Physical Therapy and Chiropractic & 0.03 & 0.25 & 0.12 & 0.53 & 0.42 & 1.25 \\
\hline Physical Therapy and Prayer/Spiritual Healing & -0.06 & 0.21 & -0.27 & 0.04 & 0.32 & 0.13 \\
\hline Physical Therapy and Herbal/Mineral & -0.05 & 0.21 & -0.25 & -0.22 & 0.36 & -0.61 \\
\hline \multicolumn{7}{|l|}{ Price } \\
\hline$\$ 25$ & 0.53 & 0.06 & 9.44 & 0.23 & 0.09 & 2.52 \\
\hline$\$ 50$ & 0.3 & 0.06 & 5.25 & 0.16 & 0.09 & 1.67 \\
\hline$\$ 75$ & -0.06 & 0.06 & -0.96 & -0.13 & 0.1 & -1.35 \\
\hline$\$ 100$ & -0.28 & 0.06 & -4.45 & -0.04 & 0.09 & -0.39 \\
\hline$\$ 125$ & -0.49 & 0.07 & -7.32 & -0.22 & 0.1 & -2.22 \\
\hline
\end{tabular}

None-Mild: Chi Square $=414.38(p<.001)$, Moderate-Severe: Chi Square $=169.53(p<.001)$ 
Table 25: Importance Scores by Disability

\begin{tabular}{lcc}
\hline & \multicolumn{2}{c}{ Importance Scores } \\
\cline { 2 - 3 } Attributes & None-Mild & Moderate-Severe \\
\hline Allopathic & $18.9 \%$ & $17.3 \%$ \\
CAM & $31.9 \%$ & $18.2 \%$ \\
Combination & $25.1 \%$ & $58.0 \%$ \\
Price & $23.7 \%$ & $6.5 \%$ \\
\hline
\end{tabular}

the importance scores for none-mild OA and moderate-severe OA mirror the utility values. The importance scores were similar for both groups for allopathic therapies $(18.9 \%$ vs. $17.3 \%)$. The hypothesis that the more disabled the person has become due to osteoarthritis, the more likely the person will be to value CAM was not proven, in fact the less disabled group placed a greater importance on CAM therapies (31.9\% vs $18.2 \%)$. Interestingly, price was not an important factor in treatment attributes for the moderate to severe group $(6.5 \%)$.

Product shares of preference were calculated for both disability groups (Table 26). For product shares by disability status, Table $\mathbf{2 6}$ shows a similar trend to the previous product share results. Prayer/spiritual healing was most preferred by both the non-mild and the moderate-severe group with shares of preferences of $15.85 \%$ and $17.49 \%$ respectively. Herbal/mineral supplements comprised approximately $10 \%$ of the product share for both groups. Prescription pain medication and prayer/spiritual healing had preference shares of $9.04 \%$ for the none-mild group and $10.20 \%$ for the moderate-severe group.

As it is clear that the demographic variables have little effect on utility values or share of preference, the data were analyzed using latent class analysis.

\section{Results for Latent Class Segmentation}

Demographic results for latent class segment covariates are in Table 27. Analyses were run to determine model goodness of fit for various segment numbers. The threesegmented market fit the model best. Therefore, there are three market segments among the survey respondents. Latent Class Segment 1 (Table 28) had a strong dislike for physical therapy with a utility value of -26.65 . This group has strong preferences for prayer/spiritual healing (8.57) and herbal/mineral supplementation (6.62). Latent class segment 2 (Table 28) has striking utility values for price. They are value price more than the other two latent class segments. This group does not have strong preferences specific to any particular treatment. Latent class segment 3 places the highest utility value on prayer/spiritual healing (5.43) and the least amount of utility on physical therapy (-5.04) and physical therapy with prayer/spiritual healing (-10.77), All groups have preference for prayer/spiritual healing, but latent class segment 3 has the highest preference for 
Table 26: Product Shares of Preference for Disability

\begin{tabular}{|c|c|c|c|c|}
\hline Treatments & None-Mild & SE & Moderate-Severe & SE \\
\hline Prescription Pain Medication & 0.74 & 0.07 & 0.46 & 0.07 \\
\hline Prescription OA Medication & 0.40 & 0.03 & 0.29 & 0.04 \\
\hline Over the Counter Medication & 0.75 & 0.07 & 0.47 & 0.08 \\
\hline Physical Therapy & 0.51 & 0.05 & 0.35 & 0.07 \\
\hline Massage & 6.61 & 0.32 & 6.05 & 0.56 \\
\hline Acupuncture & 2.84 & 0.23 & 2.54 & 0.36 \\
\hline Chiropractic & 1.63 & 0.09 & 1.44 & 0.15 \\
\hline Prayer/Spiritual Healing & 15.85 & 0.94 & 17.49 & 1.62 \\
\hline Herbal/Mineral & 10.38 & 0.92 & 10.60 & 1.58 \\
\hline $\begin{array}{l}\text { Prescription Pain Medication } \\
\text { and Massage }\end{array}$ & 4.16 & 0.28 & 3.71 & 0.45 \\
\hline $\begin{array}{l}\text { Prescription Pain Medication } \\
\text { and Acupuncture }\end{array}$ & 1.18 & 0.05 & 1.03 & 0.09 \\
\hline $\begin{array}{l}\text { Prescription Pain Medication } \\
\text { and Chiropractic }\end{array}$ & 0.97 & 0.06 & 0.84 & 0.10 \\
\hline $\begin{array}{l}\text { Prescription Pain Medication } \\
\text { and Prayer/Spiritual Healing }\end{array}$ & 9.04 & 0.61 & 10.20 & 1.07 \\
\hline $\begin{array}{l}\text { Prescription Pain Medication } \\
\text { and Herbal/Mineral }\end{array}$ & 3.86 & 0.17 & 3.77 & 0.30 \\
\hline $\begin{array}{l}\text { Prescription OA Medication } \\
\text { and Massage }\end{array}$ & 2.69 & 0.19 & 2.46 & 0.30 \\
\hline $\begin{array}{l}\text { Prescription OA Medication } \\
\text { And Acupuncture }\end{array}$ & 0.73 & 0.03 & 0.68 & 0.06 \\
\hline $\begin{array}{l}\text { Prescription OA Medication } \\
\text { and Chiropractic }\end{array}$ & 0.62 & 0.04 & 0.56 & 0.07 \\
\hline $\begin{array}{l}\text { Prescription OA Medication } \\
\text { and Prayer/Spiritual Healing }\end{array}$ & 6.39 & 0.51 & 7.54 & 0.87 \\
\hline $\begin{array}{l}\text { Prescription OA Medication } \\
\text { and Herbal/Mineral }\end{array}$ & 2.45 & 0.11 & 2.52 & 0.19 \\
\hline $\begin{array}{l}\text { Over the Counter Medication } \\
\text { and Massage }\end{array}$ & 4.29 & 0.30 & 3.83 & 0.48 \\
\hline $\begin{array}{l}\text { Over the Counter Medication } \\
\text { and Acupuncture }\end{array}$ & 1.20 & 0.05 & 1.05 & 0.09 \\
\hline $\begin{array}{l}\text { Over the Counter Medication } \\
\text { and Chiropractic }\end{array}$ & 1.00 & 0.07 & 0.87 & 0.11 \\
\hline $\begin{array}{l}\text { Over the Counter Medication } \\
\text { and Prayer/Spiritual Healing }\end{array}$ & 8.99 & 0.58 & 10.09 & 1.02 \\
\hline $\begin{array}{l}\text { Over the Counter Medication } \\
\text { and Herbal/Mineral }\end{array}$ & 3.90 & 0.17 & 3.81 & 0.30 \\
\hline Physical Therapy and Massage & 3.05 & 0.31 & 2.63 & 0.50 \\
\hline
\end{tabular}


Table 26 (continued)

\begin{tabular}{lcccc}
\hline \multicolumn{1}{c}{ Treatments } & None-Mild & SE & Moderate-Severe & SE \\
\hline $\begin{array}{l}\text { Physical Therapy and } \\
\text { Acupuncture }\end{array}$ & 0.65 & 0.05 & 0.52 & 0.09 \\
$\begin{array}{l}\text { Physical Therapy and } \\
\quad \text { Chiropractic }\end{array}$ & 0.71 & 0.07 & 0.60 & 0.11 \\
$\begin{array}{c}\text { Physical Therapy and } \\
\text { Prayer/Spiritual Healing }\end{array}$ & 2.78 & 0.23 & 2.29 & 0.36 \\
$\begin{array}{l}\text { Physical Therapy and } \\
\text { Herbal/Mineral }\end{array}$ & 1.63 & 0.12 & 1.31 & 0.20 \\
\hline $\begin{array}{l}\text { Sample Sizes: Disability Levels none-mild }(\mathrm{n}=130) \text {, moderate-severe }(\mathrm{n}=51) \\
\end{array}$ &
\end{tabular}


Table 27: Demographics for Latent Class Segments

\begin{tabular}{|c|c|c|c|}
\hline Variables & $\begin{array}{l}\text { Segment } 1 \\
\text { Freq }(\%)\end{array}$ & $\begin{array}{c}\text { Segment } 2 \\
\text { Freq (\%) }\end{array}$ & $\begin{array}{c}\text { Segment } 3 \\
\text { Freq }(\%)\end{array}$ \\
\hline \multicolumn{4}{|l|}{ Gender } \\
\hline Male & $15(40.54)$ & $50(39.37)$ & $7(43.75)$ \\
\hline Female & $22(59.45)$ & $77(60.63)$ & $9(56.25)$ \\
\hline \multicolumn{4}{|l|}{ Race } \\
\hline White & $22(59.45)$ & $62(48.88)$ & $5(31.25)$ \\
\hline Black & $15(40.54)$ & $64(50.39)$ & $11(68.75)$ \\
\hline \multicolumn{4}{|l|}{ Education } \\
\hline Less than High School & $3(8.10)$ & $19(14.96)$ & $3(18.75)$ \\
\hline High School Graduate & $12(32.43)$ & $55(43.31)$ & $7(43.75)$ \\
\hline Trade School or Community & $10(27.02)$ & $34(26.77)$ & $3(18.75)$ \\
\hline \multicolumn{4}{|l|}{ College } \\
\hline College Graduate & $11(29.72)$ & $18(14.17)$ & $3(18.75)$ \\
\hline Graduate School & $1(2.70)$ & $1(0.79)$ & $0(0.00)$ \\
\hline \multicolumn{4}{|l|}{ Income } \\
\hline$\$ 0-\$ 10,000$ & $1(2.70)$ & $8(6.29)$ & $1(6.25)$ \\
\hline$\$ 10,001-\$ 15,000$ & $3(8.10)$ & $20(15.74)$ & $1(6.25)$ \\
\hline$\$ 15,001-\$ 20,000$ & $7(18.91)$ & $22(17.32)$ & $5(31.25)$ \\
\hline$\$ 20,001-\$ 30,000$ & $4(10.81)$ & $33(25.98)$ & $4(25.00)$ \\
\hline$\$ 30,001-\$ 40,000$ & $14(37.83)$ & $26(20.47)$ & $3(18.75)$ \\
\hline$\$ 40,001-\$ 50,000$ & $3(8.10)$ & $9(7.08)$ & $1(6.25)$ \\
\hline More than $\$ 50,000$ & $5(13.51)$ & $8(6.29)$ & $1(6.25)$ \\
\hline \multicolumn{4}{|l|}{ Severity of Osteoarthritis } \\
\hline None - Mild & $24(64.86)$ & $94(74.02)$ & $10(62.50)$ \\
\hline Moderate & $5(13.51)$ & $19(14.96)$ & $2(12.50)$ \\
\hline Severe & $8(21.62)$ & $14(11.02)$ & $4(25.00)$ \\
\hline \multicolumn{4}{|l|}{ Duration } \\
\hline Less than one year & $0(0.00)$ & $2(1.57)$ & $0(0.00)$ \\
\hline $1-5$ years & $9(24.32)$ & $27(21.26)$ & $2(12.50)$ \\
\hline $6-10$ years & $8(21.62)$ & $48(37.80)$ & $3(18.75)$ \\
\hline $10+$ years & $20(54.05)$ & $50(39.37)$ & $11(68.75)$ \\
\hline
\end{tabular}

Segment Mean age (SD) : 1: 77.13 (7.89); 2: 74.9 (6.93); 3: 78.62 (6.58) 
Table 28: Utility Values for Latent Class Groups

\begin{tabular}{|c|c|c|c|c|c|c|}
\hline \multirow[b]{2}{*}{ Attributes } & \multicolumn{2}{|c|}{ Latent Class Group 1} & \multicolumn{2}{|c|}{ Latent Class Group 2} & \multicolumn{2}{|c|}{ Latent Class Group 3} \\
\hline & Effect & t-Value & Effect & t-Value & Effect & t-Value \\
\hline \multicolumn{7}{|l|}{ Allopathic Treatment } \\
\hline Prescription Pain Medication & 8.99 & 0.22 & 0.19 & 2.98 & 2.63 & 3.5 \\
\hline Prescription OA Medication & 8.73 & 0.21 & -0.23 & -3.35 & 1.4 & 2.25 \\
\hline Over the Counter Medication & 8.93 & 0.22 & 0.24 & 3.84 & 1.06 & 1.63 \\
\hline Physical Therapy & -26.65 & -0.22 & -0.21 & -3.04 & -5.09 & -5.04 \\
\hline \multicolumn{7}{|l|}{ Complementary and } \\
\hline \multicolumn{7}{|l|}{ Alternative Treatment } \\
\hline Massage & -4.71 & -0.05 & 0.35 & 4.74 & -2.74 & -3.47 \\
\hline Acupuncture & -5.24 & -0.05 & -0.51 & -6.06 & -5.2 & -3.46 \\
\hline Chiropractic & -5.23 & -0.05 & -0.44 & -5.43 & -7.97 & -3.5 \\
\hline Prayer/Spiritual Healing & 8.57 & 0.21 & 0.47 & 6.54 & 16.23 & 5.43 \\
\hline Herbal/Mineral & 6.62 & 0.16 & 0.13 & 1.77 & -0.32 & -0.65 \\
\hline \multicolumn{7}{|l|}{ Combination Treatment } \\
\hline $\begin{array}{l}\text { Prescription Pain Medication and } \\
\text { Massage }\end{array}$ & 4.46 & 0.05 & -0.24 & -1.28 & -4.14 & -2.06 \\
\hline $\begin{array}{l}\text { Prescription Pain Medication and } \\
\text { Acupuncture }\end{array}$ & 5.07 & 0.05 & 0.45 & 2.16 & 1.02 & 0.45 \\
\hline $\begin{array}{l}\text { Prescription Pain Medication and } \\
\text { Chiropractic }\end{array}$ & 4.22 & 0.04 & -0.24 & -1.19 & 0.49 & 0.18 \\
\hline $\begin{array}{l}\text { Prescription Pain Medication and } \\
\text { Prayer/Spiritual Healing }\end{array}$ & -7.86 & -0.19 & 0.08 & 0.44 & 6.16 & 1.41 \\
\hline $\begin{array}{l}\text { Prescription Pain Medication and } \\
\text { Herbal/Mineral }\end{array}$ & -5.89 & -0.15 & -0.05 & -0.25 & -3.53 & -2.13 \\
\hline $\begin{array}{l}\text { Prescription OA Medication and } \\
\text { Massage }\end{array}$ & 4.92 & 0.05 & 0.04 & 0.19 & -2.98 & -1.43 \\
\hline $\begin{array}{l}\text { Prescription OA Medication and } \\
\text { Acupuncture }\end{array}$ & 3.79 & 0.04 & -0.14 & -0.62 & 2.09 & 1.04 \\
\hline
\end{tabular}




\begin{tabular}{|c|c|c|c|c|c|c|}
\hline \multirow[b]{2}{*}{ Attributes } & \multicolumn{2}{|c|}{ Latent Class Group 1} & \multicolumn{2}{|c|}{ Latent Class Group 2} & \multicolumn{2}{|c|}{ Latent Class Group 3} \\
\hline & Effect & t-Value & Effect & t-Value & Effect & t-Value \\
\hline $\begin{array}{l}\text { Prescription OA Medication and } \\
\text { Chiropractic }\end{array}$ & 4.91 & 0.05 & 0.19 & 0.88 & -2.76 & -0.68 \\
\hline $\begin{array}{l}\text { Prescription OA Medication and } \\
\text { Prayer/Spiritual Healing }\end{array}$ & -7.79 & -0.19 & 0 & 0.02 & 3.74 & 0.76 \\
\hline $\begin{array}{l}\text { Prescription OA Medication and } \\
\text { Herbal/Mineral }\end{array}$ & -5.83 & -0.14 & -0.09 & -0.42 & -0.09 & -0.07 \\
\hline $\begin{array}{l}\text { Over the Counter Medication and } \\
\text { Massage }\end{array}$ & 4.69 & 0.05 & 0 & -0.01 & 1.1 & 0.65 \\
\hline $\begin{array}{l}\text { Over the Counter Medication and } \\
\text { Acupuncture }\end{array}$ & 4.76 & 0.05 & -0.03 & -0.16 & -0.39 & -0.09 \\
\hline $\begin{array}{l}\text { Over the Counter Medication and } \\
\text { Chiropractic }\end{array}$ & 3.95 & 0.04 & -0.03 & -0.16 & -0.57 & -0.14 \\
\hline $\begin{array}{l}\text { Over the Counter Medication and } \\
\text { Prayer/Spiritual Healing }\end{array}$ & -8.55 & -0.21 & -0.13 & -0.7 & 0.87 & 0.15 \\
\hline $\begin{array}{l}\text { Over the Counter Medication and } \\
\text { Herbal/Mineral }\end{array}$ & -4.86 & -0.12 & 0.2 & 1.03 & -1.01 & -0.81 \\
\hline Physical Therapy and Massage & -14.08 & -0.05 & 0.21 & 1.11 & 6.02 & 2.92 \\
\hline $\begin{array}{l}\text { Physical Therapy and } \\
\text { Acupuncture }\end{array}$ & -13.62 & -0.04 & -0.27 & -1.16 & -2.71 & -0.44 \\
\hline $\begin{array}{l}\text { Physical Therapy and } \\
\text { Chiropractic }\end{array}$ & -13.08 & -0.04 & 0.09 & 0.4 & 2.83 & 0.49 \\
\hline $\begin{array}{l}\text { Physical Therapy and } \\
\text { Prayer/Spiritual Healing }\end{array}$ & 24.2 & 0.2 & 0.04 & 0.22 & -10.77 & -4.4 \\
\hline $\begin{array}{l}\text { Physical Therapy and } \\
\text { Herbal/Mineral }\end{array}$ & 16.58 & 0.14 & -0.06 & -0.33 & 4.63 & 2.83 \\
\hline \multicolumn{7}{|l|}{ Price } \\
\hline$\$ 25$ & 0.35 & 2.15 & 0.54 & 9.79 & 0.22 & 0.54 \\
\hline
\end{tabular}


Table 28 (continued)

\begin{tabular}{|c|c|c|c|c|c|c|}
\hline \multirow[b]{2}{*}{ Attributes } & \multicolumn{2}{|c|}{ Latent Class Group 1} & \multicolumn{2}{|c|}{ Latent Class Group 2} & \multicolumn{2}{|c|}{ Latent Class Group 3} \\
\hline & Effect & t-Value & Effect & t-Value & Effect & t-Value \\
\hline$\$ 50$ & 0.27 & 1.76 & 0.27 & 4.88 & 1.2 & 2.81 \\
\hline$\$ 75$ & -0.07 & -0.45 & -0.09 & -1.58 & -0.68 & -1.66 \\
\hline$\$ 100$ & -0.15 & -0.93 & -0.22 & -3.63 & -0.68 & -1.57 \\
\hline$\$ 125$ & -0.4 & -2.54 & -0.49 & -7.43 & -0.06 & -0.11 \\
\hline
\end{tabular}

Chi Square $=531.66(\mathrm{p}<.001)$

Sample Sizes: Latent Class Segment $1(n=37)$, Latent Class Segment $2(n=128)$, Latent Class Segment $3(n=16)$ 
prayer/spiritual healing with a utility value of 16.23. Prescription OA medicine with prayer/spiritual healing has vastly different effect sizes. For latent class segment 1 it is not preferred $(-7.70)$ for latent class segment 2 it has a zero utility value, and for latent class segment 3 , it has a positive utility and among the highest for this group (3.74).

Table 29 shows the varying importance scores for the three latent class segments. Price is an important attribute for latent class 2 with $24.7 \%$. Price has an importance score of $0.4 \%$ and $2.7 \%$ for latent class segments 1 and 3 , respectively. Allopathic treatment is most important to latent class segment 1 , with an importance score of $21.4 \%$, followed by $6.3 \%$ and $9.8 \%$ for latent classes 2 and 3 . CAM is similarly as important for latent class groups 2 and 3 with importance scores of $29.2 \%$ and $31.3 \%$, respectively.

The product shares of preference for the latent class segments are explored in Table 30. Segment 1 has a high share of preference (22.79) for over the counter medication with herbal/mineral supplementation. Segment 2 does not really have a significant treatment that has a much higher share of preference, but the highest is prescription pain medication and prayer/spiritual healing (7.58). Latent class segment 3 has an extremely striking share of preference, with $97.3 \%$ of this group would choose prescription pain medication and prayer/spiritual healing if given the choice.

The marginal WTP for the latent class segments (Tables 31-33) mirror the product shares of preference and the utility values. The latent class group 1 (Table 31) was price insensitive. Latent class segment 1 were willing to pay nine dollars more than the referent of prescription OA medication for prescription pain medication. They were not willing to pay anymore for prescription pain medication with massage, prescription pain medicine and acupuncture, prescription pain medicine and chiropractic care, or prescription pain medication and herbal/mineral supplements. They were willing to pay $\$ 125$ less than the referent for physical therapy with acupuncture, physical therapy with chiropractic care, physical therapy and prayer/spiritual healing, and physical therapy with herbal/mineral supplements. Latent class segment 2 was very price sensitive (Table 32). They comprised the majority of the sample, with 128 respondents being grouped into latent class segment 2 . They were only willing to pay two dollars more for prescription pain medication than the referent (prescription OA medicine and massage). This group of respondents prefers inexpensive treatments. Latent class segment 3 (Table 33) was the minority of the sample, with only 16 people in this group. They were willing to pay more than the referent for prescription pain medicine and prayer/spiritual healing and over the

Table 29: Importance Scores for Latent Class Segments

\begin{tabular}{lccc}
\hline & \multicolumn{3}{c}{ Importance Scores } \\
\cline { 2 - 4 } Attributes & Segment 1 & Segment 2 & Segment 3 \\
\hline Allopathic & $21.4 \%$ & $6.3 \%$ & $9.8 \%$ \\
CAM & $12.2 \%$ & $29.2 \%$ & $31.3 \%$ \\
Combination & $65.7 \%$ & $39.6 \%$ & $56.0 \%$ \\
Price & $0.4 \%$ & $24.7 \%$ & $2.7 \%$ \\
\hline
\end{tabular}


Table 30: Product Shares of Preferences for Latent Class Groups

\begin{tabular}{|c|c|c|c|c|c|c|}
\hline \multirow[b]{2}{*}{ Treatments } & \multicolumn{2}{|c|}{ Latent Class Group 1} & \multicolumn{2}{|c|}{ Latent Class Group 2} & \multicolumn{2}{|c|}{ Latent Class Group 3} \\
\hline & \% Share & SE & \% Share & SE & \% Share & SE \\
\hline Prescription Pain Medication & 4.61 & 0.02 & 4.08 & 0.02 & 0.00 & 0.00 \\
\hline Prescription OA Medication & 3.52 & 0.01 & 2.70 & 0.01 & 0.00 & 0.00 \\
\hline Over the Counter Medication & 4.28 & 0.03 & 4.30 & 0.02 & 0.00 & 0.00 \\
\hline Physical Therapy & 0.00 & 0.00 & 2.73 & 0.02 & 0.00 & 0.00 \\
\hline Massage & 0.00 & 0.00 & 2.02 & 0.01 & 0.00 & 0.00 \\
\hline Acupuncture & 0.00 & 0.00 & 2.02 & 0.01 & 0.00 & 0.00 \\
\hline Chiropractic & 0.00 & 0.00 & 2.02 & 0.01 & 0.00 & 0.00 \\
\hline Prayer/Spiritual Healing & 0.00 & 0.00 & 2.02 & 0.01 & 0.00 & 0.00 \\
\hline Herbal/Mineral & 0.00 & 0.00 & 2.02 & 0.01 & 0.00 & 0.00 \\
\hline $\begin{array}{l}\text { Prescription Pain Medication and } \\
\text { Massage }\end{array}$ & 3.64 & 0.04 & 4.50 & 0.03 & 0.00 & 0.00 \\
\hline $\begin{array}{l}\text { Prescription Pain Medication and } \\
\text { Acupuncture }\end{array}$ & 3.85 & 0.03 & 3.84 & 0.02 & 0.00 & 0.00 \\
\hline $\begin{array}{l}\text { Prescription Pain Medication and } \\
\text { Chiropractic }\end{array}$ & 1.63 & 0.02 & 2.05 & 0.01 & 0.00 & 0.00 \\
\hline $\begin{array}{l}\text { Prescription Pain Medication and } \\
\text { Prayer/Spiritual Healing }\end{array}$ & 9.88 & 0.24 & 7.58 & 0.32 & 97.33 & 0.22 \\
\hline $\begin{array}{l}\text { Prescription Pain Medication and } \\
\text { Herbal/Mineral }\end{array}$ & 9.36 & 0.07 & 4.44 & 0.03 & 0.00 & 0.00 \\
\hline $\begin{array}{l}\text { Prescription OA Medication and } \\
\text { Massage }\end{array}$ & 4.36 & 0.04 & 3.94 & 0.03 & 0.00 & 0.00 \\
\hline $\begin{array}{l}\text { Prescription OA Medication and } \\
\text { Acupuncture }\end{array}$ & 0.83 & 0.01 & 1.41 & 0.01 & 0.00 & 0.00 \\
\hline $\begin{array}{l}\text { Prescription OA Medication and } \\
\text { Chiropractic }\end{array}$ & 2.49 & 0.03 & 2.08 & 0.02 & 0.00 & 0.00 \\
\hline $\begin{array}{l}\text { Prescription OA Medication and } \\
\text { Prayer/Spiritual Healing }\end{array}$ & 7.96 & 0.15 & 4.54 & 0.12 & 2.52 & 0.19 \\
\hline
\end{tabular}


Table 30 (continued)

\begin{tabular}{|c|c|c|c|c|c|c|}
\hline & \multicolumn{2}{|c|}{ Latent Class Group 1} & \multicolumn{2}{|c|}{ Latent Class Group 2} & \multicolumn{2}{|c|}{ Latent Class Group 3} \\
\hline & \% Share & SE & \% Share & SE & \% Share & SE \\
\hline \multicolumn{7}{|l|}{ Treatments } \\
\hline $\begin{array}{l}\text { Prescription OA Medication and } \\
\text { Herbal/Mineral }\end{array}$ & 7.73 & 0.05 & 2.83 & 0.02 & 0.00 & 0.00 \\
\hline $\begin{array}{l}\text { Over the Counter Medication } \\
\text { and Massage }\end{array}$ & 4.30 & 0.04 & 6.05 & 0.04 & 0.00 & 0.00 \\
\hline $\begin{array}{l}\text { Over the Counter Medication } \\
\text { and Acupuncture }\end{array}$ & 2.66 & 0.02 & 2.50 & 0.02 & 0.00 & 0.00 \\
\hline $\begin{array}{l}\text { Over the Counter Medication } \\
\text { and Chiropractic }\end{array}$ & 1.21 & 0.02 & 2.66 & 0.02 & 0.00 & 0.00 \\
\hline $\begin{array}{l}\text { Over the Counter Medication } \\
\text { and Prayer/Spiritual Healing }\end{array}$ & 4.61 & 0.08 & 6.26 & 0.09 & 0.15 & 0.03 \\
\hline $\begin{array}{l}\text { Over the Counter Medication } \\
\text { and Herbal/Mineral }\end{array}$ & 22.79 & 0.24 & 5.96 & 0.04 & 0.00 & 0.00 \\
\hline Physical Therapy and Massage & 0.00 & 0.00 & 4.76 & 0.03 & 0.00 & 0.00 \\
\hline $\begin{array}{l}\text { Physical Therapy and } \\
\text { Acupuncture }\end{array}$ & 0.00 & 0.00 & 1.24 & 0.01 & 0.00 & 0.00 \\
\hline $\begin{array}{l}\text { Physical Therapy and } \\
\text { Chiropractic }\end{array}$ & 0.00 & 0.00 & 1.91 & 0.02 & 0.00 & 0.00 \\
\hline $\begin{array}{l}\text { Physical Therapy and } \\
\text { Prayer/Spiritual Healing }\end{array}$ & 0.29 & 0.01 & 4.59 & 0.03 & 0.00 & 0.00 \\
\hline $\begin{array}{l}\text { Physical Therapy and } \\
\text { Herbal/Mineral }\end{array}$ & 0.00 & 0.00 & 2.94 & 0.02 & 0.00 & 0.00 \\
\hline
\end{tabular}


Table 31: Marginal WTP for Treatment for Latent Class Segment 1

\begin{tabular}{lc}
\hline Treatments & MWTP \\
\hline Prescription Pain Medication & $\$ 9.00$ \\
Over the Counter Medication & $\$ 4.00$ \\
Physical Therapy & $\$ 3.00$ \\
Massage & $\$ 3.00$ \\
Acupuncture & $\$ 1.00$ \\
Chiropractic & $\$ 1.00$ \\
Prayer/Spiritual Healing & $\$ 1.00$ \\
Herbal/Mineral & $\$ 1.00$ \\
Prescription Pain Medication and Massage & $\$ 0.00$ \\
Prescription Pain Medication and Acupuncture & $\$ 0.00$ \\
Prescription Pain Medication and Chiropractic & $\$ 0.00$ \\
Prescription Pain Medication and Herbal/Mineral & $\$ 0.00$ \\
Prescription OA Medication and Massage & $-\$ 1.00$ \\
Prescription OA Medication and Acupuncture & $-\$ 2.00$ \\
Prescription OA Medication and Chiropractic & $-\$ 3.00$ \\
Prescription OA Medication and Prayer/Spiritual Healing & $-\$ 4.00$ \\
Prescription OA Medication and Herbal/Mineral & $-\$ 6.00$ \\
Over the Counter Medication and Massage & $-\$ 9.00$ \\
Over the Counter Medication and Acupuncture & $-\$ 9.00$ \\
Over the Counter Medication and Chiropractic & $-\$ 50.00$ \\
Over the Counter Medication and Prayer/Spiritual Healing & $-\$ 55.00$ \\
Over the Counter Medication and Herbal/Mineral & $-\$ 57.00$ \\
Physical Therapy and Massage & $-\$ 57.00$ \\
Physical Therapy and Acupuncture & $-\$ 125.00$ \\
Physical Therapy and Chiropractic & $-\$ 125.00$ \\
Physical Therapy and Prayer/Spiritual Healing & $-\$ 125.00$ \\
Physical Therapy and Herbal/Mineral & $-\$ 125.00$ \\
\hline
\end{tabular}

Referent: Prescription OA Medication 
Table 32: Marginal WTP for Treatment for Latent Class Segment 2

\begin{tabular}{lc}
\hline Treatments & MWTP \\
\hline Prescription Pain Medication & $\$ 2.00$ \\
Prescription OA Medication & $\$ 2.00$ \\
Over the Counter Medication & $\$ 1.00$ \\
Physical Therapy & $\$ 1.00$ \\
Massage & $\$ 1.00$ \\
Acupuncture & $\$ 0.00$ \\
Chiropractic & $\$ 0.00$ \\
Prayer/Spiritual Healing & $\$ 0.00$ \\
Herbal/Mineral & $\$ 0.00$ \\
Prescription Pain Medication and Massage & $\$ 0.00$ \\
Prescription Pain Medication and Acupuncture & $\$ 0.00$ \\
Prescription Pain Medication and Chiropractic & $\$ 0.00$ \\
Prescription Pain Medication and Prayer/Spirituality & $-\$ 1.00$ \\
Prescription Pain Medication and Herbal/Mineral & $-\$ 1.00$ \\
Prescription OA Medication and Acupuncture & $-\$ 1.00$ \\
Prescription OA Medication and Chiropractic & $-\$ 1.00$ \\
Prescription OA Medication and Prayer/Spiritual Healing & $-\$ 1.00$ \\
Prescription OA Medication and Herbal/Mineral & $-\$ 1.00$ \\
Over the Counter Medication and Massage & $-\$ 1.00$ \\
Over the Counter Medication and Acupuncture & $-\$ 2.00$ \\
Over the Counter Medication and Chiropractic & $-\$ 2.00$ \\
Over the Counter Medication and Prayer/Spiritual Healing & $-\$ 2.00$ \\
Over the Counter Medication and Herbal/Mineral & $-\$ 2.00$ \\
Physical Therapy and Massage & $-\$ 2.00$ \\
Physical Therapy and Acupuncture & $-\$ 2.00$ \\
Physical Therapy and Chiropractic & $-\$ 3.00$ \\
Physical Therapy and Prayer/Spiritual Healing & $-\$ 4.00$ \\
Physical Therapy and Herbal/Mineral & $-\$ 4.00$ \\
\hline Refrit Pral &
\end{tabular}

Referent: Prescription OA Medication and Massage 
Table 33: Marginal WTP for Treatment for Latent Class Segment 3

\begin{tabular}{lr}
\hline Treatments & MWTP \\
\hline Prescription Pain Medication and Prayer/Spiritual Healing & $\$ 6.00$ \\
Over the Counter Medication and Prayer/Spiritual Healing & $\$ 5.00$ \\
Prescription Pain Medication & $-\$ 125.00$ \\
Prescription OA Medication & $-\$ 125.00$ \\
Over the Counter Medication & $-\$ 125.00$ \\
Physical Therapy & $-\$ 125.00$ \\
Massage & $-\$ 125.00$ \\
Acupuncture & $-\$ 125.00$ \\
Chiropractic & $-\$ 125.00$ \\
Prayer/Spiritual Healing & $-\$ 125.00$ \\
Herbal/Mineral & $-\$ 125.00$ \\
Prescription Pain Medication and Massage & $-\$ 125.00$ \\
Prescription Pain Medication and Acupuncture & $-\$ 125.00$ \\
Prescription Pain Medication and Chiropractic & $-\$ 125.00$ \\
Prescription Pain Medication and Herbal/Mineral & $-\$ 125.00$ \\
Prescription OA Medication and Massage & $-\$ 125.00$ \\
Prescription OA Medication and Acupuncture & $-\$ 125.00$ \\
Prescription OA Medication and Chiropractic & $-\$ 125.00$ \\
Prescription OA Medication and Herbal/Mineral & $-\$ 125.00$ \\
Over the Counter Medication and Massage & $-\$ 125.00$ \\
Over the Counter Medication and Acupuncture & $-\$ 125.00$ \\
Over the Counter Medication and Chiropractic & $-\$ 125.00$ \\
Over the Counter Medication and Herbal/Mineral & $-\$ 125.00$ \\
Physical Therapy and Massage & $-\$ 125.00$ \\
Physical Therapy and Acupuncture & $-\$ 125.00$ \\
Physical Therapy and Chiropractic & $-\$ 125.00$ \\
Physical Therapy and Prayer/Spiritual Healing & $-\$ 125.00$ \\
Physical Therapy and Herbal/Mineral & $-\$ 125.00$ \\
\hline Referent: Prescription OA Medication and Prayer/ Spiritual Healing \\
\hline
\end{tabular}


counter medication and prayer. They were willing to pay $\$ 125$ less than the referent for every other treatment. Segment 3 was willing to pay high prices for treatments they preferred. 


\section{CHAPTER 5. DISCUSSION}

\section{Summary of Findings}

Overall, for the total sample, prayer/spiritual healing had the highest utility value (.71). Therefore, all groups did not place higher utility on allopathic treatments over CAM treatments as hypothesized. When looking at product shares of preference, prayer/spiritual healing also had the highest share of preference $(16.32 \%)$.

When the sample was segmented by gender, women did not place higher utility on CAM treatments as hypothesized. They were slightly different, however. Males preferred herbal mineral supplements more than women (.39 vs. .01) and women preferred massage over men (.39 vs. -.06). Men and women had virtually the same negative utility values for chiropractic care and acupuncture, and the same positive utility values for prayer.

When the sample was segmented by race, blacks did not place higher utility on CAM than whites, and whites did not place higher utility on allopathic treatments then blacks. However, whites did place higher utility on herbal/mineral supplements (.26 vs. .07) than blacks. As hypothesized blacks did place a higher utility on prayer/spiritual healing than did whites (1.56 vs.-0.03).

When the sample was segmented by race and gender, the data showed that overall preferences for osteoarthritis treatments among different cohorts of people (black men, black women, white men, and white women) were very different. Black men preferred prayer/spiritual healing (1.52) and also showed strong preferences for prescription pain medication (.53), herbal/mineral supplements (.36), and over the counter medication and massage (.57). . Black women also preferred prayer/spiritual healing above all other treatments (1.65), and also preferred prescription pain medication (.58), prescription pain medicine plus acupuncture (.72), and physical therapy plus acupuncture (.69). White men preferred the combination therapy of over the counter medication and herbal/mineral supplements the most (.91) and also individually preferred over the counter medication (.42) and herbal/mineral supplements (.48). White women preferred over the counter medication (.47), massage (.49), and prescription pain medication plus acupuncture (.53). Prayer/spiritual healing made a large part of the market share for all race/gender groups.

Duration and disability did not prove to affect CAM utility. Regarding, duration, all duration groups placed a high utility on prayer/spiritual healing and herbal/mineral supplementation. The only group that did not place a high utility on massage was the group that has suffered from OA for eleven or more years. Disability followed the same trend, with high utility for prayer/spiritual healing and herbal/mineral supplements but massage was only valued for the none-mild group. . 
Although the data show that prayer/spiritual healing is considered by participants to be of value, it is not the only treatment option that the survey participants want. This may be a reflection of a desire for a more holistic view of health and healthcare.

\section{Clinical Implications}

These data indicate that doctors and other healthcare providers should be encouraged to develop methods to involve patients in making treatment decisions and take the time to understand the patients' treatment preferences. This would create a two way exchange of information, allowing providers to inform patients about current knowledge regarding treatment effectiveness and patients to inform providers about treatment acceptability, with both healthcare provider and patient arriving at consensus. Although time is a concern, it is possible that early consensus may better assure compliance and heighten treatment effectiveness, ultimately reducing both overall time and cost.

It is clear that this sample of patients desire treatments in addition to normal prescription or over the counter medications. We know that patients we sampled prefer herbal/mineral supplements. Herbal/mineral supplements can interfere with many medications; therefore it is important to stress the question about herbal/mineral supplementation and other CAM treatments while taking a patient's health history.

This research helps to solidify the need for clinicians to be aware of the value placed on CAM therapies by their patients. Clinicians also might explore the use of CAM therapy as a complement to their usual practice. This would require sufficient clinical evidence regarding improved outcomes, however. Regarding the high value placed on prayer/spiritual healing, it is important for health care providers to understand their patients' interest in this form of health maintenance and be willing to allow patients to integrate their religion/spirituality into their treatment regimen.

\section{Health Policy Implications}

Understanding how patients value different aspects of healthcare is important to the ability to best design and implementation of treatments and health programs. The incorporation of patient preferences into health policy decision making will result in a better reflection of the values of patients. If patient preferences are included in clinical practice, drug development, and health policy decisions, the compliance with and therefore effectiveness of health programs will improve. Improved clinical effectiveness may point out opportunities for improved cost-effectiveness.

This research suggests the need for Medicare to examine the restructuring of their reimbursement for chiropractic therapy as well as physical therapy. This sample preferred chiropractic care and physical therapy the least among all treatments. Physical therapy

and chiropractic care are quite expensive. This research also suggests that OA sufferers in this study population want treatment options not currently offered by Medicare. 
This study also underscores the importance of the National Center for Complementary and Alternative Medicine and its efforts to identify the clinical effectiveness and risk of CAM therapies. The use of CAM therapies in conjunction with allopathic medicine is common. However, the utilization of unstudied supplements and/or treatments can result in wasted resources and possibly harm. Therefore it is important to continue the study of supplements and unconventional therapies. Current outcomes and efficacy studies are not sufficient enough to make pricing decisions. This study suggests that people do want CAM therapy in conjunction with their usual care, and illustrates cost points in their willingness to pay for such therapy. However, the questions of clinical and costeffectiveness have not been answered.

\section{Social Implications}

As the marginal WTP for prayer/spiritual healing was quite high, especially in latent class segment 3 , the high valuation placed on such therapy by patients is well illustrated. For the sample surveyed, there is a clear desire for increased integration of spirituality and medicine. It is well established that religion/spiritual healing is a significant part of the lives of older adults. The social implication of this is vast. Community support for wellness centers with an emphasis on faith may improve outcomes for those with osteoarthritis. Future studies may expand this to other disease states. If community and faith-based treatment opportunities have a high patient acceptance, this may be an under explored healthcare business opportunity.

\section{Future Research}

This study assesses what a sample of Medicare-eligible OA patients wand regarding their osteoarthritis treatment. Further refinement of this assessment is needed. The study did not determine why patients prefer specific therapy regimens, nor how they would prefer to receive those therapies. As this study was undertaken in the bible-belt, the results of this study may not be replicated in another part of the country. Future research should explore cost-differentials between CAM therapy in community and faith-based settings as compared to traditional clinical settings. Finally, as options for CAM alone and in conjunction with usual treatments become increasingly available, it is vital to examine clinical effectiveness of CAM, including the relationship between the individual preferences illustrated by his study and individual health outcomes.

\section{Limitations and Confounding Factors}

As there are no standardized rules for creating a conjoint analysis survey, best practices in conjoint analysis have not reached consensus. In most conjoint analysis studies in the healthcare or pharmaceutical fields, efficacy is included in the profile. However, due to lack of efficacy studies to date on CAM therapies, this was not possible in this study. 
This study was performed while the United States was in the midst of a recession. Thus, the findings may reflect the need for those on fixed incomes to avoid some costs associated with traditional therapies including transportation and co-pays. Due to nonrandom sampling of the survey participants this study cannot be considered generally representative. 


\section{LIST OF REFERENCES}

(1) Katz P, Lee F. Racial/Ethnic Differences in the Use of Complementary and Alternative Medicine in Patients with Arthritis. Journal of Clinical Rheumatology 2007;13(1):3-11.

(2) Hsiao A, Wong MD, Goldstein MS, Yu HJ, Anderson RM, Brown ER, Becerra LM, Wenger NS. Variation in Complementary and Alternative Medicine (CAM) Use Across Racial/Ethnic Groups and the Development of Ethnic-Specific Measures of CAM Use. The Journal of Alternative and Complementary Medicine 2007;12(3):281-90.

(3) Orme B. Getting Started With Conjoint Analysis. Madison, WI: Research Publishers LLC;2005.

(4) What is CAM? National Center for Complementary and Alternative Medicine 2007. Available at: http://nccam.nih.gov. Accessed November 17, 2007.

(5) Weir M. What is Complementary and Alternative Medicine? Bond University, Faculty of Law;2005.

(6) Ryan M. Using conjoint analysis to take account of patient preferences and go beyond health outcomes: an application to in vitro fertilisation. Social Science Medicine 1999;48(4):535-46.

(7) Altman R, Hochberg M, Moskowitz R, Schnitzer T. Recommendations for the Medical Management of Osteoarthritis of the Hip and Knee. Arthritis \& Rheumatism 2000;43(9):1905-15.

(8) Herman C, Allen P, Hunt W, Prasad A, Brady T. Use of Complementary Therapies Among Primary Care Clinic Patients with Arthritis. Preventing Chronic Diseases 2004;1(4).

(9) Hansen K, Elliott M. Osteoarthritis. In: DiPiro J, Talbert R, Yee G, Matzke G, Wells B, Posey L, editors. Pharmacotherapy. 6 ed. New York: McGraw Hill, Medical Publishing Division;2005:1685-700.

(10) Issa M, Fenter T, Black L, Grogg A, Kreup E. An Assessment of the Diagnosed Prevalence of Disease in Men 50 Years of Age or Older. American Journal of Managed Care 2006;12:S83-S89.

(11) Greenstone CL. Clinician's Corner: Osteoarthritis: A Lifestyle Medicine Assessment of Risks, Prevention, and Treatment. American Journal of Lifestyle Medicine 2007 August 1;1(4):256-9. 
(12) Ramsey SD, Spencer AC, Topolski TD, Belza B, Patrick DL. Use of alternative therapies by older adults with osteoarthritis. Arthritis \& Rheumatism 2001;45(3):222-7.

(13) Osborn C, Baxter GD, Barlas P, Barlow J. Complementary and alternative medicine and rheumatology nurses: A survey of current use and perceptions. Nursing Times Research 2004;9(2):110-9.

(14) Bower K, Frail D, Twohig P, Putnam W. What Influences Seniors' Choice of Medications for Osteoarthritis? Canadian Family Physician 2006;52:342-3.

(15) Manek N, Lane N. Osteoarthritis:Current Concepts in Diagnosis and Management. American Family Physician 2000;6(16):1795-804.

(16) Hill A. Conjoint Analysis in Health: A Stated Choice Method. The Second Conjoint Analysis in Health Conference, Chapel Hill, North Carolina. Aug 2; 2007.

(17) Dieppe P, Brandt K. What is important in treating osteoarthritis? Whom shouldwe treat and how should we treat them? Rheumatic Disease Clinics of North America 2003;29:687-713.

(18) Mansfield C, Mitchell J, King D. The doctor as God's mechanic? Beliefs in the Southeastern United States. Social Science in Medicine 2007;54:399-409.

(19) Hunter D, Felson D. Osteoarthritis. British Medical Journal 2006;332:639-42.

(20) Boh L. Osteoarthritis. In: DiPiro J, Yee G, Matzke G, Wells B, Posey L, editors. Pharmacotherapy: A Pathophysiologic Approach. 4th ed. Stamford, Connecticut: Appleton and Lange;1999:1441-65.

(21) Felson DT. An update on the pathogenesis and epidemiology of osteoarthritis. Radiologic Clinics of North America 2004;42(1):1-9.

(22) Felson D, Anderson J, Naimark A, Walker A, Meenen R. Obesity and Knee Osteoarthritis: The Framingham Study. Annals of Internal Medicine 1988;109:1824.

(23) Greenstone CL. Clinician's Corner: Osteoarthritis: A Lifestyle Medicine Assessment of Risks, Prevention, and Treatment. American Journal of Lifestyle Medicine 2007;1(4):256-9.

(24) Osteoarthritis. Arthritis Foundation 2007. Available at: www.arthritis.org. Accessed November 22, 2008. 
(25) University of Maryland Medical Center. Osteoarthritis. University of Maryland Medical Center 2006. Available at: http://www.umm.edu/ency/article/000423.htm Accessed November 28, 2006.

(26) Arcury TA, Bell RA, Vitolins MZ, Quandt SA. Rural Older Adults' Beliefs and Behavior Related to Complementary and Alternative Medicine Use. Complementary Health Practice Review 2005;10(1):33-44.

(27) Ni H, Simile C, Hardy A. Utilization of complementary and Alternative Medicine by United States Adults. Medical Care 2002;40(4):353-8.

(28) What is CAM? National Center for Complementary and Alternative Medicine 2007. Available at: http://nccam.nih.gov. Accessed November 28, 2006.

(29) The Use of Complementary and Alternative Medicine in the United States. National Center for Complementary and Alternative Medicine 2006. Available at: http://nccam.nih.gov/news/camsurvey_fs1.htm. Accessed January 29, 2007.

(30) Rao JK, Mihaliak K, Kroenke K, Bradley J, Tierney WM, Weinberger M. Use of complementary therapies for arthritis among patients of rheumatologists. Annals of Internal Medicine 1999;131(6):409-16.

(31) Astin JA. Why patients use alternative medicine: results of a national study. Journal of the American Medical Association 1998;279(19):1548-53.

(32) Barnes PM, Bloom B, Nahi R. Complementary and Alternative Medicine Use Among Adults and Children in the United States. CDC National Health Statistics Reports 2007;12:1-24.

(33) Quandt SA, Chen H, Grzywacz JG, Bell RA, Lang W, Arcury TA. Use of complementary and alternative medicine by persons with arthritis: results of the National Health Interview Survey. Arthritis \& Rheumatism 2005;15;53(5):74855.

(34) Long L, Soeken K, Ernst E. Herbal medicines for the treatment of osteoarthritis: a systematic review. Rheumatology 2001;40(7):779-93.

(35) Ibrahim S. Variation in perceptions of treatment and self-care practices in elderly with osteoarthritis: a comparison between African American and white patients. Arthritis Care and Research 2001;45(4):340-5.

(36) Bridges J, Bauber B, Marshall D. A Checklist for Good Research Practices for the Application of Conjoint Analysis in Health. Conjoint Analysis Taskforce of the International Society of Pharmacoeconomics and Outcomes Research 2009:1-17. 
(37) Yoon SL, Horne CH, Adams C. Herbal Product Use by African American Older Women. Clinical Nursing Research 2004 November 1;13(4):271-88.

(38) Bell RA, Suerken C, Quandt SA, Grzywacz JG, Lang W, Arcury TA. Prayer for Health among U.S. Adults: The 2002 National Health Interview Survey. Complementary Health Practice Review 2005;10(3):175-88.

(39) Wellman G, Vidican C. Pilot study of a hierarchical Bayes method for utility estimation in a choice-based conjont analysis of prescription benefit plans including medication therapy management services. Research in Social and Administrative Pharmacy 2008;4:218-30.

(40) Luce R, Tukey J. Simultaneous Conjoint Measurement: A New Type of Fundamental Measurement. Journal of Mathematical Psychology 1964;1:1-27.

(41) McFadden D. Conditional Logit Analysis of Qualitative Choice Behavior. Analysis of Qualitative Choice Behavior.Berkley, California: University of California at Berkley 1974;105-42.

(42) Johnson R. Trade-Off Analysis of Consumer Values. Journal of Marketing Research 1974;11(2):121-7.

(43) Huber J. Conjoint: What it Can and and Cannot Do. The Second Conjoint Analysis in Health Conference, Chapel Hill, North Carolina: Aug 2; 2007.

(44) Lancaster K. A New Approach to Consumer Theory. The Journal of Political Economy 1966;74(2):132-157.

(45) Telser H, Zweifel P. Measuring Willingness-to-pay for risk reduction: an application of conjoint analysis. Health Economics 2002;11:129-139.

(46) Comparison of Contingent Valuation and Conjoint Analysis. Sawtooth Software Educational Papers 2007. Available at: http://www.sawtoothsoftware.com. Accessed January 29, 2007.

(47) Phillips K, Maddala T, Johnson F. Measuring Preferences for Health Care Interventions Using Conjoint Analysis: An Application to HIV Testing. Health Services Research 2002;37(6):1681-1705.

(48) Protiere C, Donaldson C, Luchini S, Moatti JP, Shackley P. The impact of information on non-health attributes on willingness to pay for multiple health care programmes. Social Science \& Medicine 2004;58(7):1257-69.

(49) Lanscar E. Using Discrete Choice Experiments to Investigate Subject Preferences for Preventative Asthma Medication. Respirology 2007;12(1):127-36. 
(50) Ratcliffe J, Buxton M, McGarry T, Sheldon R, Chancellor J. Patients' preferences for characteristics associated with treatments for osteoarthritis. Rheumatology (Oxford) 2004;43(3):337-45.

(51) Ratcliffe J, Buxton M, McGarry T, Sheldon R, Chancellor J. Patients' preferences for characteristics associated with treatments for osteoarthritis. Rheumatology (Oxford) 2004;43(3):337-45.

(52) Mohamed A, Johnson F, Hauber A, Leibman C, Arrighi H. The Importance of Modifying the Course of Alzheimer's Disease: Older Americans' Risk-Benefit Preferences for New Treatments. Value in Health 2007;3(1):167-75.

(53) Ratcliffe J, Van Haselen R, Buxton M, Hardy K, Colehan J, Partridge M. Assessing patients' preferences for characteristics associated with homeopathic and conventional treatment of asthma: a conjoint analysis study. Thorax 2002;57:503-8.

(54) Mele N. Conjoint Analysis: Using a Market-Based Research Model for Healthcare Decision Making. Nursing Research 2008;57(3):220-4.

(55) Johnson FR, Desvousges WH, Ruby MC, Stieb D, De Civita P. Eliciting Stated Health Preferences: An Application to Willingness to Pay for Longevity. Medical Decision Making 1998;18(2):S57-S67.

(56) Johansson G. Asthma Treatment Preference Study: A Conjoint Analysis of Preferred Drug Treatments. Chest 2004;125:916-23.

(57) Walzer S. What do parents want from their child's asthma treatment? Therapeutics and Clinical Risk Management 2007;3(1):167-75.

(58) Ryan M, Farrar S. Using conjoint analysis to elicit preferences for health care. British Medical Journal 2000;320(7248):1530-3.

(59) Protiere C, Donaldson C, Luchini S, Moatti JP, Shackley P. The impact of information on non-health attributes on willingness to pay for multiple health care programmes. Social Science \& Medicine 2004;58(7):1257-69.

(60) Louviere J, Eagle T, Cohen S. Conjoint Analysis: Methods, Myths and Much More. CenSoc Working Paper 2005; No. 05-001.

(61) Vermunt J, Magidson J. Latent Class Analysis. Statistical Innovations 2006. Available at: www.statisticalInnovations.com. Accessed November 12, 2008.

(62) Orme B. Sample Size Issues for Conjoint Analysis.Madison, Wisconsin: Research Publishers, LLC.; 2006. 
(63) American Factfinder. United States Census 2006. Available at: www.factfinder.census.gov. Accessed September 23, 2006.

(64) American Factfinder. United States Census 2006. Available at: www.factfinder.census.gov. Accessed September 23, 2006.

(65) Shumway-Cook A. Mobility Limitations in the Medicare Population: Prevalence and Sociodemographic and Clinical Correlates. Journal of the American Geriatrics Society 2007;53:1217-21.

(66) Kapstad H, Hanestad B, Langeland N, Rustoen T, Stavem K. Cutpoints for mild, moderate and severe pain in patients with osteoarthritis of the hip or knee ready for joint replacement surgery. Musculoskeletal Disorders 2008;9(55):1-9.

(67) Ozdemir S, Johnson FR, Hauber AB. Hypothetical bias,cheap talk,and stated willingness to pay for health care. Journal of Health Economics 2009;28(4):894901.

(68) Sawtooth Software [computer program]. Version CBC/Web Version 2009. Available at: www.sawtoothsoftware.com. Accessed August 10, 2008. 


\section{APPENDIX A. CONJOINT ANALYSIS SURVEY}

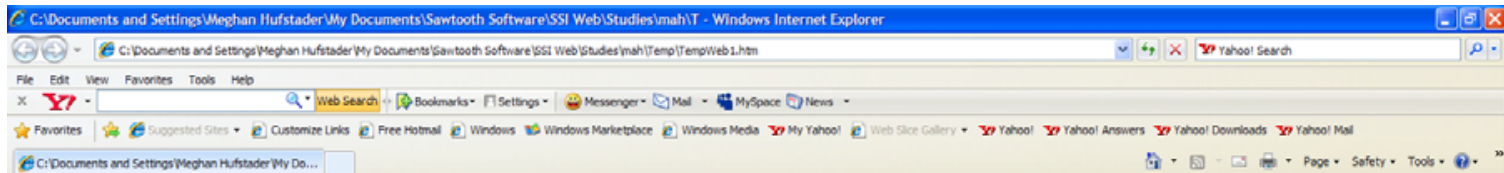

\section{About this Survey}

This survey is part of a research study that aims to determine Medicare beneficiaries' preferences and willingness to pay for different osteoarthritis treatments The research is being conducted by Meghan Hutstader at the University of Tennessee, Heath Science Center College of Pharmacy.

This study does not have any risks and you will receive a small gift:

The interview does not pose any foreseeable risks to you. Through your participation in this study, you may become aware of the various treatment options for osteoarthritis. You will also contribute to the advancement about osteoarthritis, and the treatment preferences of patients like you that suffer from osteoarthritis. At the completion of the interview, you will be receiving a small gift as a token of

\section{This Study is Voluntary:}

Your participation in this study is totally voluntary. You have the right to withdraw from this study at any time with no penalty or loss of rights to which you are entitled. For the confidentiality of your interview responses, your name will not be asked during the intervew.

Next

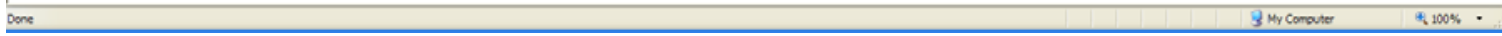

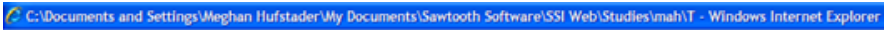

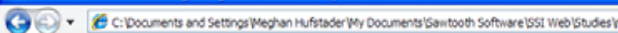

$\checkmark, \times x$ Yohool serch

Fle Ede New Favoun ton the

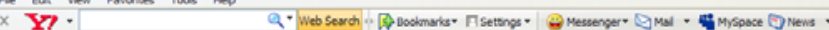

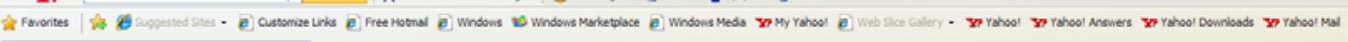

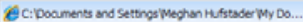

\section{How old are you?}

Next

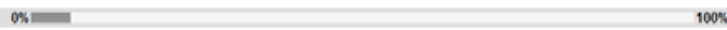




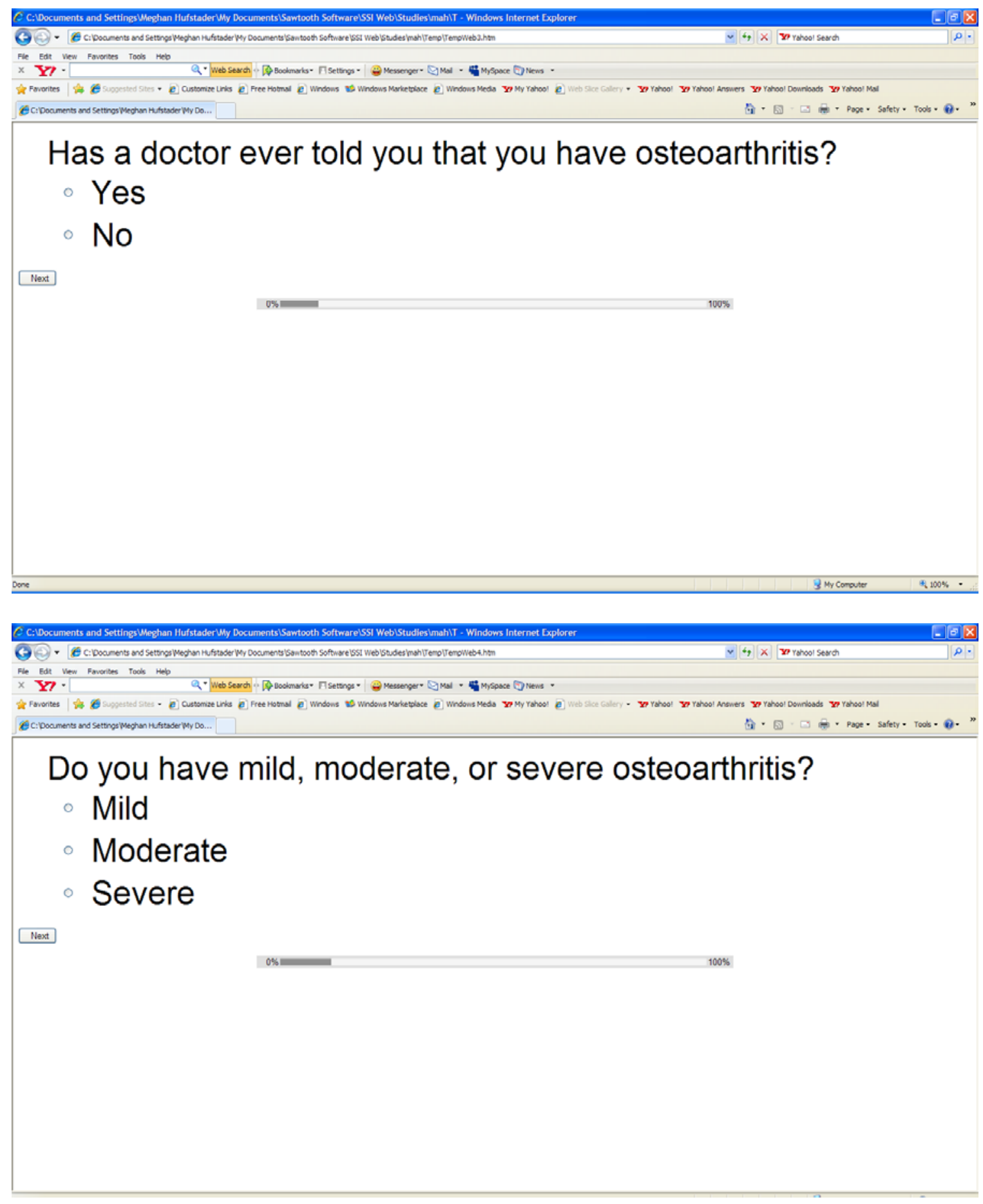




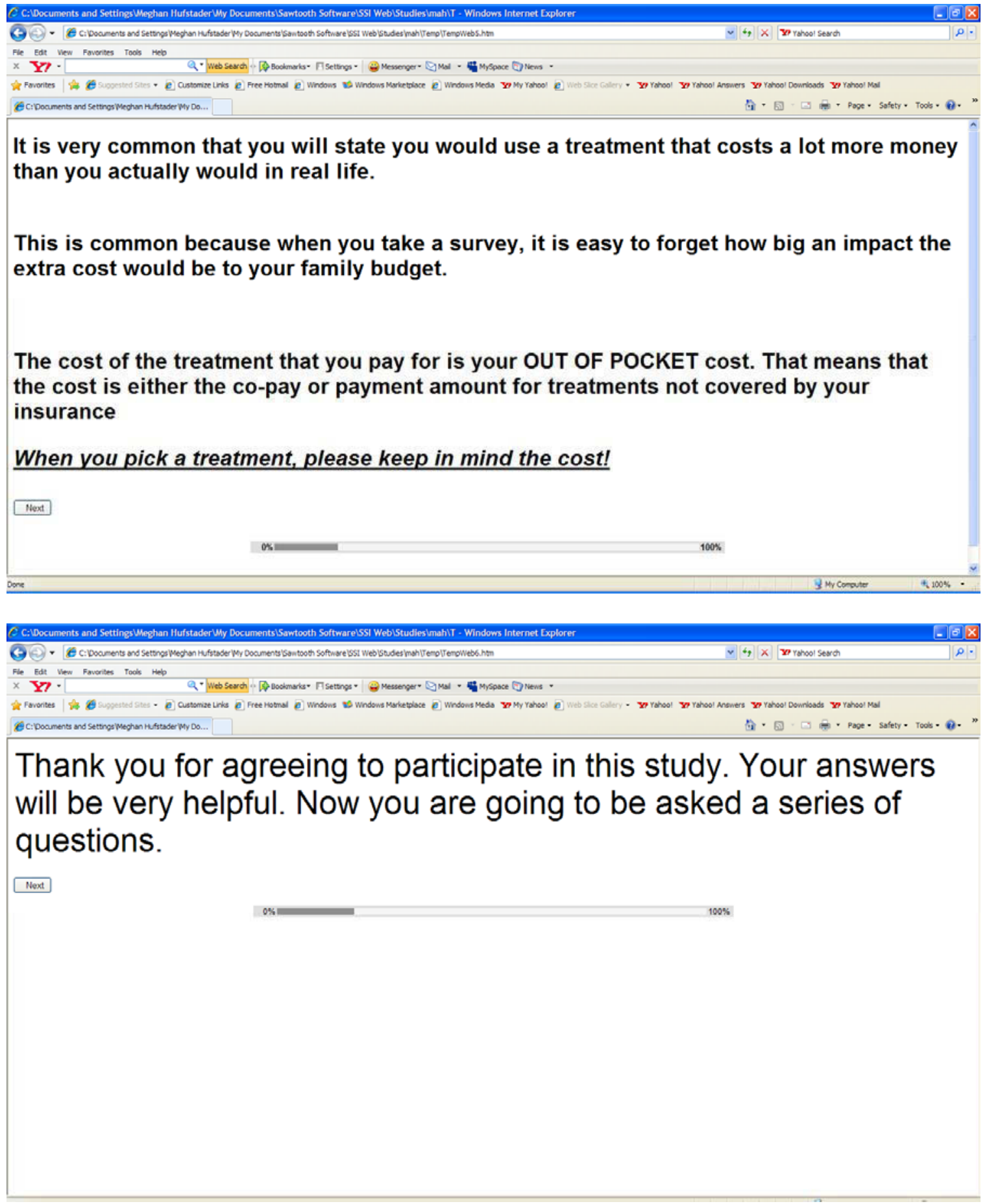




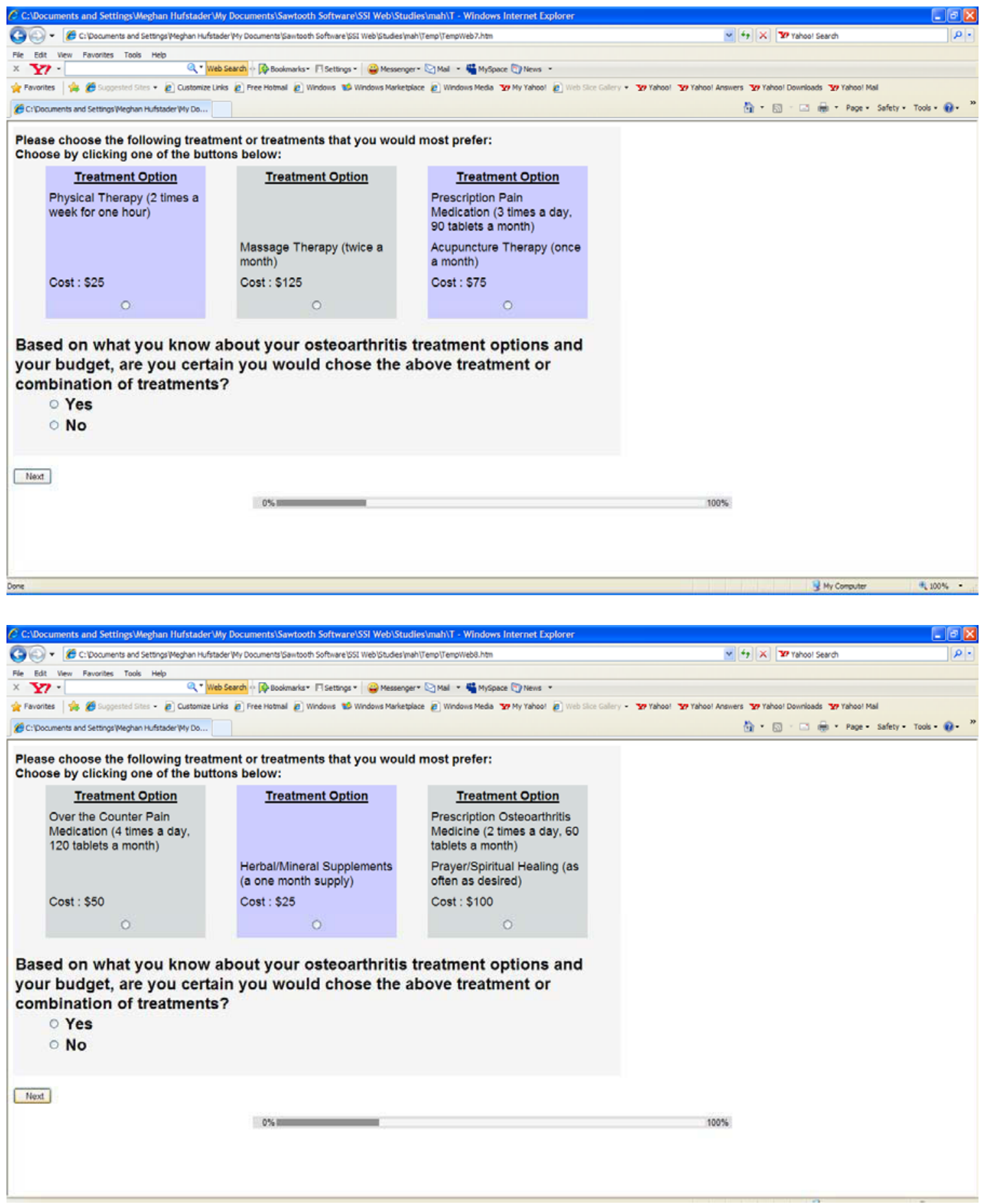




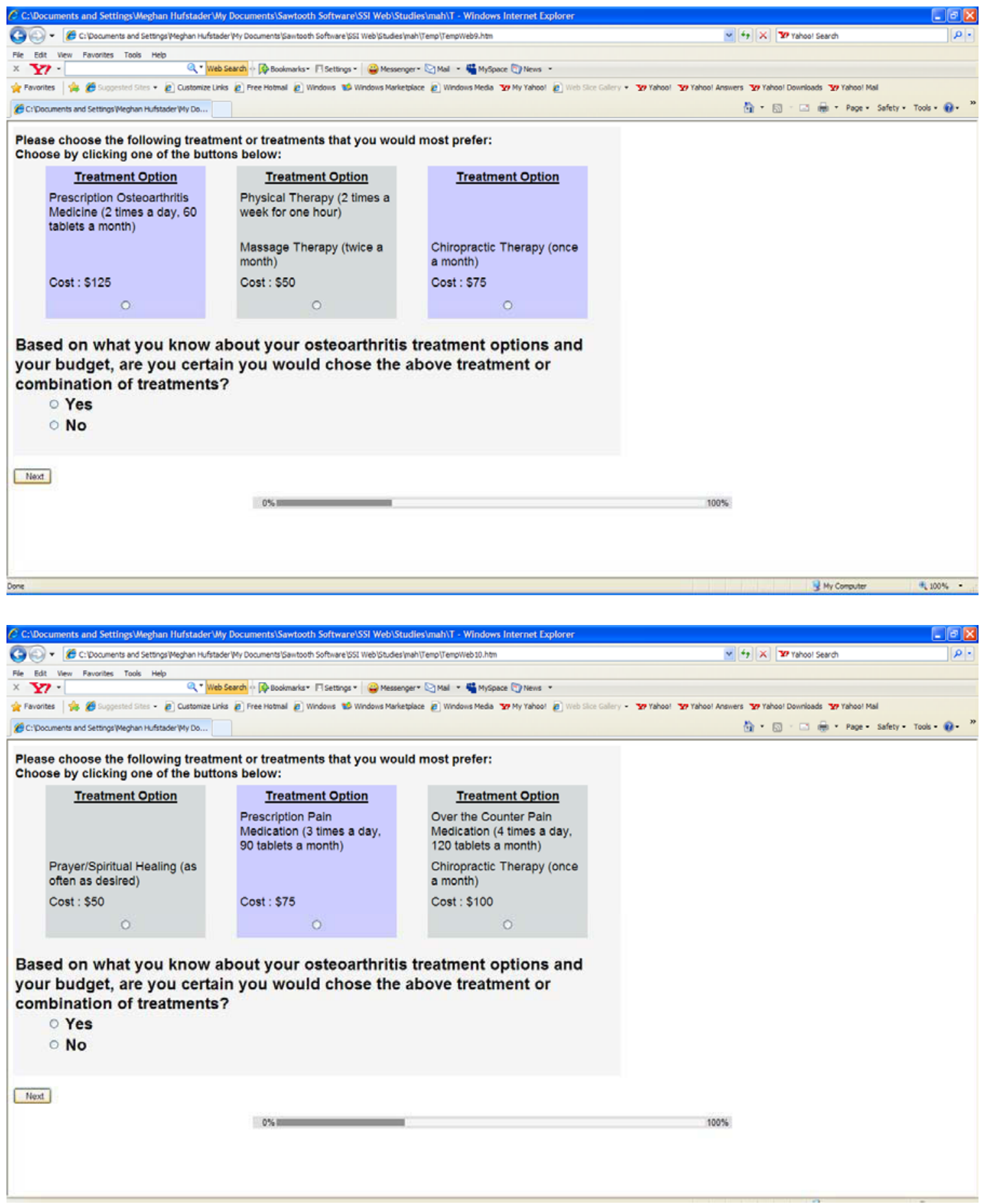




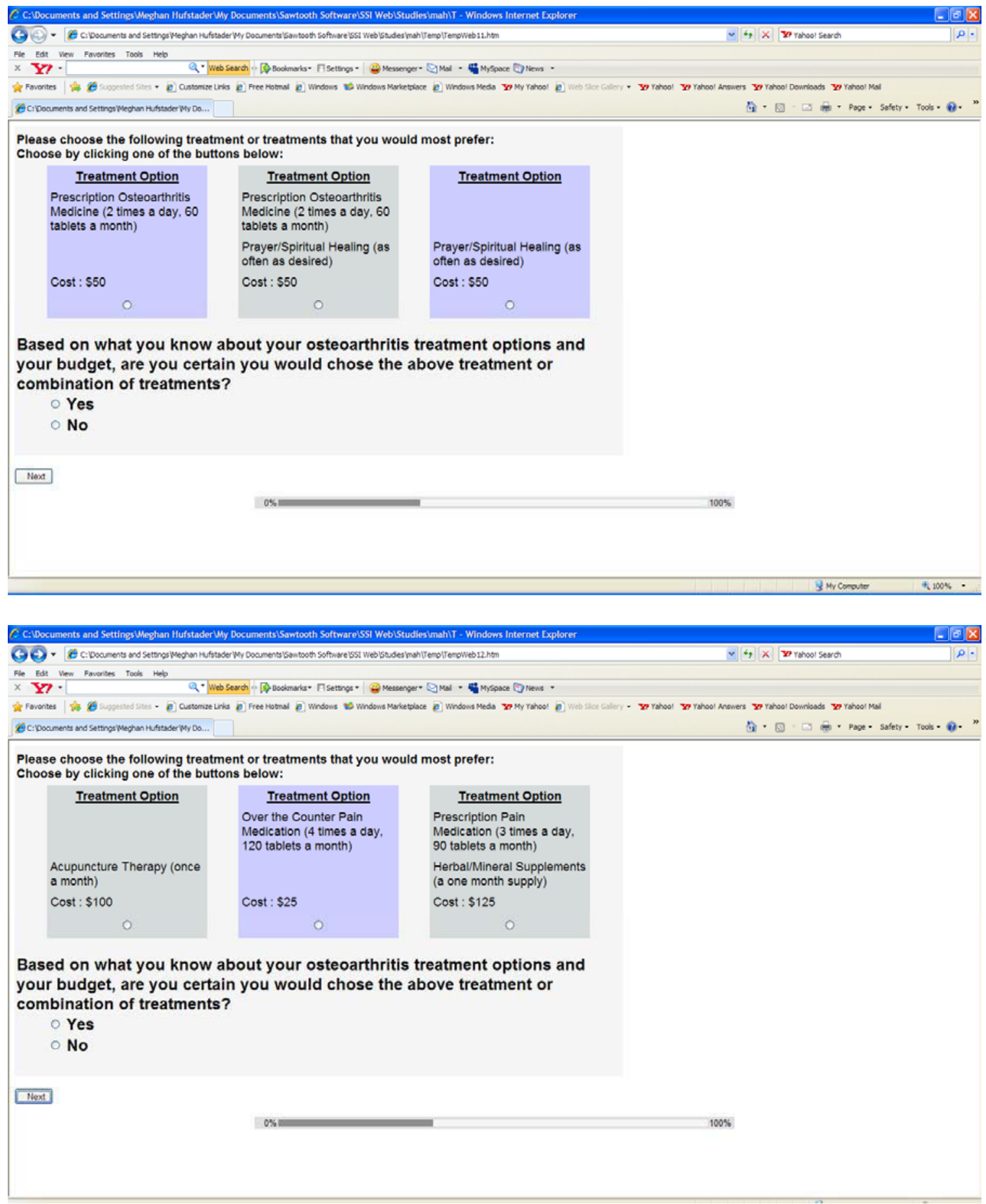




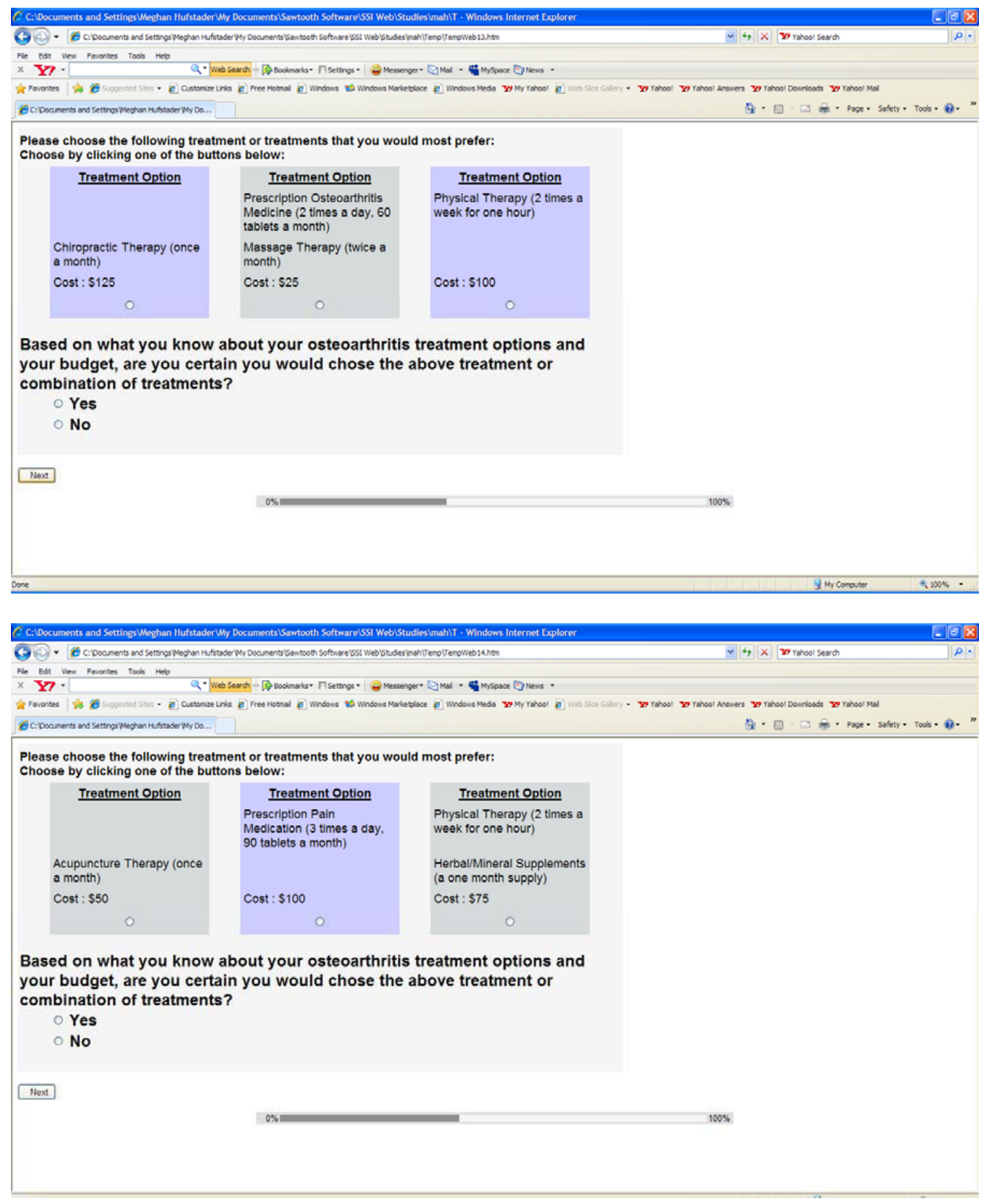




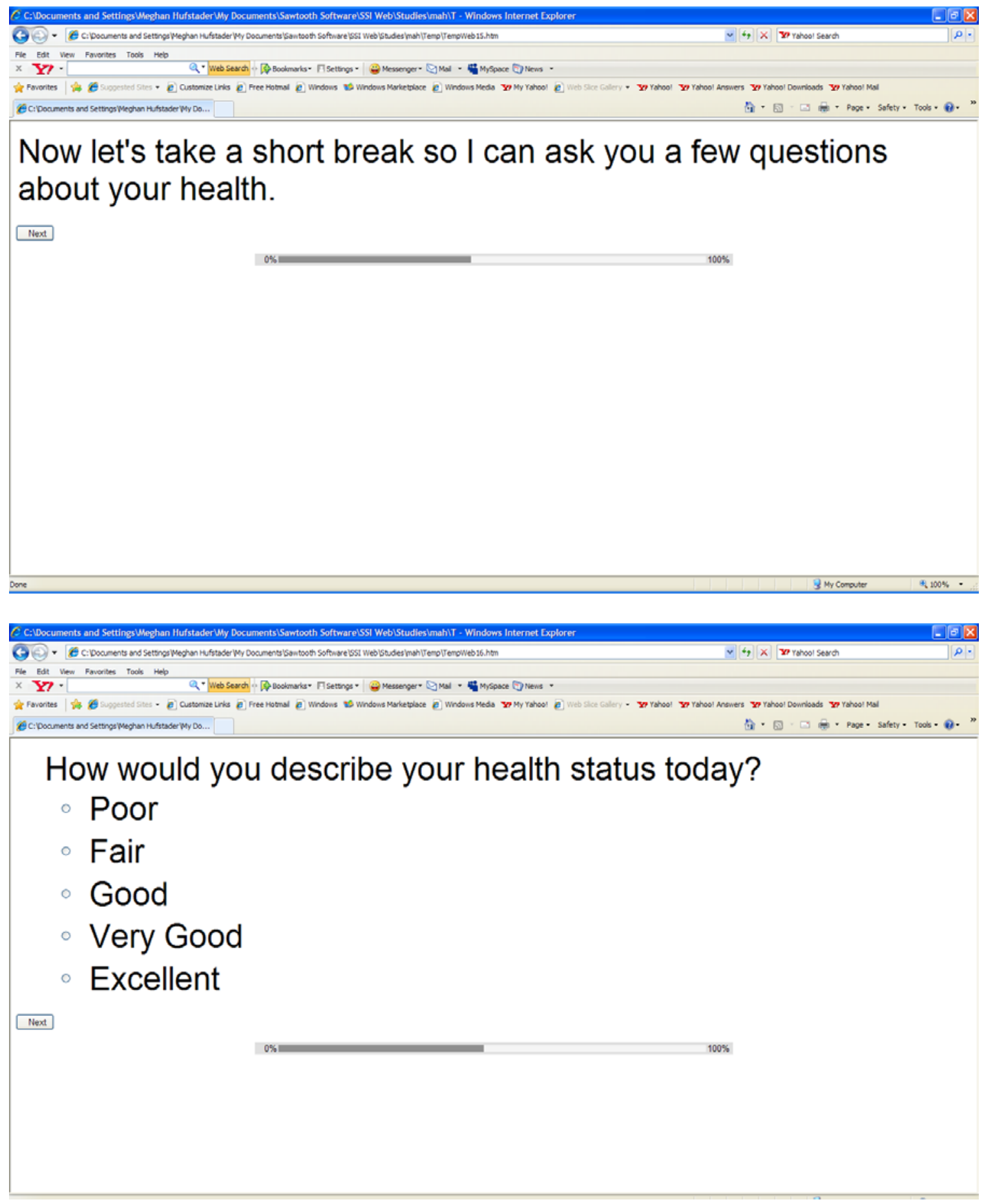




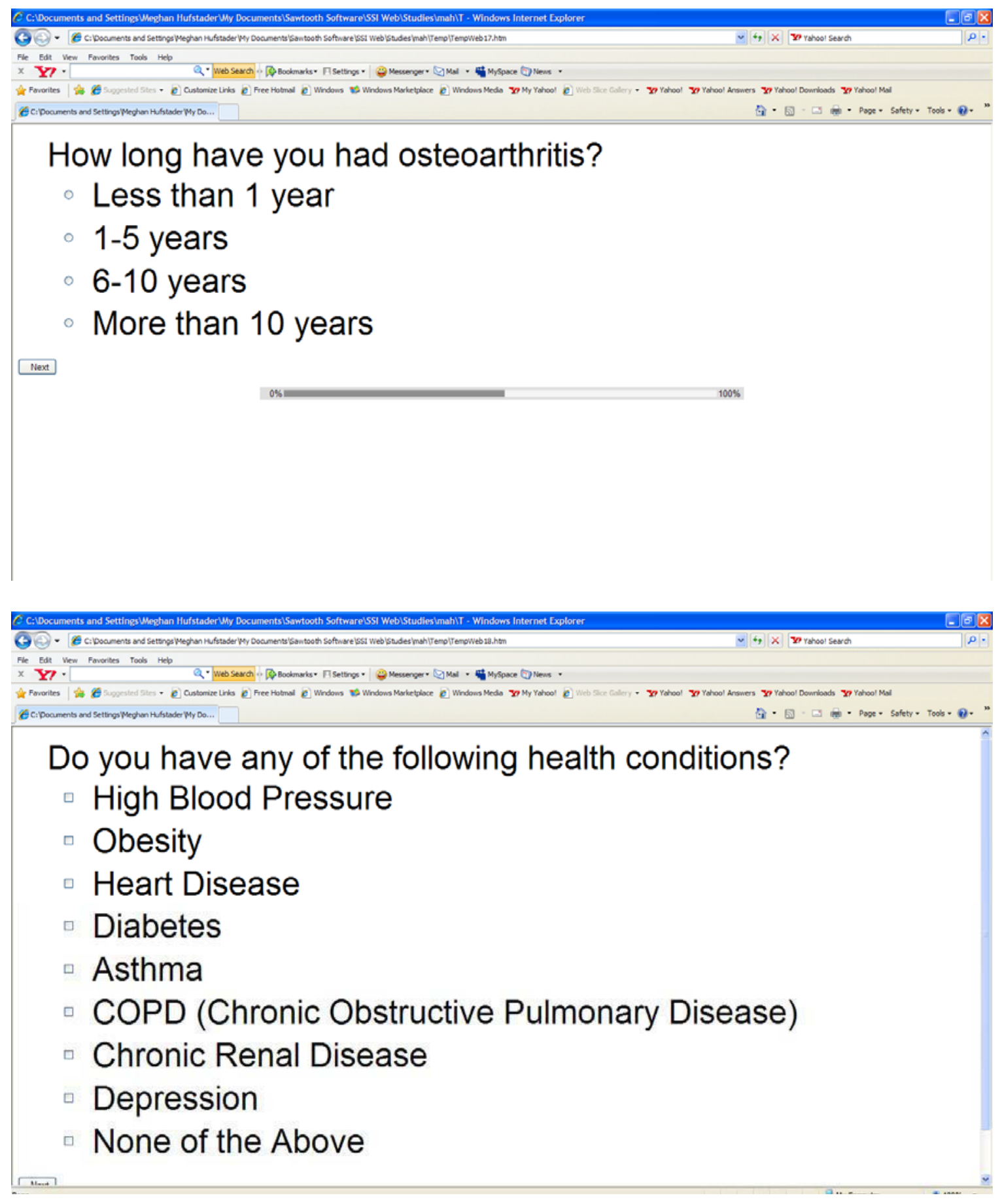




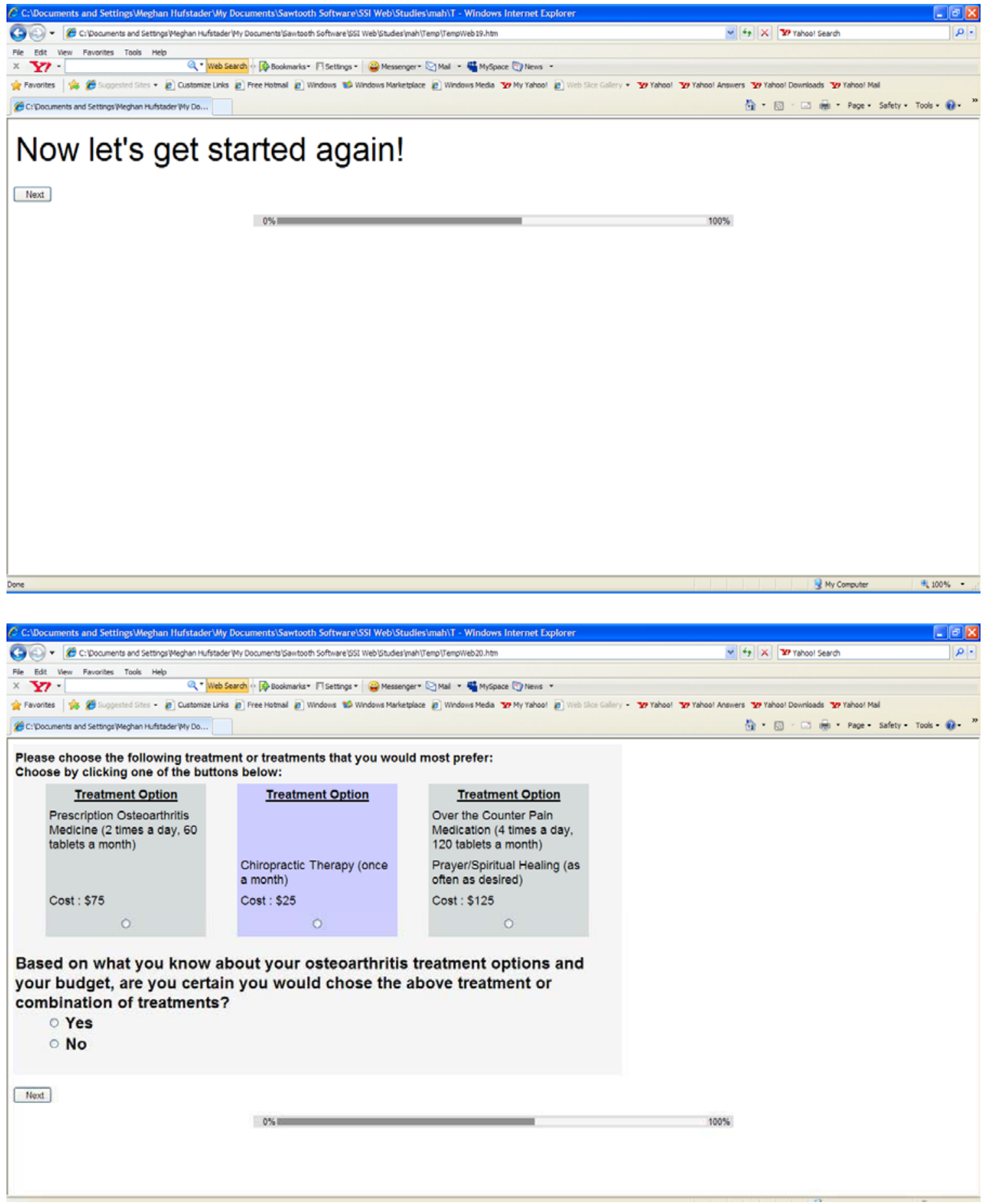




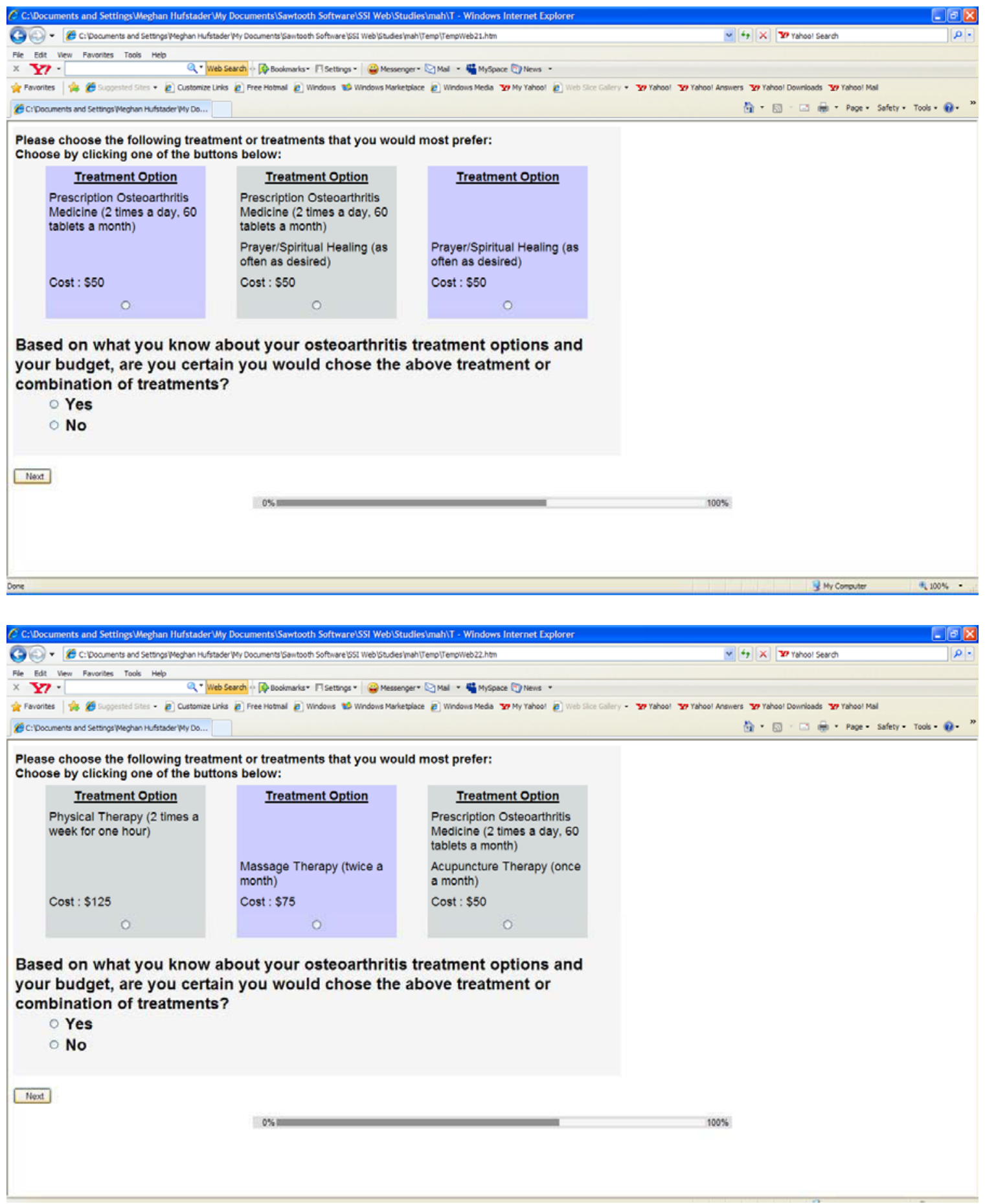




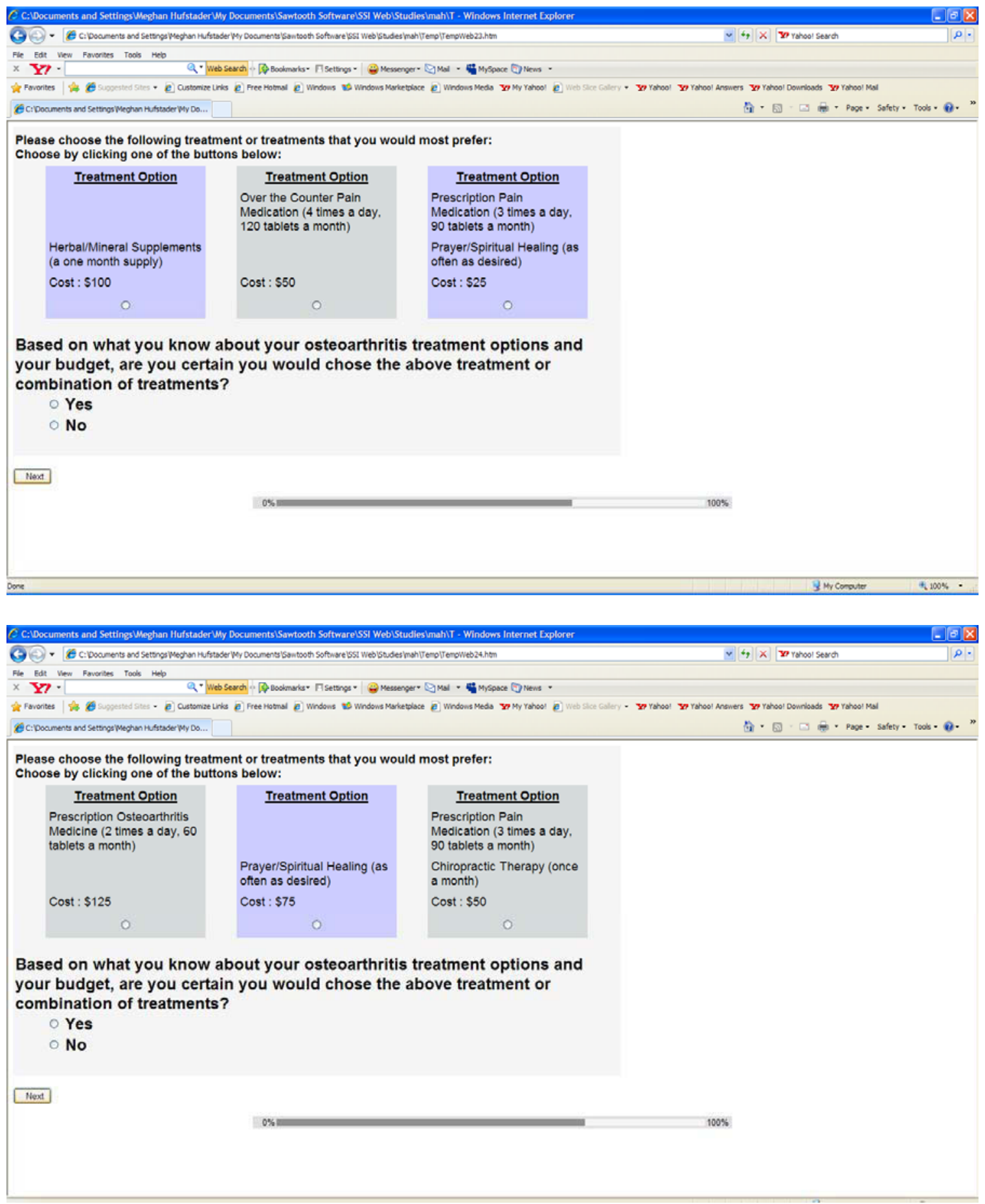




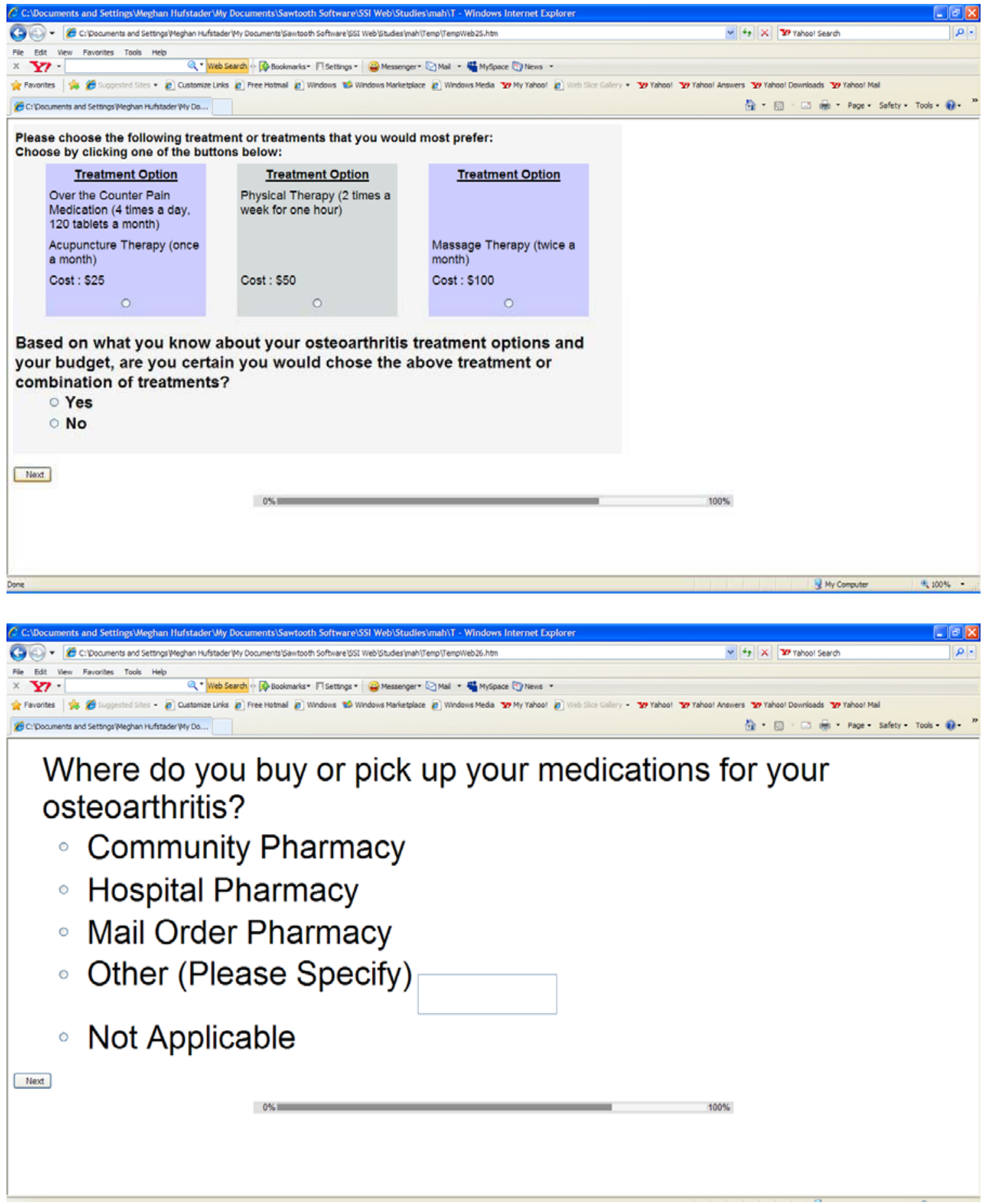




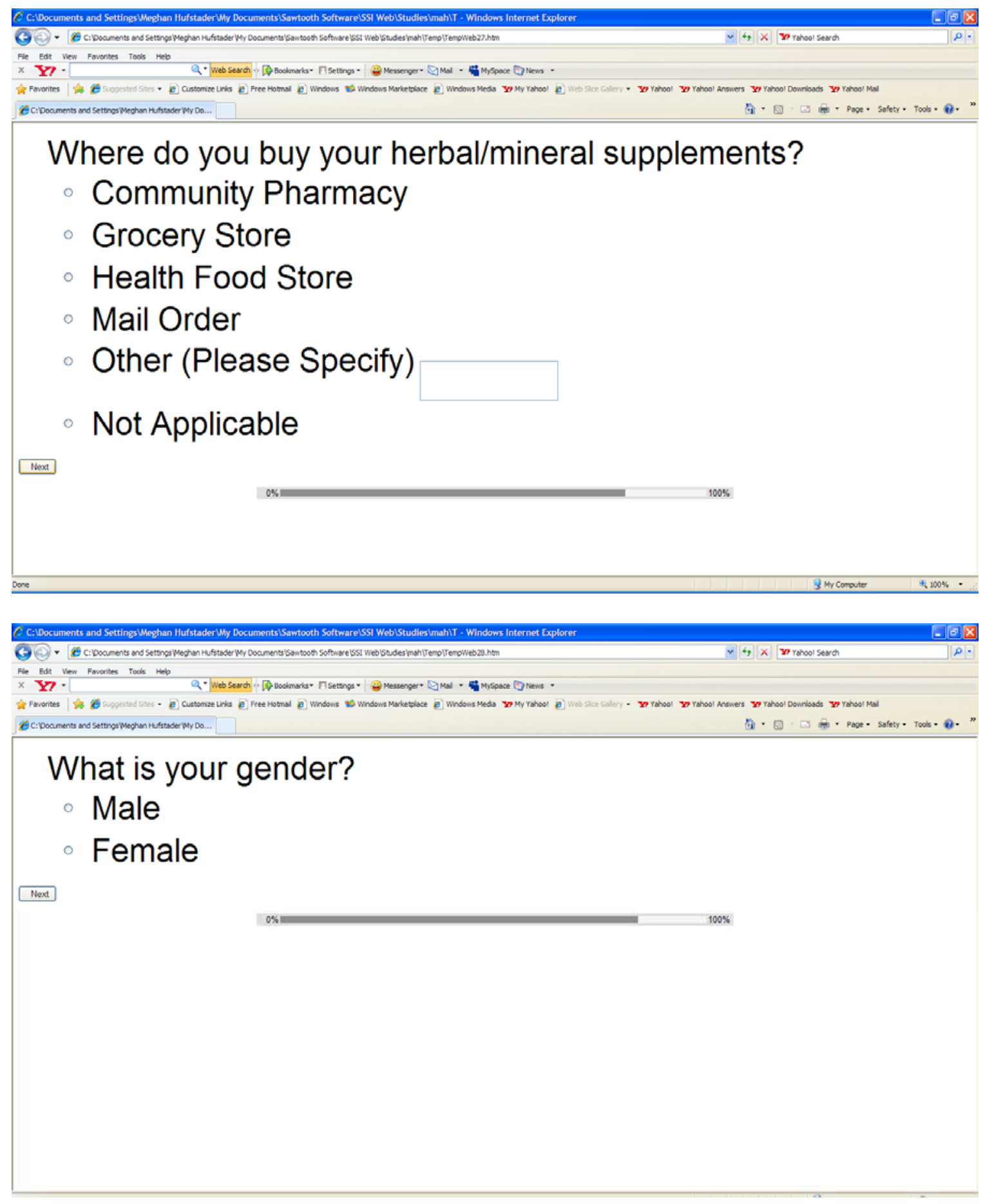




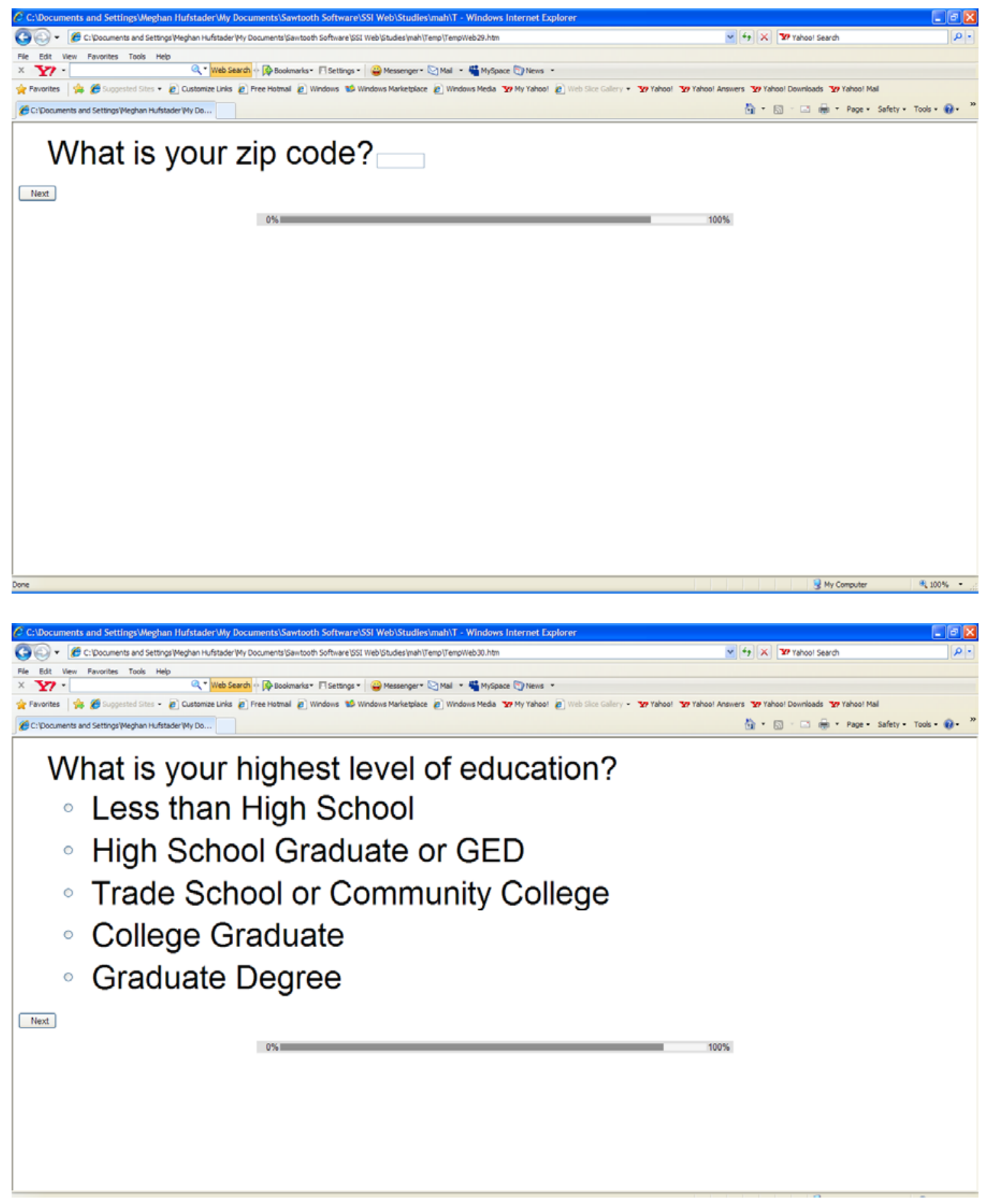




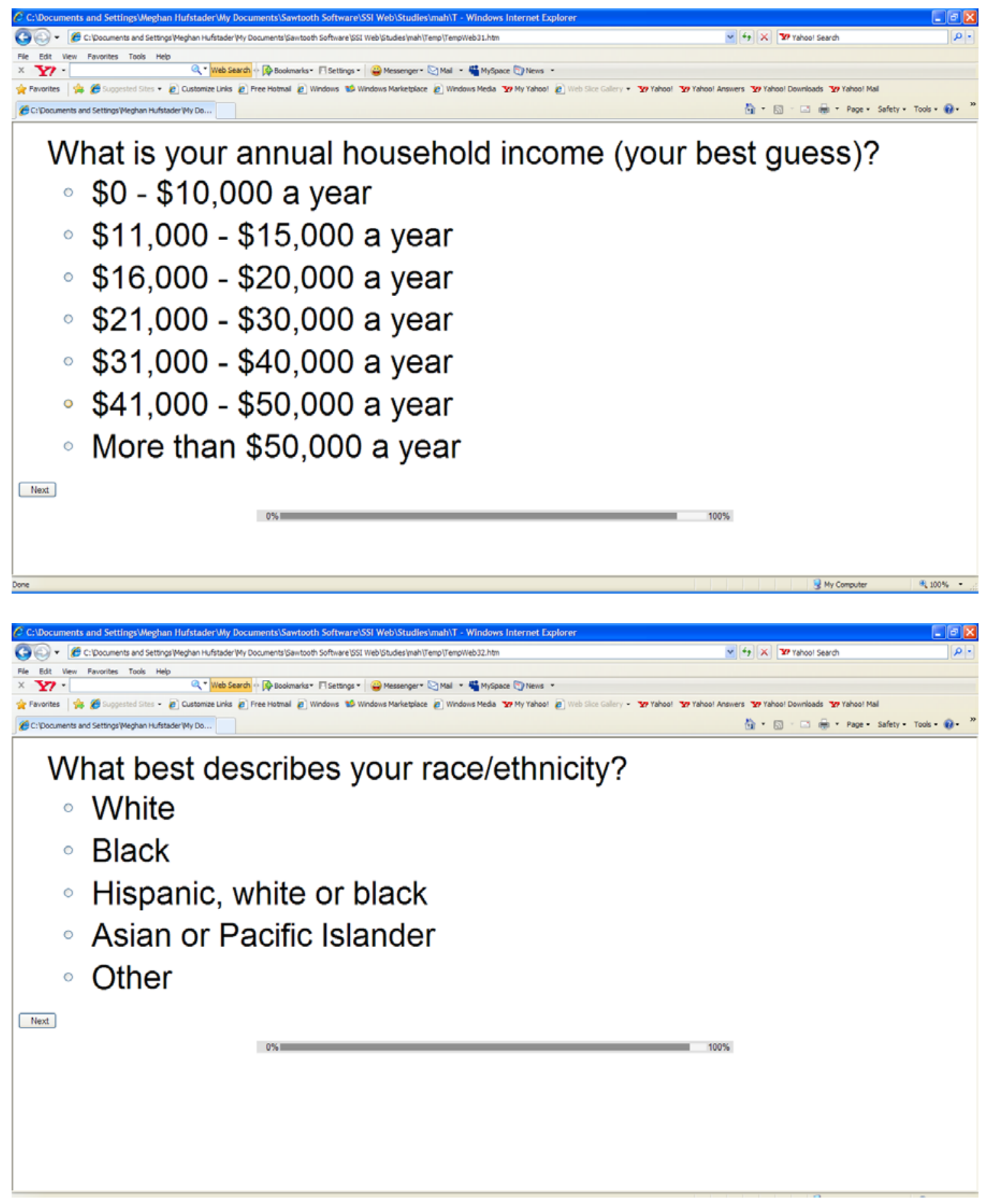




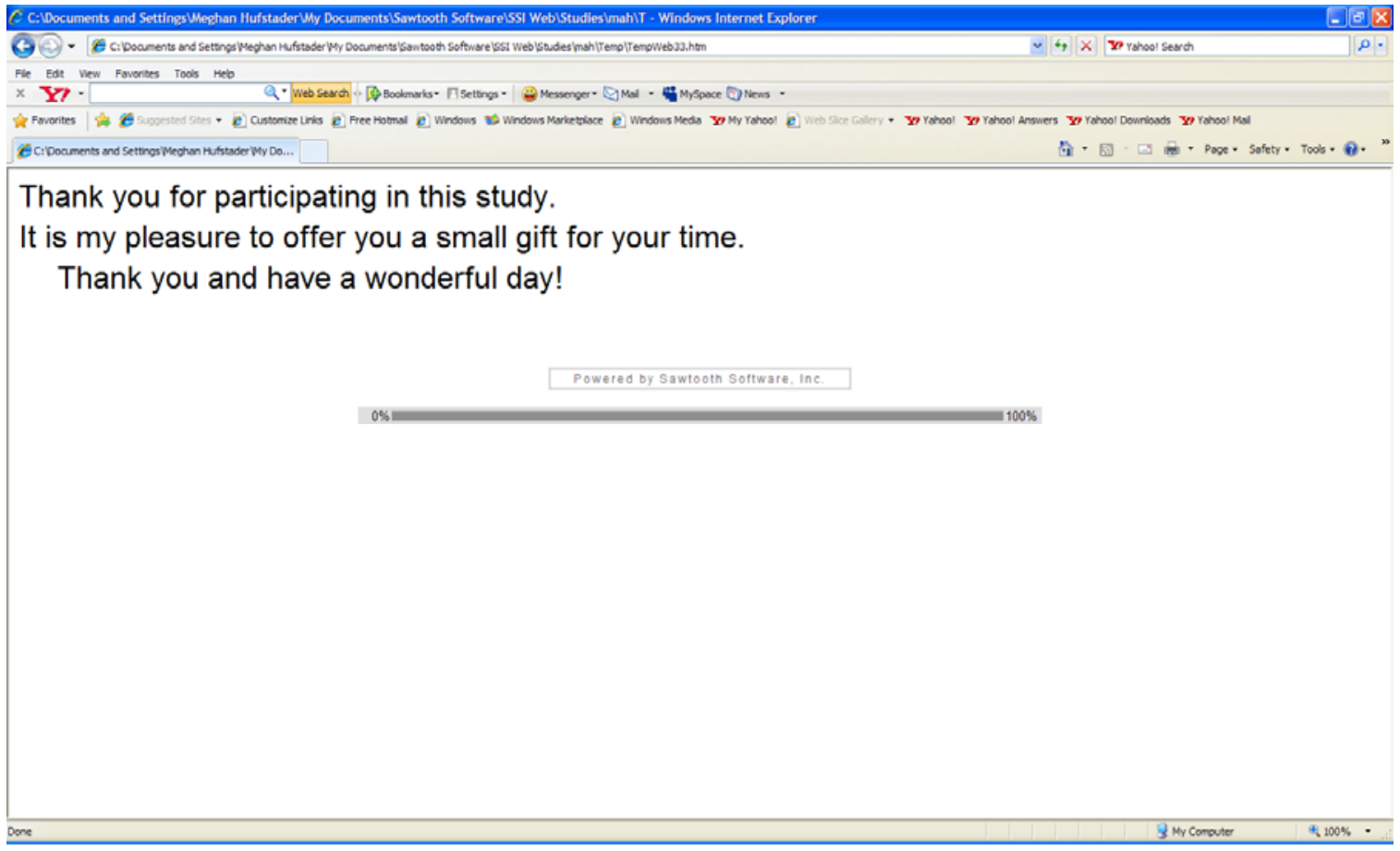




\title{
APPENDIX B. BRIEF PAIN INVENTORY LICENSE AND SURVEY
}

\author{
THE UNIVERSITY OF TEXAS \\ MDANDERSON \\ CANCERCENTER
}

February 11, 2009

Ms. Meghan Hufstader

University of Tennesee Health Science Center

847 Monroe Avenue, Suite 205K

Memphis, TN 38163

Dear Ms. Hufstader:

I am pleased that you have considered using the Brief Pain Inventory ${ }^{\ominus} \mathrm{BPI}$ ) in your upcoming study. The study description you provided seems to be congruent with the intended use of the BPI. You may reproduce the BPI but your copyright use is limited only to this specific study. In addition, the following should appear in your reproduced copy.

Copyright 1991 Charles S. Cleeland, Ph.D.

Pain Research Group

Used by permission.

Additional information can be found by visiting our website:

www.mdanderson.org/department/prg

It is greatly appreciated if a summary of your results could be provided after the completion of your project so that we can continue to evaluate the performance of our instrument.

Sincerely,

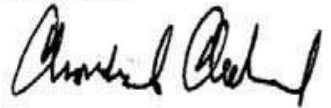

Charles S. Cleeland, Ph.D

McCullough Professor of Cancer Research

Chairman, Department of Symptom Research

Division of Internal Medicine

CSC:Ifs

Cc: Tito R. Mendoza, Ph.D.

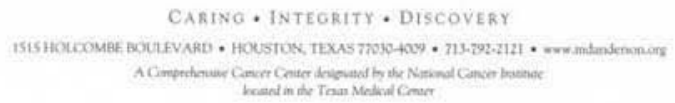


STUDY ID \#:-_---_--- DO NOT WRITE ABOVE THIS LINE HOSPITAL \#:

\section{Brief Pain Inventory (Short Form)}

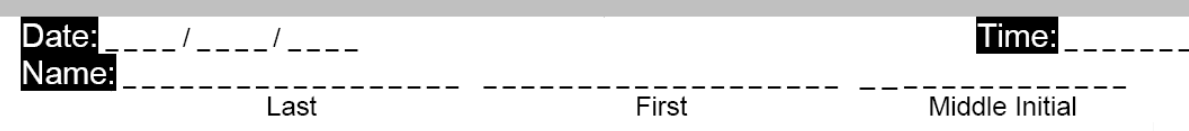

1. Throughout our lives, most of us have had pain from time to time (such as minor headaches, sprains, and toothaches). Have you had pain other than these everyday kinds of pain today?

1. Yes

2. No

2. On the diagram, shade in the areas where you feel pain. Put an $\mathrm{X}$ on the area that hurts the most.

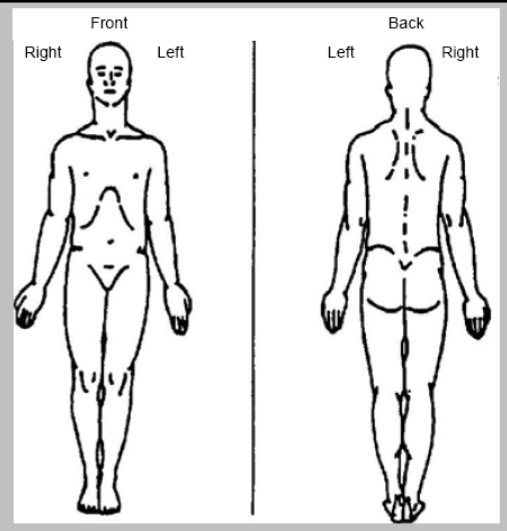

3. Please rate your pain by circling the one number that best describes your pain at its worst in the last 24 hours.

$\begin{array}{lllllllllll}0 & 1 & 2 & 3 & 4 & 5 & 6 & 7 & 8 & 9 & \begin{array}{l}10 \\ \text { Pain as bad as } \\ \text { you can imagine }\end{array} \\ \text { Pain } & & & & & & & & & & \end{array}$

4. Please rate your pain by circling the one number that best describes your pain at its least in the last 24 hours.

$\begin{array}{lllllllllll}0 & 1 & 2 & 3 & 4 & 5 & 6 & 7 & 8 & 9 & \begin{array}{l}10 \\ \text { Pain as bad as } \\ \text { you can imagine }\end{array} \\ \text { Pain } & & & & & & & & & & \\ \text { Pain }\end{array}$

5. Please rate your pain by circling the one number that best describes your pain on the average.

$\begin{array}{lllllllllll}0 & 1 & 2 & 3 & 4 & 5 & 6 & 7 & 8 & 9 & \begin{array}{l}10 \\ \text { Pain as bad as } \\ \text { No } \\ \text { Pain can imagine }\end{array}\end{array}$

6. Please rate your pain by circling the one number that tells how much pain you have right now.

$\begin{array}{lllllllllll}0 & 1 & 2 & 3 & 4 & 5 & 6 & 7 & 8 & 9 & \begin{array}{l}10 \\ \text { Pain as bad as } \\ \text { you can imagine }\end{array} \\ \text { Pain } & & & & & & & & & & \\ \text { you can }\end{array}$

Page 1 of 2 
STUDY ID \#:-_-_-_-_-_- DO NOT WRITE ABOVE THIS LINE HOSPITAL \#: --_-_-_-_--

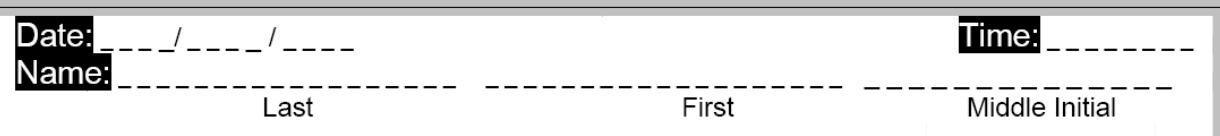

7. What treatments or medications are you receiving for your pain?

8. In the last 24 hours, how much relief have pain treatments or medications provided? Please circle the one percentage that most shows how much relief you have received.
$\begin{array}{lllllllllll}0 \% & 10 \% & 20 \% & 30 \% & 40 \% & 50 \% & 60 \% & 70 \% & 80 \% & 90 \% & 100 \%\end{array}$
No $\quad$ Complete
Relief
Relief

9. Circle the one number that describes how, during the past 24 hours, pain has interfered with your:

\begin{tabular}{|lrlllllllll} 
A. & \multicolumn{2}{c|}{ General Activity } & & & & & & 10 \\
0 & 1 & 2 & 3 & 4 & 5 & 6 & 7 & 8 & 9 & $\begin{array}{c}10 \\
\text { Completely } \\
\text { Interferes }\end{array}$ \\
$\begin{array}{l}\text { Does not } \\
\text { Interfere }\end{array}$ & & & & & & & & &
\end{tabular}

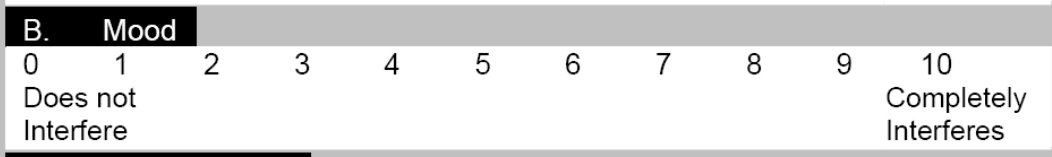

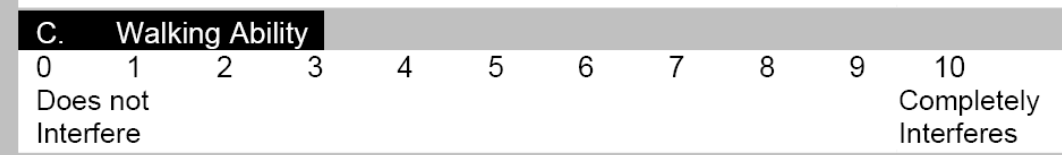

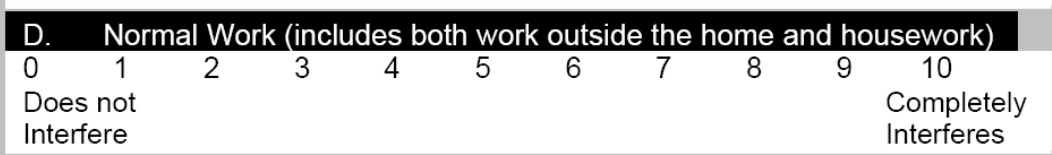

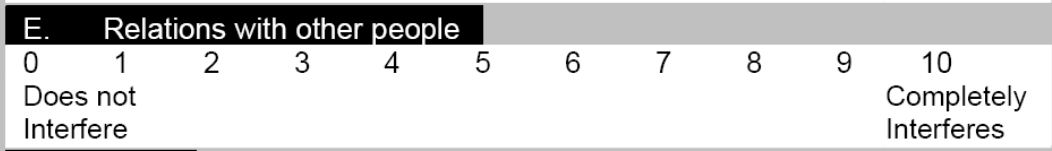

\begin{tabular}{|c|c|c|c|c|c|c|c|c|c|}
\hline Sle & & & & & & & & & \\
\hline $\begin{array}{lc}0 & 1 \\
\text { Does not } \\
\text { Interfere }\end{array}$ & 2 & 3 & 4 & 5 & 6 & 7 & 8 & 9 & $\begin{array}{l}10 \\
\text { Completely } \\
\text { Interferes }\end{array}$ \\
\hline
\end{tabular}

\begin{tabular}{lllllllllll} 
G. & \multicolumn{2}{c}{ Enjoyment of life } \\
0 & 1 & 2 & 3 & 4 & 5 & 6 & 7 & 8 & 9 & $\begin{array}{c}10 \\
\text { Completely } \\
\text { Interferes }\end{array}$ \\
$\begin{array}{l}\text { Does not } \\
\text { Interfere }\end{array}$ & & & & & & &
\end{tabular}

Page 2 of 2

Copyright 1991 Charles S. Cleeland, PhD Pain Research Group
All rights reserved 


\title{
APPENDIX C. INFORMED CONSENT
}

\author{
THE UNIVERSITY OF TENNESSEE
}

Health Science Center

College of Pharmacy

Department of Pharmaceutical Sciences

Health Outcomes and Policy Research

847 Monroe Avenue, Suite 205 D

Memphis, TN 38163

Tel: (901) 448-5140 • Fax: (901) 448-4731

Dear Participant:

This survey is part of a research study that aims to determine Medicare beneficiaries' preferences and willingness to pay for different osteoarthritis treatments. The research is being conducted by Meghan Hufstader at the University of Tennessee, Health Science Center College of Pharmacy.

You are being asked to participate in this study because you are a Medicare beneficiary who suffers from osteoarthritis. We are visiting senior centers in the city of Memphis and its surrounding suburbs to ask you to participate in an interview of approximately 20 minutes. During the interview, you will be asked a few questions about what different osteoarthritis treatments you would prefer. Also, you will be asked about your age, gender, race, income, education, and perceived health status. If you get tired at any time, you may ask for a break.

The interview does not pose any foreseeable risks or discomfort to you. Through your participation in this study, you may become aware of the various treatment options for osteoarthritis. At the completion of the interview, you will be receiving a small gift as a token of appreciation.

Your participation in this study is totally voluntary. You have the right to withdraw from this study at any time with no penalty or loss of rights to which you are entitled. For the confidentiality of your interview responses, your name will not be asked during the interview. We will not ask you for any identifying information such as your name, address, or phone number.

If you have any questions about the research, you may contact Meghan Hufstader at 901448-1738 (daytime M-F). If you have any questions about your rights as a research subject or concerning a research related injury, you can contact Dr. Terrence F. Ackerman, Ph.D., UTHSC IRB Chairman at 901-448-4824.

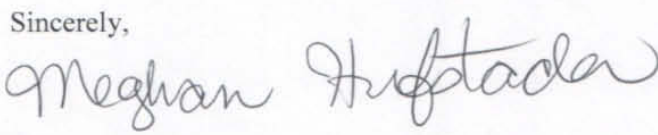

Meghan Hufstader, Ph.D Candidate

University of Tennessee Health Science Center 
APPENDIX D. INSTITUTIONAL REVIEW BOARD APPROVAL LETTER

\begin{tabular}{lr}
\hline THE UNIVERSITY OF TENNESSEE \\
Health Science Center
\end{tabular}

January 30,2009

Meghan A Hufstader, Pharm.D

College of Pharmacy

Department of Pharmaceutical Sciences

Johnson Building

Suite 205

UTHSC

Re: IRB\# 08-00246-XM: Study Title: Using Conjoint Analysis to determine preferences and willingness to pay for osteoarthritis treatment among the $65+$ population

Dear Dr. Hufstader,

The Administrative Section of the UTHSC Institutional Review Board (IRB) reviewed your application for the above referenced project.

The Administrative Section of the IRB determined your application to be consistent with the guidelines for exempt review under 45CFR46.101(b)(2). In accord with 45 CFR 46.116(d), informed consent may be altered, with the cover statement used in lieu of an informed consent interview. The requirement to secure a signed consent form is waived under 45 CFR 46.117 (c)(2). Willingness of the subject to participate will constitute adequate documentation of consent.

Therefore your application has been determined to comply with proper consideration for the rights and welfare of human subjects and the regulatory requirements for the protection of human subjects. This letter constitutes full approval of your application, consent cover statement and survey, stamped approved by the IRB on January 30, 2009 for the above referenced study.

In the event that volunteers are to be recruited using solicitation materials, such as brochures, posters, webbased advertisements, etc., these materials must receive prior approval of the IRB.

Any alterations (revisions) in the protocol, consent cover statement, or survey must be promptly submitted to and approved by the UTHSC Institutional Review Board prior to implementation of these revisions. You have individual responsibility for reporting to the Board in the event of unanticipated or serious adverse events and subject deaths.

Sincerely,

Terrence F. Ackerman, Ph.D.

Chairman

UTHSC IRB

Donna Stallings, CIM

IRB Administrator 


\section{VITA}

Meghan Hufstader was born in 1980 in Millington, TN, to Robert and Marilyn Hufstader. During her childhood she lived in California, Korea, Cuba, Maryland, Florida, Iceland, and Virginia. She received her B.A. from University of Florida in 2002. She then worked for the Virginia Department of Health in Alexandria, VA. In 2004 she entered the Health Outcomes and Policy Research graduate program at the University of Tennessee Health Science Center and will graduate with her Ph.D. in December 2009. 